UNIVERSIDADE ESTADUAL PAULISTA "JÚLIO DE MESQUITA FILHO" FACULDADE DE MEDICINA - BOTUCATU

RENATA KERCHE ALVAIDES SISTO

"EFEITOS DA ADMINISTRAÇÃO PERIDURAL DE NEOSTIGMINA ASSOCIADA OU NÃO A CLONIDINA SOBRE A CONCENTRAÇÃO ALVEOLAR MÍNIMA DO ISOFLURANO EM CÃES" 
Renata Kerche Alvaides Sisto

\section{“EFEITOS DA ADMINISTRAÇÃO PERIDURAL DE NEOSTIGMINA ASSOCIADA OU NÃO A CLONIDINA SOBRE A CONCENTRAÇÃO ALVEOLAR MÍNIMA DO ISOFLURANO EM CÃES"}

Dissertação apresentada à Faculdade de Medicina Universidade Estadual Paulista "Julio de Mesquita Filho", Campus de Botucatu para obtenção do título de Mestre em Anestesiologia.

Orientador: Prof. Dr. Francisco José Teixeira Neto 
FICHA CATALOGRÁFICA ELABORADA PELA SEÇÃO TÉCNICA DE AQUISIÇÃO E TRATAMENTO DA INFORMAÇÃO

DIVISÃO TÉCNICA DE BIBLIOTECA E DOCUMENTAÇÃO - CAMPUS DE BOTUCATU - UNESP BIBLIOTECÁRIA RESPONSÁVEL: Selma Maria de Jesus

Sisto, Renata Kerche Alvaides.

Efeitos da administração peridural de neostigmina associada ou não a clonidina sobre a concentração alveolar mínima do isoflurano em cães /

Renata Kerche Alvaides Sisto. - Botucatu : [s.n.], 2010

Dissertação (mestrado) - Universidade Estadual Paulista, Faculdade de Medicina Veterinária e Zootecnia, Botucatu, 2010

Orientador: Francisco José Teixeira Neto

Assunto CAPES: 50501011

1. Cão - Anestesia

CDD 636.7089796

Palavras-chave: Concentração alveolar mínima; Clonidina; Neostigmina;

Peridural; Isoflurano 


\section{Dedicatóría}


Has mens pais... Maria de Laurdese Gasé Antania, minha avá... Aparecida

e minha irma... Natalia

pela apaia na minha educaçãa,

canfianca na minha capacidade e

pela "parta segura" das mamentas dificeis... sempre!

Aa mew marida... Tefersan Radriga Sista, pela amar incandicianal, paciência e campreensãa cam a minha ausência,campanheirisma e incentiva durante a faculdade, residência e mestrada... nãa estaria aqui sem uacê... 
Agradecimentos 
Aa praf. Dr. Francisca Yasé Geixeira Metapela canfiança na mew trabalha, par me aceitar cama arientada de Iniciaçãa Científica e Mestrada, pelas canselhas, "puxães de arelha" e apartunidades desde a graduaçãa, residência, até a canclusãa deste trabalha, e pelas muitas ensinamentas transmitidas durante tados esses anas... Aprendi muita cam vacê!!!

A Flávia Angusta de Cliveira, Daniela Campagnal, Matache Arauca Garafala e Lidia Matsubara pela apaia e ajuda durante a vealizaçãa da parte experimental deste trabalha;

A $\mathcal{F} \mathscr{A P C O} \mathcal{E P}$ (halsa de mestrada prac n 07/57771-3) pela auxilia financeira indispensável para a realizaçãa deste estuda;

Aas cães da canil experimental da Serviça de Anestesialagia Veterinária da FMVД-UNESP Batucatw: Bani, Branguinha e Kate. E aas cães da canil experimental da Labaratária Clínica Veterinária da FMVD-U VESP Batucatu (salu respansalilidade da praf Dra. Regina Kiami Takahira): Amarela (Clâ), Belinha e Cacá.. A amizade e carinha incandicianal de uacês fai fundamental... serei eternamente grata!

Aa praf. Titular. Stelia Pacca Laureira Luna pelas canhecimentas, apaia e ajuda durante a graduaçãa, residência e realizaçãa deste estuda e pela cantriluiçãa científica transmitida durante tadas esses anas;

Aa praf. Ass. Dr. Antania Gasé de Araúja Aguiar pelas canhecimentas transmitidas, arientaçãa durante a residência, canselhas, amizade e canfiança; 
Aa praf. Dr. Tasé Eduarda Carrente pela realizaçãa da análise estatística deste estuda.

As funcianárias da departamenta de Cirurgia e Anestesialagia Veterinária da FMVD - UVESP Batucatu, Ana Maria Gardiva e Vanessa Visatta Bassetta, pela atençãa e ajuda durante tada a tempa que trabalhamas juntas...

Aas funcianárias da Departamenta de Anestesialagia da Faculdade de Medicina - UNESP Batucatw: Meli e Andrépela infinita atençãa e ajuda na durante estes 2 anas;

Aas funcianárias da seçãa de Pás Graduaçãa da Faculdade de Medicina - UVESP Batucatu pela atençãa, educaçãa e pranta atendimenta de tadas questães referentes a este cursa de pás graduaçãa;

Aas residentes e ex-residentes da Serviça de Anestesialagia Veterinária da FMVZ - UVESP Batucatw: Fláia (Flavitas), Wangles (Giazãa), Caral, Flávia (LLanga), Thaisa (Popa) e Larissa (Guaia) pela paciência e ajuda durante estes 2 anas de trabalha...

Aas residentes da Labaratária Clínica, Diagnástica par Imagem (Danuta) e Elínica Veterinária (Nilciene e Yarge) da FMVI- UVESP Batucatu pela apaia na realizaçãa das exames labaratariais, radiagráficas e candutas clínicas nas cães utilizadas neste estuda.

A tadas as ex-residentes e pás graduandas em Anestesialagia Veterinária: Caral Ricca, Radriga Marucia, Paula Steagall (Pankeka), Mi, Gui, Yuri (Bambi), Gati Giardana e Sw, 
Agradecimentos

pela incentiva e ajuda, cada à sua maneira fai muita impartante na minha escalha desta especialidade... fai um prazer aprender e trabalhar cam vacês...

As amigas Sil e Camila Danati (Gudy), pela amizade, canfiança e "haspedagem"...

wacês sãa incrúueis...

Aas meus amigas de sempre: LLu, Ri, Rê Rase e Fer pela ambra amiga em tadas as haras, campreensãa da minha ausência e paciência cam as minhas reclamaçães e mal humar... e às amigas "mais recentes" Gaque e L Li pela incentiva e apaia nesta nava fase da minha carreira prafissianal... Chrigada par tuda!! 
Epigrafe 
Uma noite eu tive um sonho...

Sonhei que estava andando na praia com o Senhor,

E através do Céw, passavam cenas de minha vida. Para cada cena que passava, percebi pegadas na areía; Uma era minha e a outra do Senhor. Quando a última cena de minha vída passou diante de nós, othei para as pegadas na areia,

Notei que muitas vezes no caminho da minha vida havia apenas um par de pegadas na areia. Notei também que isso aconteceu nos momentos mais dificeis da minha vida.

Isso me aborreceu deveras e perguntei então ao Senhor: - Senhor, Tu me disseste que, uma vez que eu resolvi Te seguir,

Tw andarias sempre comigo, todo o caminho, - Mas notei que nos momentos das maiores atribulaçóes do meu viver havia na areia dos caminhos da vida, apenas um par de pegadas.

- Não compreendo...Porque nas horas em que eu mais necessitava Tu me deixastes?

O Senhor respondew:

Meuprecioso fitho, Eute amo e jamais te deixaria nas horas da tua prova e do teu sofrimento. Quando vistes na areia apenas um par de pegadas, foi exatamente aíque

TE CARREGUEI EM MEUS BRAÇOS! (autor desconhecido) 
Resumo 
Alvaides Sisto, RK, Efeitos da administração peridural de neostigmina associada ou não a clonidina sobre a concentração alveolar mínima do isoflurano em cães. Botucatu. 2010. 115 p. Dissertação de Mestrado. Faculdade de Medicina Universidade Estadual Paulista "Julio de Mesquita Filho" Campus de Botucatu.

Os agentes anticolinesterásicos (neostigmina), quando associados com agonistas de receptores alfa-2 adrenérgicos (clonidina) pela via espinhal, resultam sinergismo no que se refere à analgesia promovida em ratos, ovinos e humanos. $\mathrm{Na}$ presente pesquisa, formulou-se a hipótese de que a administração peridural de neostigmina potencializaria a redução da concentração alveolar mínima (CAM) do isoflurano proporcionada pela clonidina peridural em cães. Seis cadelas hígidas (14,9 $\pm 2,9 \mathrm{~kg})$ foram anestesiadas com isoflurano em 3 ocasiões distintas, com intervalo de 7 dias. Durante as anestesias foi empregada a ventilação controlada a pressão para prevenção da hipercapnia (PaCO2 $>45 \mathrm{mmHg}$ ) e a temperatura esofágica foi mantida entre 37,5 a 38,5oC por meios de aquecimento artificiais. Em cada anestesia, os animais receberam aleatoriamente 1 de 3 tratamentos pela via peridural: neostigmina (10 $\mu \mathrm{g} / \mathrm{kg})$, clonidina $(20 \mu \mathrm{g} / \mathrm{kg})$, ou a associação clonidina $(20 \mu \mathrm{g} / \mathrm{kg})$ e neostigmina $(10 \mu \mathrm{g} / \mathrm{kg})$. A CAM do isoflurano, mensurada por meio de estimulação nociceptiva do membro pélvico (50 V, $50 \mathrm{~Hz}, 10 \mathrm{~ms}$ ), foi registrada após 2 horas da indução da anestesia (CAM basal) e após 2,5 e 5 horas da administração dos tratamentos peridurais. Em um dos animais, tanto a clonidina como a clonidina/neostigmina resultou em elevação paradoxal da CAM (8-9 \%). Nos demais animais estudados $(n=5)$, os valores de CAM basal (média \pm desvio padrão) foram de 1,49 \pm 0,26, 1,51 \pm 0,23 e 1,49 0,26 vol\%, nos tratamentos clonidina, neostigmina e clonidina/neostigmina, respectivamente, não havendo diferença entre tratamentos. As reduções da CAM observadas após a administração peridural de neostigmina não foram significativas $(p<0,05)$ (reduções percentuais de $11 \pm 5 \%$ e $8 \pm 9 \%$ após 2,5 e 5 horas, respectivamente). Houve redução significativa da CAM após a administração peridural de clonidina (reduções percentuais de $35 \pm 9 \%$ e $22 \pm$ 14\% após 2,5 e 5 horas, respectivamente) e da associação clonidina/ 


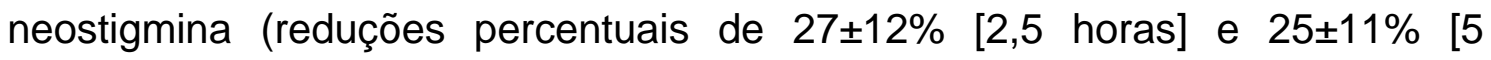
horas]). Após 2,5 horas da administração peridural, o tratamento clonidina apresentou valores de da CAM significativamente menores que os valores de CAM do tratamento neostigmina. Após 2,5 e 5 horas da administração peridural, a freqüência cardíaca foi significativamente menor nos tratamentos clonidina e associação clonidina/neostigmina. Não foram observadas diferenças significativas entre tratamentos nos tempos de recuperação da anestesia. Conclui-se que a administração neostigmina pela via peridural não potencializa de forma importante a redução da CAM do isoflurano associada a administração peridural de clonidina em cães. Embora a clonidina peridural tenha reduzido a CAM do isoflurano na maioria dos animais estudados, eventuais reações idiosincráticas podem ser observadas após a administração peridural deste alfa-2 agonista.

Palavras chave: Concentração alveolar mínima, clonidina, isoflurano, neostigmina, peridural 
Abstract 
Alvaides Sisto, RK, Effects of peridural administration of neostigmine, clonidine or their associciation on the minimum alveolar concentration of isoflurane in dogs. Botucatu. 2010. 115 p. Dissertação de Mestrado. Faculdade de Medicina Universidade Estadual Paulista "Julio de Mesquita Filho" Campus de Botucatu.

Spinal administration of anticholinesterase drugs (neostigmine) in combination with alpha-2 adrenergic receptor agonists (clonidine) results in a synergistic analgesic effect in rats, sheep and humans. The hypothesis of the present study was that the epidural administration of neostigmine would enhance the isoflurane minimum alveolar concentration (MAC) reduction induced by the epidural injection of clonidine in dogs. Six healthy bitches $(14,9 \pm 2,0 \mathrm{~kg})$ were anesthetized with isoflurane on 3 distinct occasions, with 7 day intervals among experiments. During the anesthetic episodes, animals were maintained under pressure controlled ventilation to prevent hypercapnia $(\mathrm{PaCO} 2>45 \mathrm{mmHg})$ and esophageal temperature was maintained between 37.5 and 38.5 oC by means of artificial heating devices. During each anesthetic, animals were randomly allocated to receive 1 of 3 epidural treatments: neostigmine $(10 \mu \mathrm{g} / \mathrm{kg})$, clonidine $(20 \mu \mathrm{g} / \mathrm{kg})$, or the combination of clonidine $(20 \mu \mathrm{g} / \mathrm{kg})$ and neostigmine $(10 \mu \mathrm{g} / \mathrm{kg})$. Isoflurane MAC, determined by means of electric stimulation of the pelvic $\operatorname{limb}(50 \mathrm{~V}, 50 \mathrm{~Hz}, 10 \mathrm{~ms})$, was recorded 2 hours after induction of anesthesia (baseline MAC) and 2.5 and 5 hours after epidural injections. In 1 of the animals, clonidine and clonidine/neostigmine caused paradoxical increases in MAC (8-9 \% increases). For the remaining animals $(n=5)$, baseline MAC values (mean \pm standard deviation) were $1.49 \pm 0.26,1.51 \pm 0.23$ e $1.49 \pm 0.26$ vol\%, in the clonidine, neostigmine, and clonidine/neostigmine treatments, respectively. Baseline MAC did not differ among treatments. The isoflurane MAC reductions recorded after epidural injection of neostigmine were not significant $(p<0.05)$ (percent reductions of $11 \pm 5 \%$ and $8 \pm 9 \%$ after 2.5 and 5 hours respectively). The MAC reductions observed after epidural injection of clonidine (35 $\pm 9 \%$ and $22 \pm 14 \%$ after 2.5 and 5 hours, respectively) and clonidine/neostigmine $(27 \pm 12 \%$ [2,5 hours] and $25 \pm 11 \%$ [5 hours]) were statistically significant $(p<0.05)$. After 2.5 hours of epidural drug injection, the 
clonidine treatment resulted in significantly lower MAC values than the neostigmine treatment. The heart rate was significantly lower in the clonidine and clonidine/neostigmine treatments at 2,5 and 5 hours after epidural drug injection There we no differences among treatments in the times to recover from anesthesia.It was concluded that epidural neostigmine does not cause a clinically relevant improvement in the MAC sparing effects of epidural clonidine in dogs. Although epidural clonidine reduced isoflurane MAC in the majority of the animals, idiosyncratic reactions may eventually be observed after the epidural injection of this alpha-2 agonist.

Key words: Minimum alveolar concentration, clonidine, isoflurane, neostigmine, epidural. 
Sumárío 
LISTA DE ABREVIATURAS E SÍMBOLOS

LISTA DE TABELAS

LISTA DE FIGURAS

1. INTRODUÇÃO E JUSTIFICATIVA

2. REVISÃO BIBLIOGRÁFICA

2.1. CONCENTRAÇÃO ALVEOLAR MÍNIMA (CAM)

2.1.1. Determinação da CAM

2.1.2. Critérios para determinação da $C A M$

2.1.3. Outros fatores que interferem na CAM.

2.2. NEOSTIGMINA

2.3. CLONIDINA

2.3.1. Efeitos hemodinâmicos

2.3.2. Efeito analgésico

2.3.3. Uso peridural

2.4. INTERAÇÃO ENTRE A NEOSTIGMINA E AGONISTAS ALFA-2 ADRENÉRGICOS ADMINISTRADOS PELA VIA ESPINHAL

3. HIPÓTESE

4. OBJETIVOS 55

5. MATERIAIS E MÉTODOS

5.1. ANIMAIS 58

5.2. DELINEAMENTO E PROTOCOLO EXPERIMENTAL 58

5.3. PREPARO E INSTRUMENTAÇÃO DOS ANIMAIS 59

5.4. DETERMINAÇÃO DA CAM. 61

5.5. PARÂMETROS CARDIORESPIRATÓRIOS AVALIADOS 63

5.6. CARACTERÍSTICAS DA RECUPERAÇÃO ANESTÉSICA AVALIADAS.

5.7. ANÁLISE ESTATÍSTICA.

6. RESULTADOS

6.1. TEMPOS DE DETERMINAÇÃO E EFEITOS DA ADMINISTRAÇÃO PERIDURAL DE CLONIDINA, NEOSTIGMINA OU ASSOCIAÇÃO SOBRE OS VALORES DA CONCENTRAÇÃO ALVEOLAR MÍNIMA DO ISOFLURANO $\left(\mathrm{CAM}_{\mathrm{ISO}}\right)$ 
Sumárío

6.2. EFEITOS DA ADMINISTRAÇÃO PERIDURAL DE CLONIDINA, NEOSTIGMINA OU ASSOCIAÇÃO SOBRE OS PARÂMETROS CARDIOVASCULARES DURANTE AS DETERMINAÇÕES DE CAM

70

6.3. EFEITOS DA ADMINISTRAÇÃO PERIDURAL DE CLONIDINA, NEOSTIGMINA OU ASSOCIAÇÃO SOBRE OS VALORES DE HEMOGASOMETRIA ARTERIAL DURANTE AS DETERMINAÇÕES DE CAM

74

6.4. EFEITOS DA ADMINISTRAÇÃO PERIDURAL DE CLONIDINA, NEOSTIGMINA OU ASSOCIAÇÃO SOBRE O TEMPO DE EXTUBAÇÃO, DECÚBITO ESTERNAL E RETORNO A POSIÇÃO QUADRUPEDAL

7. DISCUSSÃO

8. CONCLUSÕES

REFERÊNCIAS BIBLIOGRÁFICAS

APÊNDICE

75

77

86

88

105 


\section{Lista de Abreviaturas e Símbotos}




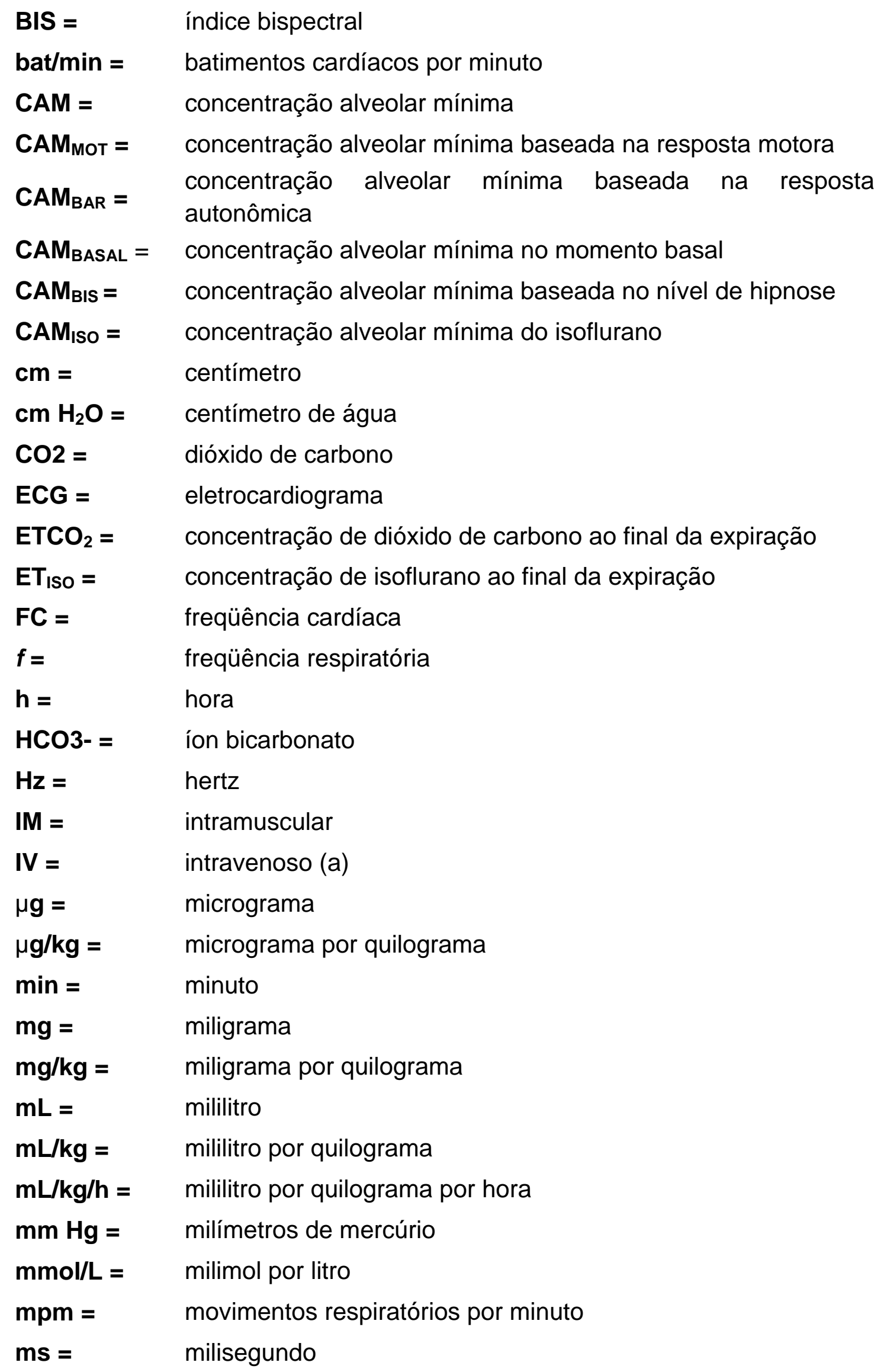




$\begin{array}{ll}\mathbf{n}= & \text { número } \\ \mathbf{O}_{2}= & \text { oxigênio } \\ \mathbf{p}= & \text { nível de significância } \\ \mathbf{P a C O}_{2}= & \text { pressão parcial de dióxido de carbono no sangue arterial } \\ \mathbf{P a O}_{2}= & \text { pressão parcial de oxigênio no sangue arterial } \\ \mathbf{P A}= & \text { pressão arterial } \\ \mathbf{P A D}= & \text { pressão arterial diastólica } \\ \mathbf{P A M}= & \text { pressão arterial média } \\ \mathbf{P A S}= & \text { pressão arterial sistólica } \\ \mathbf{p H}= & \text { potencial hidrogeniônico } \\ \mathbf{S C}= & \text { subcutâneo } \\ \mathbf{T}= & \text { temperatura corpórea } \\ \mathbf{V}= & \text { volt } \\ { }^{\circ} \mathbf{C}= & \text { graus Celsius } \\ \%= & \text { porcentagem } \\ \mathbf{E}= & \text { mais ou menos }\end{array}$




\section{Lista de Tabelas}


Tabela 1 - Valores da concentração alveolar mínima do isoflurano $\left(\mathrm{CAM}_{\mathrm{ISO}}\right)$ basal e após aproximadamente 2,5 e 5 horas da administração peridural dos tratamentos: clonidina (CLO) $20 \mu \mathrm{g} / \mathrm{kg}$, neostigmina (NEO) $10 \mu \mathrm{g} / \mathrm{kg}$ e associação clonidina $(20 \mu \mathrm{g} / \mathrm{kg})$ e neostigmina $(10 \mu \mathrm{g} / \mathrm{kg})$ (CLO/NEO) em 1 cadela.

Tabela 2 - Valores médios ( \pm desvio padrão) da concentração alveolar mínima do isoflurano (CAM $\left.\mathrm{CAO}_{\mathrm{ISO}}\right)$ após 2,5 e 5 horas da administração peridural de clonidina (CLO: 20 $\mu \mathrm{g} / \mathrm{kg}$ ), neostigmina (NEO: $10 \mu \mathrm{g} / \mathrm{kg}$ ) e da associação clonidina $(20 \mu \mathrm{g} / \mathrm{kg})$ e neostigmina $(10 \mu \mathrm{g} / \mathrm{kg})$ (CLO/NEO) em 5 cadelas. Os valores entre parêntesis representam o tempo médio (horas) \pm desvio padrão da determinação dos valores de CAM

Tabela 3 - Valores médios ( \pm desvio padrão) da freqüência cardíaca (FC), pressão arterial sistólica (PAS), pressão arterial diastólica (PAD) e pressão arterial média (PAM) observados no tempo basal, 2,5 e 5 horas após a administração peridural dos tratamentos clonidina (CLO: $20 \mu \mathrm{g} / \mathrm{kg}$ ), neostigmina (NEO: $10 \mu \mathrm{g} / \mathrm{kg}$ ) e associação clonidina $(20 \mu \mathrm{g} / \mathrm{kg})$ e neostigmina (10 $\mu \mathrm{g} / \mathrm{kg})$ (CLO/NEO) em 5 cadelas.

Tabela 4 - Valores médios ( \pm desvio padrão) do potencial hidrogeniônico $(\mathrm{pH})$ arterial, pressão parcial de $\mathrm{CO}_{2}$ $\left(\mathrm{PaCO}_{2}\right)$, pressão parcial de $\mathrm{O}_{2}\left(\mathrm{PaO}_{2}\right)$ e íon bicarbonato $\left(\mathrm{HCO}_{3}{ }^{-}\right)$freqüência cardíaca (FC), observados no tempo basal, 2,5 e 5 horas após a administração peridural dos tratamentos clonidina (CLO: $20 \mu \mathrm{g} / \mathrm{kg}$ ), neostigmina (NEO: $10 \mu \mathrm{g} / \mathrm{kg}$ ) e associação clonidina $(20 \mu \mathrm{g} / \mathrm{kg})$ e neostigmina $(10 \mu \mathrm{g} / \mathrm{kg})(\mathrm{CLO} / \mathrm{NEO})$ em cinco cadelas......

Tabela 5 - $\quad$ Tempo total de anestesia, tempo de extubação, tempo de retorno a decúbito esternal e posição quadrupedal em 5 animais anestesiados com isoflurano que receberam pela via peridural os tratamentos clonidina (CLO) $20 \mu \mathrm{g} / \mathrm{kg}$, neostigmina (NEO) $10 \mu \mathrm{g} / \mathrm{kg}$ e associação clonidina $20 \mu \mathrm{g} / \mathrm{kg}$ e neostigmina10 $\mu \mathrm{g} / \mathrm{Kg}$ (CLO/NEO). Os valores expressos como média \pm desvio padrão 


\section{Lista de Figuras}


Figura 1 - Efeito da temperatura sobre os valores de CAM. Valores expressos em média \pm DP. A) Efeito da hipertermia sobre a CAM do halotano em cães (Fonte: Steffey \& Eger, 1974).....

Figura 2 - Valores de CAM do halotano (O) e isoflurano (ם) em relação à idade em humanos. Valores expressos em média \pm DP. (Fonte: Stevens et al., 1975).

Figura 3 - Tempo de latência (seg) da resposta de pele ao estímulo térmico versus o tempo de infusão peridural (dias) de salina, clonidina 80, 200 e 320 $\mu \mathrm{g} / \mathrm{h}$ em cães. (Fonte: Yaksh et al., 1994).

Figura 4 - Valores médios ( \pm desvio padrão) da concentração alveolar mínima do isoflurano (CAM $\left.\mathrm{CSO}_{\mathrm{SO}}\right)$ após 2,5 e 5 horas da administração peridural de clonidina (CLO: $20 \mu \mathrm{g} / \mathrm{kg}$ ), neostigmina (NEO: $10 \mu \mathrm{g} / \mathrm{kg}$ ) e da associação clonidina (20 $\mu \mathrm{g} / \mathrm{kg})$ e neostigmina $(10 \mu \mathrm{g} / \mathrm{kg})(\mathrm{CLO} / \mathrm{NEO})$ em 5 cadelas..

Figura 5 - Valores médios ( \pm desvio padrão) da porcentagem de redução da CAM Iso após 2,5 e 5 horas da administração peridural de clonidina (CLO: $20 \mu \mathrm{g} / \mathrm{kg}$ ), neostigmina (NEO: $10 \mu \mathrm{g} / \mathrm{kg})$ e da associação clonidina (20 $\mu \mathrm{g} / \mathrm{kg})$ e neostigmina $(10 \mu \mathrm{g} / \mathrm{kg})(\mathrm{CLO} / \mathrm{NEO})$ em 5 cadelas.

Figura 6 - Valores médios ( \pm desvio padrão) da freqüência cardíaca (FC) observados no tempo basal, 2,5 e 5 horas após a administração peridural dos tratamentos clonidina (CLO: 20 $\mu \mathrm{g} / \mathrm{kg}$ ), neostigmina (NEO: $10 \mu \mathrm{g} / \mathrm{kg}$ ) e associação clonidina $(20 \mu \mathrm{g} / \mathrm{kg})$ e neostigmina $(10 \mu \mathrm{g} / \mathrm{kg})$ (CLO/NEO) em 5 cadelas

Figura 7 - Valores médios ( \pm desvio padrão) da pressão arterial sistólica (PAS), observados no tempo basal, 2,5 e 5 horas após a administração peridural dos tratamentos clonidina (CLO: $20 \mu \mathrm{g} / \mathrm{kg}$ ), neostigmina (NEO: $10 \mu \mathrm{g} / \mathrm{kg}$ ) e associação clonidina $(20 \mu \mathrm{g} / \mathrm{kg})$ e neostigmina $(10 \mu \mathrm{g} / \mathrm{kg})$ (CLO/NEO) em 5 cadelas.

Figura 8 - Valores médios ( \pm desvio padrão) da pressão arterial diastólica (PAD) observados no tempo basal, 2,5 e 5 horas após a administração peridural dos tratamentos clonidina (CLO: $20 \mu \mathrm{g} / \mathrm{kg}$ ), neostigmina (NEO: $10 \mu \mathrm{g} / \mathrm{kg}$ ) e associação clonidina $(20 \mu \mathrm{g} / \mathrm{kg})$ e neostigmina $(10 \mu \mathrm{g} / \mathrm{kg})$ (CLO/NEO) em 5 cadelas. 
Figura 9 - Valores médios ( \pm desvio padrão) da pressão arterial média (PAM) observados no tempo basal, 2,5 e 5 horas após a administração peridural dos tratamentos clonidina (CLO: 20 $\mu \mathrm{g} / \mathrm{kg}$ ), neostigmina (NEO: $10 \mu \mathrm{g} / \mathrm{kg}$ ) e associação clonidina $(20 \mu \mathrm{g} / \mathrm{kg})$ e neostigmina $(10 \mu \mathrm{g} / \mathrm{kg})$ (CLO/NEO) em 5 cadelas. 


\section{Introduçãoe Justificativa}


Diante dos efeitos sistêmicos colaterais indesejáveis de alguns fármacos analgésicos, a via peridural torna-se uma opção para administração uma vez que a dose necessária para obtenção do efeito desejado pode ser menor que a dose parenteral preconizada, porém com efeitos analgésicos mais duradouros e com menor intensidade de efeitos colaterais. ${ }^{1,2}$ Doses reduzidas de morfina $(0,1 \mathrm{mg} / \mathrm{kg})$ administradas pela via peridural induzem analgesia mais prolongada e com menor incidência de efeitos colaterais que doses similares administradas pela via sistêmica. ${ }^{1}$ A exemplo disso, a morfina quando administrada nas doses de 0,3-1,0 mg/kg pelas via IM, SC ou IV apresenta efeito analgésico que pode perdurar por até 1-4 horas cães ${ }^{3}$, por outro lado, doses reduzidas de morfina peridural $(0,1 \mathrm{mg} / \mathrm{kg})$ apresentam início de ação entre 20 e 60 minutos, com duração da analgesia entre 16 e 24 horas nesta mesma espécie. ${ }^{4}$ Valverde ${ }^{5}$ et al. (1989) estudaram os efeitos da administração peridural de morfina $(0,1 \mathrm{mg} / \mathrm{kg}$ diluída em $0,13 \mathrm{ml} / \mathrm{kg}$ ou 0,26 $\mathrm{ml} / \mathrm{kg}$ de solução salina) sobre a CAM do halotano em cães. Estes autores observaram que a administração peridural deste opióide resultou em redução no requerimento de anestésico de maneira segmentar; ou seja, houve uma maior redução da CAM do halotano nos membros posteriores (redução média de 40\%) em relação aos membros anteriores (redução média de 32\%). A potencialização do halotano proporcionada pela morfina peridural resulta em melhora da função hemodinâmica, quando concentrações equipotentes de halotano associado à morfina peridural $(0,1 \mathrm{mg} / \mathrm{kg})$ são comparadas com o halotano isoladamente. ${ }^{6}$

Assim sendo, o emprego de fármacos analgésicos pela via peridural apresenta vantagens em relação ao seu uso parenteral, uma vez que possibilita a obtenção de analgesia mais prolongada com o emprego de doses menores em relação às doses preconizadas pela via parenteral. ${ }^{1,2,7}$

A diminuição na dose empregada deve-se em grande parte a proximidade dos fármacos aos receptores localizados a medula espinhal. ${ }^{1} \mathrm{O}$ objetivo de se combinarem analgésicos pela via espinhal é a obtenção de um 
efeito sinérgico através da inibição da nocicepção por meio de mecanismos farmacológicos distintos. ${ }^{1,8}$

Os agentes colinomiméticos (ex: neostigmina) são comumente empregados em anestesia no antagonismo farmacológico dos efeitos dos bloqueadores neuromusculares não despolarizantes ${ }^{9}$. As propriedades antinociceptivas da administração espinhal de agentes colinomiméticos foram primeiramente documentadas em ratos e felinos. ${ }^{10} \mathrm{~A}$ neostigmina foi primeiramente descrita como analgésico para o período pós-operatório, quando administrada pela via intratecal em ovelhas sendo caracterizada como um fármaco eficaz no controle da dor no período pós-operatório imediato. ${ }^{11}$ Embora a administração intratecal resulte em analgesia no homem, esta vem sendo abandonada devido à elevada incidência de náusea e êmese. ${ }^{12-15}$ No entanto, há um interesse renovado no uso da neostigmina uma vez que a sua administração em associação com outros fármacos (ex: lidocaína, bupivacaína e morfina) pela via peridural melhora significativamente o controle da dor pósoperatória, estando aparentemente associada a uma menor incidência de náusea e êmese que a via intratecal. ${ }^{16-18} \mathrm{Em}$ estudo realizado no laboratório de anestesiologia experimental da FMVZ, UNESP, Campus de Botucatu, a administração peridural de neostigmina $(10 \mu \mathrm{g} / \mathrm{kg})$ resultou em analgesia pósoperatória satisfatória após ovariosalpingohisterectomia em cadelas; embora não tenha se observado um sinergismo analgésico quando o colinomimético foi associado com a morfina peridural. ${ }^{19}$ Devido ao fato dos anestésicos gerais intravenosos e inalatórios serem desprovidos de ação analgésica específica, fármacos analgésicos administrados pela via peridural são frequentemente associados aos anestésicos gerais. Embora a administração de analgésicos pela via peridural possa contribuir para uma redução da dose de anestésico geral necessária a manutenção da anestesia ${ }^{5}$, não se encontram estudos publicados até a presente momento avaliando os efeitos da neostigmina peridural sobre o requerimento de anestésicos inalatórios.

Os agonistas de receptores alfa-2 adrenérgicos (clonidina e dexmedetomidina), apresentam grande eficácia analgésica e sedativa podendo 
ser utilizados com o objetivo de redução do requerimento de anestésicos gerais inalatórios e intravenosos. ${ }^{20-23}$ A clonidina é um fármaco amplamente empregado como analgésico no período perioperatório em humanos ${ }^{24-28}$ seu uso peridural é associado a uma redução no requerimento de analgésicos no período pós operatório. ${ }^{29-30}$ Estudos a respeito da toxicidade, não demonstraram sinais de alterações morfológicas na medula espinhal em cães, após dose única ou administração peridural crônica de clonidina. ${ }^{31-32}$ Em cães a administração intravenosa de clonidina 5 e 20 $\mu \mathrm{g} / \mathrm{kg}$ proporcionou efeito redutor na concentração alveolar mínima (CAM) do halotano em torno de 45\% após aproximadamente $2,5 \mathrm{~h}^{20}$

A associação da neostigmina com agonistas de receptores alfa-2 adrenérgicos pela via intratecal e peridural foi estudada no homem e em ovinos. $^{33-35} \mathrm{Em}$ ovinos os efeitos analgésicos da dexmedetomidina e da clonidina intratecal foram potencializados quando a neostigmina foi administrada pela mesma via. ${ }^{35} \mathrm{Em}$ humanos a associação neostigmina $(750 \mu \mathrm{g})$ e clonidina $(75 \mu \mathrm{g})$, pela via peridural, demonstrou maior eficácia analgésica durante o parto que a neostigmina ou clonidina de forma isolada. ${ }^{33}$ Tal potencialização na antinocicepção é possivelmente atribuída ao aumento da liberação de acetilcolina e da síntese óxido nítrico induzida pela neostigmina. ${ }^{36-37}$

Diante das vantagens e possíveis benefícios do uso de neostigmina associada ou não a clonidina pela via peridural em cães e escassez de estudos nesta espécie até a literatura atual, torna-se importante investigar o efeito destes fármacos sobre o requerimento de anestésicos voláteis (isoflurano) na espécie canina. 
2. Revisão Búbliográfica 


\subsection{CONCENTRAÇÃO ALVEOLAR MÍNIMA (CAM)}

O termo concentração alveolar mínima (CAM) foi inicialmente proposto por Merkel \& Eger $^{38}$ (1963) sendo definido como "a concentração alveolar mínima de um anestésico necessária para prevenir a resposta motora a um estímulo doloroso em cães". Em 1964, Saidman \& Eger ${ }^{39}$ descreveram a CAM no homem, como sendo a "concentração alveolar onde 50\% dos pacientes apresentaram resposta motora após incisão cirúrgica". Tais estudos demonstraram grande consistência e reprodutibilidade da CAM tanto em animais quanto no homem tornando-a um importante índice de comparação da potência entre agentes anestésicos inalatórios. ${ }^{40-41}$

Atualmente o termo CAM é mais amplamente definido como sendo a concentração alveolar mínima de um anestésico inalatório a 1 atmosfera, correspondendo portanto à pressão parcial alveolar do agente anestésico, capaz de prevenir a resposta motora em 50\% de uma população frente a um estímulo nociceptivo, assim sendo 1 CAM corresponderia à dose efetiva em $50 \%$ da população $\left(\mathrm{DE}_{50}\right)$ dos anestésicos injetáveis. ${ }^{41-42}$

O conhecimento dos valores de CAM e a monitoração da concentração alveolar do anestésico (melhor estimada pela concentração expirada) durante a anestesia possibilita o acompanhamento da profundidade anestésica uma vez que a pressão parcial do agente volátil no alvéolo rapidamente se equilibra com a pressão parcial deste no sistema nervoso central (SNC). ${ }^{42}$ Além disso, a CAM não se restringe apenas a um índice de comparação entre anestésicos inalatórios, sendo utilizada também investigar os efeitos de diversas condições clínicas como hipovolemia, hipertensão, temperatura corporal, acidose ou alcalose metabólica, gestação e até mesmo idade sobre o requerimento de anestésicos inalatórios. ${ }^{41}$ A CAM também pode ser considerada uma ferramenta importante na determinação da potência antinociceptiva de fármacos analgésicos quando associados à agentes inalatórios, uma vez que a redução da CAM proporcionada por estes fármacos permite a comparação entre diferentes substâncias analgésicas. ${ }^{43}$ Tais observações não resultam apenas dos efeitos antinociceptivos dos fármacos empregados mas sim de uma complexa interação entre o fármaco e o agente inalatório empregado. ${ }^{43}$ 


\subsubsection{Determinação da CAM}

Para a determinação da CAM são necessários três requisitos básicos: utilização de um estímulo nociceptivo supramáximo, resposta motora bem definida e estabilidade na concentração de anestésico expirada. ${ }^{41}$

Um padrão de estimulação nociceptiva ideal para a determinação de potência anestésica deve ser bem definido, fácil de ser executado, apresentar repetibilidade, possuir resultados consistentes e não causar lesões teciduais. ${ }^{44}$ O estímulo nociceptivo é considerado supramáximo quando um incremento na intensidade da estimulação não resulta em aumento no valor de CAM. ${ }^{40-41}$

Os métodos comumente utilizados para obtenção do estímulo nociceptivo supramáximo em cães podem ser através de "pinçamento" (aplicado com pinça hemostática na base da cauda ou extremidade de membros); ou corrente elétrica subcutânea. ${ }^{38,40,45}$ A comparação entre estes estímulos demonstra não haver diferença entre a técnica de pinçamento na base da cauda ou estimulação através de corrente elétrica subcutânea (30 ou $50 \mathrm{~V}, 50 \mathrm{~Hz}$ por $10 \mathrm{~ms}$ ), no entanto estímulos como pinçamento interdigital, estímulo elétrico de baixa voltagem $(10 \mathrm{~V}, 50 \mathrm{~Hz}, 10 \mathrm{~ms})$, movimentação da sonda endotraqueal no seu eixo longitudinal e incisão de pele apresentaram valores de CAM significativamente menores que os outros tipos de estímulo, não sendo portanto considerados como supramáximos em cães. ${ }^{40}$

A validação e padronização do tipo de estímulo utilizado para a determinação dos valores de CAM é de fundamental importância para a sua repetibilidade e confiabilidade. Valverde et al. ${ }^{45}$ (2003) compararam e validaram diferentes tipos de estímulo nociceptivos supramáximos utilizados na determinação da CAM do isoflurano e do halotano aplicados em diferentes regiões anatômicas, em cães e coelhos. Os resultados encontrados corroboram com os encontrados por Eger et al. ${ }^{40}$ (1965) onde o uso de estímulo elétrico (50V, $50 \mathrm{~Hz}, 10 \mathrm{~ms}$ ) apresentou valores de CAM similares ao obtidos através de pinçamento. Porém a incisão de pele, por ter resultado em valores que CAM 
significativamente menores que os obtidos por pinçamento ou por estimulação elétrica, não foi considerada um estímulo supramáximo. ${ }^{45}$

Outro aspecto importante na determinação da CAM é a caracterização das respostas motoras após estímulo doloroso supramáximo. A resposta motora evidente (resposta positiva) é considerada como um "movimento muscular grosseiro", definido por rotação de cabeça, flexão de membros ou movimentos de pedalagem. ${ }^{41}$ Segundo a definição clássica da CAM, respostas autonômicas (aumentos da freqüência cardíaca, respiratória e pressão arterial), tosse, deglutição ou mastigação ou a ainda a contração do membro submetido à estimulação nociceptiva podem ser de natureza reflexa não são considerados resposta motora evidente e são classificados como resposta negativa. ${ }^{41,43,45}$

O conceito de CAM assume que a concentração expirada, pressão parcial de anestésico alveolar, arterial e no SNC estejam estáveis e em equilíbrio antes da aplicação do estímulo nociceptivo. ${ }^{41} \mathrm{O}$ período considerado suficiente para atingir este equilíbrio é de no mínimo 15 minutos para o halotano, tempo necessário para permitir aproximadamente 95\% de equilíbrio entre a concentração de anestésico presente no sangue arterial e no SNC. ${ }^{40}$ Quanto menor o coeficiente de solubilidade sangue/gás mais rapidamente ocorrerá o equilíbrio entre a concentração arterial e cerebral do agente inalatório; portanto, para os anestésicos voláteis de uso contemporâneo (isoflurano, sevoflurano, desfluorano) o tempo de 15 minutos permite equilíbrio ainda mais próximo de 100\% uma vez que todos estes fármacos apresentam coeficiente de solubilidade menor que o halotano. ${ }^{40}$

A concentração expirada de um anestésico é considerada uma aproximação razoável da pressão parcial alveolar, sendo possíveis erros minimizados quando a diferença entre pressão parcial inspirada e expirada do anestésico é pequena, ou seja, com o uso de anestésicos de baixa solubilidade ou em situações normais de débito cardíaco e relação ventilação/perfusão. ${ }^{40}$ 


\subsubsection{Critérios para determinação da CAM}

Embora o conceito clássico de CAM esteja baseado na resposta motora, a determinação de CAM pode ser baseada na resposta autonômica $\left(\mathrm{CAM}_{\mathrm{BAR}}\right)^{46}$, ou nível de hipnose $\left(\mathrm{CAM}_{\mathrm{BIS}}\right){ }^{47-49}$ Uma limitação neurofisiológica da determinação da CAM com base na resposta motora reside no fato de que os movimentos obtidos durante a resposta positiva podem ser de origem medular reflexa sem a participação do córtex cerebral, ou seja, sem envolver uma reposta de despertar do estado de inconsciência. ${ }^{50-51}$ Além disso, estudos sugerem que a capacidade de agentes inalatórios, como o isoflurano, em produzir imobilidade é relacionada a estruturas subcorticais, destacando a importância destas estruturas na geração de movimentos em resposta à estímulo doloroso. ${ }^{52-53}$

Outra limitação a aplicabilidade clínica dos valores de CAM reside no o

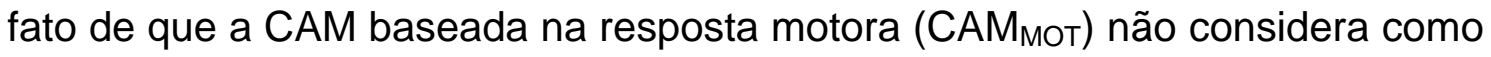
respostas positivas parâmetros que são clinicamente importantes para o julgamento da profundidade anestésica como: movimentos de deglutição, mastigação, tosse, movimentos discretos de membros, e elevações da freqüência cardíaca e pressão arterial. ${ }^{40,46}$

Assim sendo, para Roizen et al $^{46}$ (1981) um nível adequado de anestesia deve não somente prevenir a resposta motora mas sim abolir ou diminuir a resposta neuroendócrina ao estímulo nociceptivo. Baseados nisso, os autores descrevem uma metodologia de determinação de CAM utilizando como critério para uma resposta positiva a estimulação nociceptiva aumentos superiores a $10 \%$ da freqüência cardíaca, pressão arterial, diâmetro pupilar ou concentrações plasmáticas de norepinefrina, em relação aos valores basais anteriores à incisão. ${ }^{46}$ Com base no critério de resposta positiva acima descrito os valores de CAMBAR observados por Roizen et al (1981) foram cerca de 50\% maiores que os observados para a CAM MOT $_{\text {(1 }}$ CAM $_{\text {BAR }}=1.5$ CAM $_{\text {MOT }}$ ). Com base nestes achados, pode-se concluir que durante a redução progressiva da concentração expirada do anestésico volátil em animais submetidos à estimulação nociceptiva, haverá ativação autonômica (taquicardia e 
hipertensão) antes que o animal apresente movimentação. Embora a CAM BAR proporcione marcante redução da estimulação simpática e neuroendócrina, uma maior depressão da função respiratória e cardíaca podem ocorrer pela utilização de doses maiores de anestésicos voláteis. ${ }^{46}$

O índice bispectral (BIS) é uma escala numérica com limites de 0 a 100 obtida através da análise do eletroencefalograma (EEG), este índice vem sendo utilizado para monitorar o grau de hipnose durante a anestesia. ${ }^{48-49,54}$ Em humanos, valores de BIS variando entre 40-65 representam um plano adequado de anestesia, caracterizado por inibição das respostas autonômicas e motoras caudadas pelo estímulo cirúrgico. ${ }^{54}$ Este índice vem sendo utilizado como critério para caracterização de resposta positiva na determinação da CAM $\left(\mathrm{CAM}_{\mathrm{BIS}}\right)$, definida como a média aritmética entre a maior concentração alveolar que previne o aumento dos valores do BIS acima de um determinado limiar e a menor concentração alveolar que permite o aumento dos valores de BIS acima deste limiar em resposta a estimulação nociceptiva .47,49 Os resultados em ambos os estudos, demonstram que a $\mathrm{CAM}_{\mathrm{BIS}}$ apresenta valores significativamente mais elevados que os valores encontrados para a CAM MOT 47,49 sendo no entanto muito similares aos valores encontrados para a CAM $_{\text {BAR. }}{ }^{49}$. Estes achados sugerem que, durante a redução progressiva da concentração expirada do agente volátil em animais submetidos a estimulação nociceptiva, elevações do BIS acima de determinado limiar (60 para felinos ${ }^{49}$ ou 75 para caninos ${ }^{47}$ ) ocorrerão antes da observação de movimentação.

\subsubsection{Outros fatores que interferem na CAM}

Além de fatores relacionados à sua determinação, como estabilidade e equilíbrio entre a concentração arterial e cerebral do agente anestésico, tipo de estímulo nociceptivo empregado e caracterização de resposta motora evidente; fatores externos e condições clínicas podem provocar interferência nos valores obtidos de CAM. ${ }^{41}$ 


\section{- Hipo ou hipercapnia:}

Valores de $\mathrm{PaCO}_{2}$ entre 15 e $95 \mathrm{mmHg}$ não afetam a CAM do halotano em cães. No entanto, situações de hipercapnia extrema $\left(\mathrm{PaCO}_{2}>95 \mathrm{mmHg}\right)$, associadas a valores de $\mathrm{pH}$, no sangue arterial e líquido cerebroespinhal, inferiores a 7,10 produzem narcose e portanto apresentam efeito redutor sobre os valores de CAM. ${ }^{55}$

Cullen \& $\operatorname{Eger}^{56}$ (1971) demonstraram que situações de hipocapnia extrema $\left(\mathrm{PaCO}_{2}<10 \mathrm{mmHg}\right)$ em cães, não alterou os valores de CAM quando o halotano foi diluído em oxigênio, porém resultou em discreta redução (cerca de $10 \%$ ) com o emprego do halotano diluído em ar.

\section{- Acidose metabólica:}

A acidose metabólica ( $\mathrm{pH}=7,20)$ induzida pela administração de cloridrato de amônia pela via intravenosa promoveu diminuição de $19 \%$ nos valores da CAM em cães anestesiados com halotano. No entanto tal alteração, segundo os autores, poderia ser atribuída mais ao aumento das concentrações plasmáticas de amônia, um composto capaz de produzir depressão do SNC, do que a acidose metabólica. ${ }^{40}$

\section{- Hipoxemia:}

Os valores de CAM em cães anestesiados com halotano não sofrem alterações com a $\mathrm{PaO}_{2}$ entre 38 e $500 \mathrm{mmHg}$. Valores de $\mathrm{PaO}_{2}$ abaixo de 38 $\mathrm{mmHg}$, induzem narcose progressiva, ocorrendo redução dos valores de CAM em cerca de $20 \%$. $^{57}$ 


\section{- Hipovolemia e hipotensão:}

De forma geral, a redução da pressão arterial, seja pelo uso de fármacos vasodilatadores ou em decorrência de hemorragia, reduz o requerimento de anestésicos voláteis. Tanifuji \& $\operatorname{Eger}^{58}$ (1976) demonstraram o efeito da hipotensão arterial (PAM entre $40-50 \mathrm{mmHg}$ ) sobre a CAM do halotano em cães, encontrando redução dos valores de CAM em torno de $20 \%$. Situações de hipovolemia resultantes de hemorragia também podem promover uma redução da CAM dos anestésicos voláteis. Em cães anestesiados com isoflurano, após a indução de hipovolemia por hemorragia (remoção de 30 $\mathrm{mL} / \mathrm{kg}$ de sangue durante 30 minutos), a CAM do isoflurano apresentou uma redução de aproximadamente $15 \%$ em comparação com cães normovolêmicos. ${ }^{59}$

\section{- Gestação:}

Em estudo realizado em ovinos, a gestação ocasionou reduções nos valores da CAM do halotano (25\%), metoxiflurano (32\%) e isoflurano (40\%), possivelmente pela mudança na concentração plasmática de progesterona ou combinação das mudanças hormonais que ocorrem durante o período gestacional. ${ }^{60}$

\section{- Temperatura corpórea:}

A diminuição da temperatura corpórea produz uma redução linear da CAM do halotano em cães, atingindo aproximadamente $50 \%$ de redução após uma diminuição na temperatura de $38^{\circ} \mathrm{C}$ para $28^{\circ} \mathrm{C} .{ }^{61}$

Com temperaturas corpóreas acima de $37,3^{\circ} \mathrm{C}$ a CAM aumenta em $27 \%$ até uma temperatura de $40,7^{\circ}$ (em torno de $8 \%$ de aumento para cada $1^{\circ} \mathrm{C}$ ); acima de $42^{\circ} \mathrm{C}$ os valores de CAM diminuem. ${ }^{62}$ (figura 1 ) 


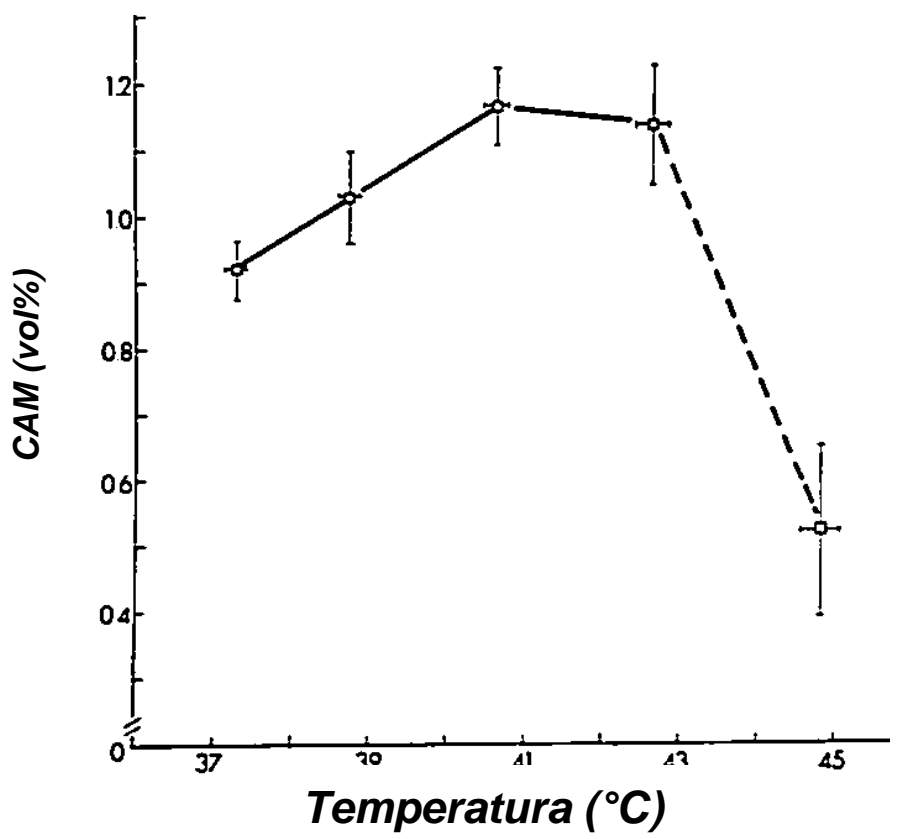

Figura 1: Efeito da temperatura sobre os valores de CAM. Valores expressos em média \pm DP. (Fonte: Steffey \& Eger, 1974).

- Idade:

De modo geral,em seres humanos, o requerimento de anestésicos inalatórios diminui com a idade, as possíveis causas para essa redução são alterações de consumo de oxigênio cerebral, densidade neuronal e fluxo sanguíneo cerebral. ${ }^{63-64}$ (figura 2)

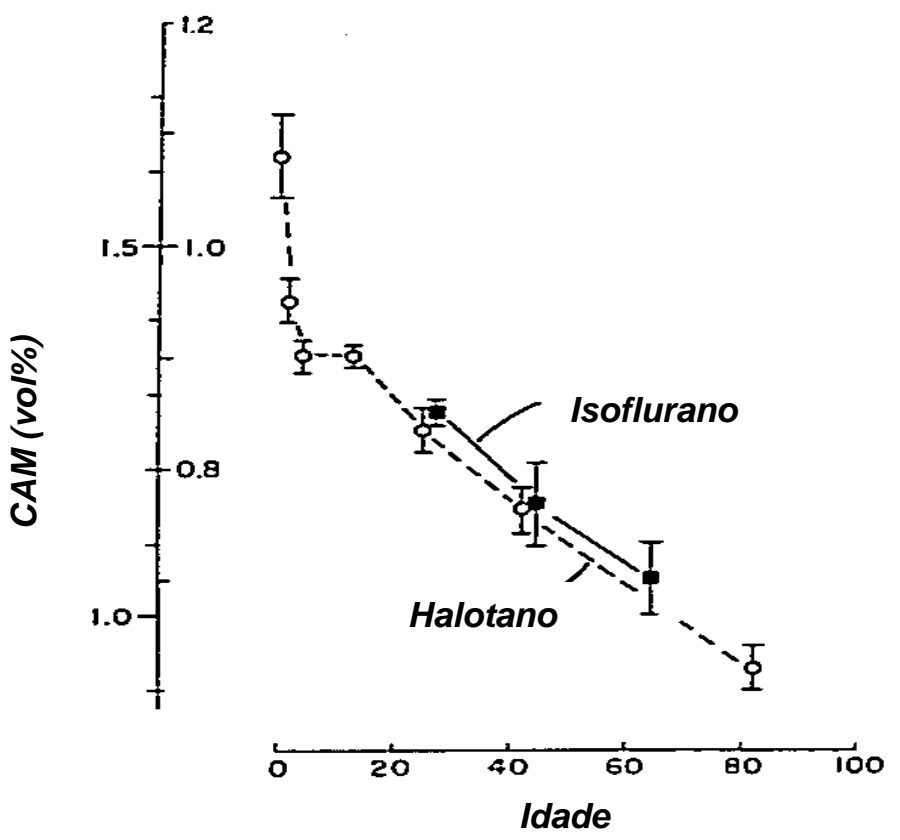

Figura 2: Valores de CAM do halotano $(O)$ e isoflurano $(\boldsymbol{\square})$ em relação à idade em humanos. Valores expressos em média \pm DP. (Fonte: Stevens et al., 1975) 
Outros fatores como ritmo circadiano, desequilíbrios hidro-eletrolíticos, hipo ou hipertireoidismo e a administração de fármacos analgésicos, sedativos, naloxona, anticolinesterásicos, anestésicos locais ou mesmo a combinação de outros anestésicos inalatórios também podem promover alterações nos valores de CAM. No entanto, a duração da anestesia (por até 500 minutos em cães anestesiados com halotano, segundo Eger et al. ${ }^{40}$ e o sexo parecem não ter influência sobre os valores de CAM. ${ }^{41}$

\subsection{NEOSTIGMINA}

A neostigmina é um agente anticolinesterásico, freqüentemente utilizada para antagonizar a ação de bloqueadores neuromusculares competitivos (ex. atracúrio, vecurônio). Seu mecanismo de ação é através da inibição de enzimas de hidrolisam a acetilcolina (colinesterases), provocando o acúmulo deste neurotransmissor junto a receptores colinérgicos encontrados na junção neuromuscular, eritrócitos, terminações nervosas e músculos ${ }^{9}$.

Os efeitos analgésicos da neostigmina isolada foram primeiramente observados em ovinos, após sua administração pela via intratecal. ${ }^{11,35}$ e sua associação com agonistas alfa 2 adrenérgicos (clonidina ou dexmedetomidina), também pela via intratecal, demonstrou uma potencialização dos efeitos antinociceptivos destes fármacos. ${ }^{36-37}$ Estudos também demonstraram que além da vantagem na potencialização analgésica da neostigmina sobre os agonistas alfa 2 adrenérgicos (clonidina), sua associação a estes fármacos pode neutralizar o efeito hipotensor produzido pela clonidina quando administrada pela via intratecal em ovinos. ${ }^{36,65}$

O mecanismo colinérgico na antinocicepção deve-se possivelmente ao aumento das concentrações de acetilcolina e da síntese de óxido nítrico na medula espinhal, ${ }^{36-37,66-67}$ relacionado à ativação de receptores muscarínicos e nicotínicos localizados na medula espinhal. ${ }^{68-69}$ No entanto, uma diferença 
entre sexo pode ocorrer uma vez que estudos em ratos evidenciaram uma maior eficácia antinociceptiva da neostigmina em fêmeas, possivelmente devido a uma maior concentração de receptores nicotínicos espinhais. ${ }^{68,70}$

As análises histopatológicas da medula espinhal após administração crônica de neostigmina intratecal, com e sem conservantes, em ratos e cães não revelaram toxicidade ${ }^{71-72} \mathrm{Em}$ ovinos, seu uso isolado ou em associação à clonidina pela via intratecal não resultou em alterações de fluxo sanguíneo na medula espinhal ${ }^{73}$. Estudos em humanos com a administração intratecal de neostigmina, com e sem conservantes, não encontraram evidência clínicas de neurotoxicidade..$^{15,74}$

No homem, a neostigmina vem sendo empregada no alivio da dor pósoperatória pela via espinhal, visando potencializar a duração e efeito analgésico de outros fármacos. ${ }^{12,16-17,34,66,75}$ Inicialmente a neostigmina foi empregada isoladamente ou em associação com outros fármacos (opióides, anestésicos locais ou agonistas de receptores alfa 2 adrenérgicos) pela via intratecal, produzindo efeitos analgésicos pós-operatórios satisfatórios em pacientes submetidos a diversos tipos de cirurgias. ${ }^{75-80}$

A neostigmina (50 $\mu \mathrm{g}, 100 \mu \mathrm{g}$ e $200 \mu \mathrm{g}$ ) apresentou eficácia dosedependente quando administrada pela via intratecal em pacientes humanos submetidos à vaginoplastia, potencializando a eficácia analgésica dos opióides (50 $\mu \mathrm{g}$ de neostigmina associada à $50 \mu \mathrm{g}$ de morfina, pela via intratecal). ${ }^{77} \mathrm{Em}$ outro estudo também realizado em pacientes submetidos a vaginoplastia, a neostigmina intratecal $(100 \mu \mathrm{g})$ apresentou eficácia analgésica similar à da morfina intratecal $(100 \mu g)$; porém a incidência de hipotensão foi menor no grupo tratado com neostigmina. ${ }^{75}$

A associação deste colinomimético também é possível com anestésicos locais pela via intratecal, uma vez que a neostigmina nas doses de $50 \mu \mathrm{g}$ e 100 $\mu \mathrm{g}$, promoveu uma redução do período de latência (de 5 minutos para aproximadamente 2 minutos) da tetracaína (15 mg dose total) além de uma maior duração do efeito analgésico no período pós-operatório de pacientes 
submetidos à herniorrafia inguinal (4 horas de analgesia da tetracaína isolada versus 6 a 9 horas quando associada a neostigmina). No entanto, a dose mais elevada de neostigmina $(100 \mu \mathrm{g})$ resultou em um aumento significativo de efeitos colaterais como tontura, ansiedade, náusea e êmese. ${ }^{80}$

Por outro lado, embora estudos comprovem sua eficácia analgésica e efeito potencializador de outros fármacos, seu uso pela via intratecal em humanos tornou-se restrito em decorrência da elevada incidência de seus efeitos colaterais como sedação ou excitação, bradicardia e principalmente náusea e êmese de forma dose dependente. ${ }^{15,75,78-80}$

Diante disto, a via peridural tornou-se uma alternativa à via intratecal uma vez que a incidência e intensidade de efeitos colaterais após administração de neostigmina por esta via parece ser ausente ou reduzida. ${ }^{16-}$

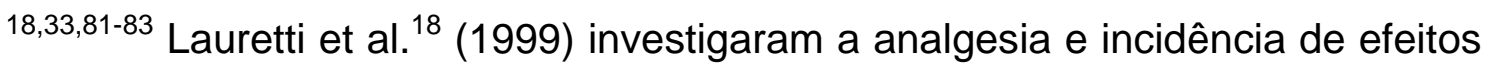

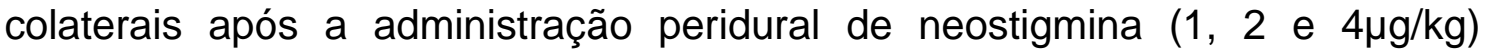
associada a lidocaína, em pacientes submetidos à cirurgia de joelho. Os resultados deste estudo demonstraram um efeito analgésico eficaz (aproximadamente $8 \mathrm{~h}$ ) quando comparados ao grupo controle com redução do consumo de fármacos de resgate no período pós operatório sem um aumento na incidência de efeitos colaterais.

Em pacientes submetidos à cirurgia em joelho a administração de 1 $\mu \mathrm{g} / \mathrm{kg}$ de neostigmina peridural resultou em analgesia pós-operatória próxima de 4 horas, similar a administração intraarticular de $500 \mu \mathrm{g}$ (dose total) de neostigmina enquanto que a dose de $1 \mu \mathrm{g} / \mathrm{kg}$ intraarticular não apresentou efeito analgésico, demonstrando que embora a neostigmina apresente eficácia analgésica por outras vias de administração, a via peridural apresenta uma melhor relação dose-efeito. ${ }^{81}$ A administração de neostigmina $(10 \mu \mathrm{g} / \mathrm{kg}) \mathrm{em}$ associação com a bupivacaína peridural, promoveu analgesia de maior duração que a utilização de bupivacaína de forma isolada ou associada à neostigmina $(5 \mu \mathrm{g} / \mathrm{kg})$ em mulheres submetidas à histerectomia abdominal. ${ }^{17}$ 
Roelants et $\mathrm{al}^{33}$. (2005) investigaram a eficácia analgésica da neostigmina ( $750 \mu \mathrm{g}$ dose total ou 8 a $9 \mu \mathrm{g} / \mathrm{Kg}$ ) administrada isoladamente pela via peridural em parturientes na primeira fase do trabalho de parto, não observando efeitos analgésicos satisfatórios, possivelmente pela sua maior eficácia analgésica na dor somática que na dor visceral. Neste estudo, os autores ainda hipotetizaram que a falta de efeitos analgésicos da neostigmina peridural poderia ser atribuída a uma dose insuficiente para se atingir a concentração espinhal necessária para analgesia. Embora a neostigmina isolada pela via peridural não apresente analgesia satisfatória em parturientes, a administração de 500 ou $750 \mu$ de neostigmina em associação a um agonista alfa 2 adrenérgico (clonidina $75 \mu \mathrm{g}$, dose total), produziu analgesia satisfatória durante o parto natural em mulheres, com ausência de efeitos colaterais. ${ }^{33}$ De forma semelhante, outros estudos demonstram um incremento na analgesia pós operatória após a associação peridural de neostigmina a outros fármacos, sem a incidência de efeitos colaterais ou déficit de deambulação. ${ }^{82-85}$

Embora a ação analgésica da neostigmina pela via intratecal e peridural venha sendo extensivamente estudada em pacientes humanos, como discutido anteriormente, as investigações da ação analgésica deste fármaco em animais de companhia é escassa. Em um estudo recente realizado em cadelas submetidas à ovariosalpingohisterectomia, a neostigmina peridural (10 $\mu \mathrm{g} / \mathrm{kg})$ reduziu a necessidade de analgesia suplementar no período pós-operatório em comparação ao grupo controle, porém, quando administrada em associação com a morfina peridural $(0,1 \mathrm{mg} / \mathrm{kg})$, não potencializou a analgesia induzida pelo opióide ${ }^{19}$. 


\subsection{CLONIDINA}

Os agonistas de receptores alfa-2 adrenérgicos são fármacos de grande utilidade em pequenos animais devido aos seus efeitos sedativos, analgésicos e miorrexalantes. ${ }^{86}$ Seu mecanismo de ação sistêmico é atribuído à estimulação de receptores alfa-2 adrenérgicos no sistema nervoso central e periférico promovendo inibição da liberação de norepinefrina pelos terminais nervosos. ${ }^{87}$ Devido aos seus efeitos analgésicos e sedativos intensos, os agonistas alfa-2 adrenérgicos são empregados na medicação pré-anestésica visando reduzir os requerimentos de anestésicos injetáveis e inalatórios necessários à indução e manutenção da anestesia. ${ }^{20,88-90} \mathrm{~A}$ administração intravenosa de clonidina nas doses de 5 ou $20 \mu \mathrm{g} / \mathrm{kg}$, em cães anestesiados com halotano, promoveu redução máxima da CAM em 42 e 48\%, respectivamente. ${ }^{20}$

Apesar destas vantagens, o uso do agonista alfa-2 adrenérgico xilazina em anestesia de pequenos animais não é aceito como prática segura por um grande número de profissionais, uma vez que o uso da xilazina foi relacionado como causa de aumento na taxa de mortalidade associada à anestesia em cães. $^{91} \mathrm{O}$ maior risco de mortalidade associada ao uso da xilazina provavelmente é associado a sua marcante interferência sobre a função cardiorrespiratória. $^{92} \mathrm{Em}$ estudos mais recentes, no entanto, fármacos agonistas alfa-2 adrenérgicos como a medetomidina não vem sendo associados a maior incidência de morbidade ou mortalidade em animais de companhia. $^{93}$

\subsubsection{Efeitos hemodinâmicos}

Os efeitos hemodinâmicos dos agonistas alfa-2 adrenérgicos são decorrentes da estimulação de receptores alfa-2 pré e pós-sinápticos, causando um efeito bifásico sobre a pressão arterial. Observa-se inicialmente elevação da pressão arterial e da pós-carga ventricular esquerda pela ativação de receptores alfa-2 pós sinápticos na musculatura lisa arterial ocasionando 
aumento da resistência vascular sistêmica. ${ }^{90,94-96}$ A elevação da pressão arterial é associada ao aumento da atividade dos baroceptores carotídeos e aórticos, resultando em aumento do tônus vagal e bradicardia reflexa. ${ }^{95,97} \mathrm{~A}$ redução da freqüência cardíaca, associada à elevação da pós-carga (aumento da resistência vascular sistêmica), resulta em redução do débito cardíaco, que apesar de diminuído é redistribuído para órgãos vitais como cérebro, coração, fígado e rins além de uma diminuição no requerimento de oxigênio para os demais órgãos. ${ }^{95,97-98}$

Após essa fase vasopressora prevalecem os efeitos pré-sinápticos destes fármacos (diminuição do tônus simpático), que resultam em diminuição da resistência vascular sistêmica e da pressão arterial. A bradicardia também persiste e a ocorrência de bradiarritmias e bloqueio átrio-vetriculares também são comuns devido à diminuição do tônus simpático e conseqüente prevalência do tônus vagal. ${ }^{95-97}$

Em pequenos animais o uso de anticolinérgicos como a atropina e o glicopirrolato para prevenir a bradicardia vagal causada pela administração de alfa-2 agonistas é geralmente contra indicado por promover taquicardia acompanhada de hipertensão severa, o que pode precipitar episódios de hipóxia de miocárdio devido a um aumento exagerado do trabalho ventricular esquerdo e do consumo de oxigênio pelo miocárdio ${ }^{99-100}$

Em cães anestesiados com halotano a administração peridural de clonidina entre a $2^{\mathrm{a}}$ vértebra lombar e $1^{\mathrm{a}}$ vértebra torácica, em doses cumulativas de $3 \mu \mathrm{g} / \mathrm{kg}$ a cada 45 minutos (dose total de $9 \mu \mathrm{g} / \mathrm{kg}$ ), causou reduções da pressão arterial, débito cardíaco e freqüência cardíaca da ordem de 15, 21 e 25\%, respectivamente. ${ }^{101}$. De acordo com os autores tais alterações hemodinâmicas foram compatíveis com uma possível absorção sistêmica e/ou distribuição cranial do fármaco no canal medular. ${ }^{101}$ Estudos mais recentes confirmam que a administração peridural de alfa-2 agonistas em cães anestesiados com isoflurano resulta em bradicardia durante a anestesia $^{23,102}$ e êmese no período pós anestésico imediato ${ }^{23}$, fenômenos provavelmente decorrentes da absorção do fármaco peridural para a circulação sistêmica. 


\subsubsection{Efeito analgésico}

O efeito analgésico obtido por estes fármacos, tanto pela via sistêmica quanto pela via intratecal ou peridural, deve-se à ativação de receptores alfa-2 adrenérgicos localizados nas terminações primárias aferentes, na lâmina superficial do corno dorsal da medula e núcleos cerebrais (locus coeruleus) envolvidos na analgesia. ${ }^{37,103-105}$ Seu efeito antinociceptivo é atribuído em parte, a inibição pré-sinaptica da liberação de neurotransmissores excitatórios (glutamato, substância P) pelas fibras nociceptivas aferentes. ${ }^{106-107}$ Além disso, a síntese de óxido nítrico, também pode estar envolvida na antinocicepção dos agonistas alfa-2 adrenérgicos administrados pela via espinhal, uma vez que a administração de um inibidor da síntese de óxido nítrico (N-metil-L-arginina) reverteu os efeitos antinociceptivos da clonidina intratecal em ovinos. ${ }^{36}$

Em humanos, a clonidina é amplamente utilizada como analgésico no período perioperatório, como adjuvante na terapia antálgica em queimados, no tratamento da dor crônica ou mesmo dor oncológica. Este alfa-2 agonista é administrado pelas vias intravenosa, intramuscular ou espinhal, apresentando vantagens em relação aos opióides (morfina) como ausência de prurido e depressão respiratória ${ }^{24-28,108}$

Na medicina veterinária seu uso não é comum, embora muitos estudos tenham sido inicialmente realizados em modelos animais ${ }^{20,31,37,109-110}$. Há uma relativa escassez de estudos controlados empregando a clonidina em cães, não se conhecendo a doses clínica recomendadas ou sua eficácia sedativa e analgésica nesta espécie.

\subsubsection{Uso peridural}

Os efeitos antinociceptivos dos agonistas de receptores alfa 2 adrenérgicos, quando administrados pela via espinhal, além de ser decorrente da liberação de neurotransmissores inibitórios (glutamato e substância P) pelos neurônios aferentes, também podem ser atribuídos a liberação de acetilcolina 
no corno dorsal da medula e conseqüente aumento da concentração deste neurotransmissor no líquido cérebro espinhal. ${ }^{37,66,111}$ Detweiler et $\mathrm{al}^{37}$. (1993) demonstraram que a administração de clonidina intratecal em ovinos causou um aumento da concentração de acetilcolina no líquido cérebro espinhal, sendo que este aumento foi potencializado pela neostigmina intratecal e bloqueado pelo idazoxan (antagonista de receptores alfa 2 adrenérgicos).

Em ratos, observou-se que o efeito antinociceptivo da administração de agonistas de receptores alfa 2 adrenérgicos pela via peridural (dexmedetomidina, clonidina e tizanidina) resulta em analgesia comparável a analgesia obtida com seu emprego pela via sistêmica, porém em doses aproximadamente 5 vezes menores. ${ }^{112}$

A utilização de peridural clonidina, em humanos, é associada a um menor requerimento de analgésico no período intra e pós operatório imediato, quando comparada à via intravenosa. ${ }^{26,29-30}$ Com o emprego de um sistema de infusão controlada pelo paciente (bolus inicial de $8 \mu \mathrm{g} / \mathrm{kg}$ seguido de administrações de $30 \mu \mathrm{g}$ [dose total] a intervalos mínimos de 15 minutos), Bernard et $\mathrm{al}^{26}$. (1995) demonstram que tanto a administração de clonidina pela via peridural como pela via intravenosa resultou em eficácia analgésica similar no período pós operatório. No entanto, a via peridural foi associada a uma dose auto-administrada de clonidina significativamente menor que no grupo intravenoso seguido de menores concentrações plasmáticas de clonidina e menor grau de sedação. ${ }^{26}$

A infusão peridural de clonidina por período prolongado em cães nas doses totais de 80, 200 ou $320 \mu \mathrm{g} / \mathrm{h}$ (aproximadamente 5, 13 ou $21 \mu \mathrm{g} / \mathrm{kg}$ ) em um volume final de $4 \mathrm{ml}$ a cada $24 \mathrm{~h}$ por 28 dias, demonstrou efeito antinociceptivo dose dependente, com redução da freqüência cardíaca, pressão arterial e freqüência respiratória, sem prejuízo da função motora ou temperatura corpórea ${ }^{31}$. Contudo, independentemente da dose de clonidina administrada, os animais desenvolveram tolerância durante a infusão crônica do alfa-2 agonista, uma vez que o limiar de resposta ao estímulo nociceptivo térmico se reduziu progressivamente com o decorrer do tempo ${ }^{31}$ (figura 3) 

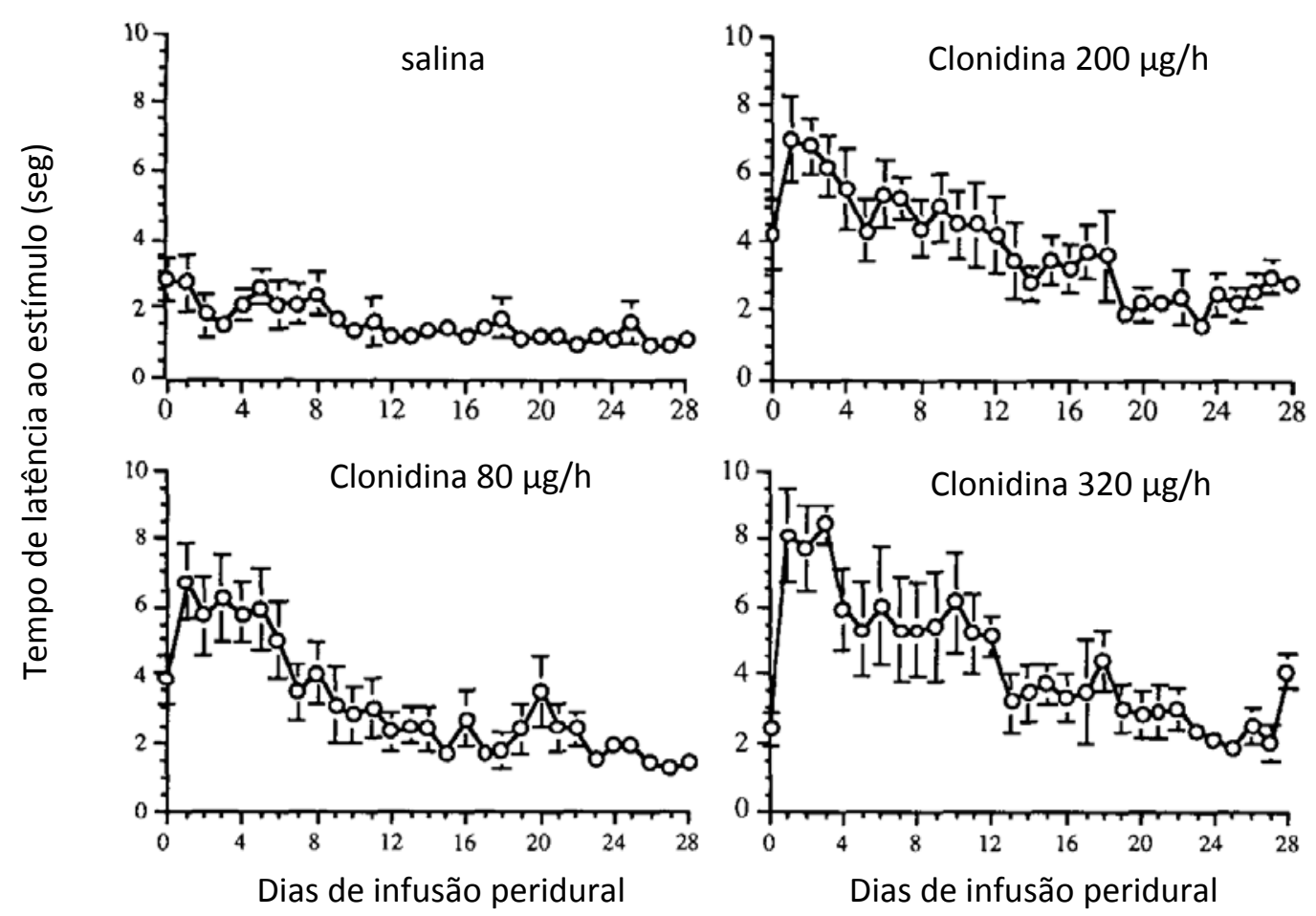

Figura 3: Tempo de latência (seg) da resposta de pele ao estímulo térmico versus o tempo de infusão peridural (dias) de salina, clonidina 80, 200 e $320 \mu \mathrm{g} / \mathrm{h}$ em cães. (Fonte: Yaksh et al., 1994)

Similarmente a administração sistêmica, a administração peridural de agonistas de receptores alfa-2 adrenérgicos potencializa os anestésicos voláteis em cães. ${ }^{23,102,113} \mathrm{Em}$ cães, as doses de 1,5 - 3 e $6 \mu \mathrm{g} / \mathrm{kg}$ de dexmedetomidina peridural resultaram em reduções da CAM do isoflurano da ordem de 13, 29 e 31\% após 2 horas da sua administração, respectivamente. Os autores observaram, no entanto, um decréscimo desta ação potencializadora do isoflurano após 4,5 horas sua administração peridural. ${ }^{23}$ Não existem estudos na literatura consultada avaliando os efeitos da administração peridural de clonidina na CAM do isoflurano em cães. 


\subsection{INTERAÇÃO ENTRE A NEOSTIGMINA E AGONISTAS ALFA-2 ADRENÉRGICOS ADMINISTRADOS PELA VIA ESPINHAL}

O mecanismo da antinocicepção dos agonistas alfa-2 adrenérgicos administrados pela via espinhal está relacionado com ativação de vias colinérgicas, mecanismo similar à analgesia induzida pela neostigmina espinhal. ${ }^{11,37,67}$ Há evidências na literatura de que se pode obter um sinergismo analgésico ao se combinar a neostigmina com agonistas alfa-2 adrenérgicos. $^{33,35,85,114}$

Estudos demonstram a existência de uma interação entre a via colinérgica e a via alfa-2 adrenérgica na antinocicepção pela via espinhal em ovinos $^{36-37}$. Embora o mecanismo ainda não seja completamente elucidado, tal potencialização deve-se possivelmente ao fato de tanto os agonistas de receptores alfa-2 adrenérgicos como os agentes colinomiméticos elevarem a concentração de acetilcolina e a síntese de óxido nítrico no líquido cérebro espinhal. $^{35-37}$

Em ovinos, a neostigmina em associação com agonistas alfa-2 adrenérgicos (clonidina ou dexmedetomidina) pela via intratecal, além de promover um incremento na antinocicepção. ${ }^{35-37}$ neutralizou a hipotensão decorrente da administração do agonista alfa-2 pela via intraespinhal. ${ }^{37,65}$ Bouaziz et al (1995) observaram que a neostigmina intratecal (1 mg, dose total) potencializou a analgesia dos agonistas alfa 2 adrenérgicos (clonidina e dexmedetomidina) administrados pela mesma via. ${ }^{35}$

Em humanos a associação de neostigmina (0,3 $\mathrm{mg}$, dose total) pela via peridural e dexmedetomidina (bolus de $1 \mu \mathrm{g} / \mathrm{kg}$, seguido $0,4 \mu \mathrm{g} / \mathrm{kg} / \mathrm{h}$ ) pela via intravenosa promoveu redução dos escores de dor pós operatória em mulheres submetidas à cirurgia ginecológica de forma mais eficaz que o uso da dexmedetomidina isoladamente. ${ }^{114}$ 
Durante o parto em humanos, o emprego de neostigmina peridural (500 a $750 \mu \mathrm{g}$ ) pode melhorar a analgesia induzida por outros fármacos administrados pela mesma via (clonidina, ropivacaína ou sulfentanil). ${ }^{33,84-85,115}$ Van de Velde et al. ${ }^{85}$ (2009) investigaram os efeitos da administração peridural de clonidina e neostigmina (75 e $500 \mu \mathrm{g}$, respectivamente) sobre o tempo de analgesia e requerimento adicional de ropivacaína peridural em mulheres durante o trabalho de parto após a injeção intratecal de ropivacaína e sulfentanil. Os resultados deste estudo corroboram com outros estudos onde a associação peridural destes fármacos prolonga o tempo de analgesia com diminuição do consumo de analgésicos adicionais ${ }^{33,84-85}$ 
3. Hípótese 
Diante da documentada ação analgésica e potencial efeito redutor sobre o requerimento de anestésicos da associação de neostigmina com clonidina pela via espinhal, hipotetizou-se no presente projeto de pesquisa que a administração peridural de neostigmina $(10 \mu \mathrm{g} / \mathrm{kg})$ potencializaria a redução da CAM do isoflurano obtida com clonidina $(20 \mu \mathrm{g} / \mathrm{kg})$ em cães. Para investigar tal hipótese. o presente estudo determinou os efeitos da administração isolada da neostigmina $(10 \mu \mathrm{g} / \mathrm{kg})$, da clonidina $(20 \mu \mathrm{g} / \mathrm{kg})$ e da associação destes fármacos pela via peridural sobre a CAM do isoflurano em cadelas. 
4. Objetivos 
O presente estudo objetivou:

$\checkmark$ Determinar os efeitos da administração peridural de neostigmina $(10 \mu \mathrm{g} / \mathrm{kg})$ sobre a concentração alveolar mínima do isoflurano (CAMISo) em cães após 2,5 e 5 horas de administração do fármaco.

$\checkmark \quad$ Determinar os efeitos da administração peridural de clonidina (20 $\mu \mathrm{g} / \mathrm{kg}$ ) sobre a CAM ${ }_{\mathrm{ISO}}$ em cães após 2,5 e 5 horas de administração do fármaco.

$\checkmark \quad$ Determinar os efeitos da associação de neostigmina (10 $\mu \mathrm{g} / \mathrm{kg}) \mathrm{e}$ clonidina $(20 \mu \mathrm{g} / \mathrm{kg})$ peridural, sobre CAM Iso em cães, após 2,5 e 5 horas de administração dos fármacos.

Avaliar os efeitos cardiovasculares resultantes da administração peridural de neostigmina (10 $\mu \mathrm{g} / \mathrm{kg})$, clonidina $(20 \mu \mathrm{g} / \mathrm{kg})$ ou associação, em cães anestesiados com isoflurano.

Avaliar as características da recuperação anestésica após administração peridural de neostigmina $(10 \mu \mathrm{g} / \mathrm{kg})$, clonidina $(20 \mu \mathrm{g} / \mathrm{kg})$ ou associação, em cães anestesiados com isoflurano. 


\section{Materiais e Métodos}


Esta pesquisa foi aprovada pela Câmara de Ética em Experimentação Animal da Faculdade de Medicina da Universidade Estadual Paulista "Júlio de Mesquita filho", Campus de Botucatu/SP, sob o protocolo $n^{\circ} 37 / 2008-$ CEEA, de acordo com os princípios éticos adotados pelo Colégio Brasileiro de Experimentação Animal.

\subsection{ANIMAIS}

Foram utilizados seis cães adultos fêmeas, sem raça definida, castradas, pesando $14,9 \pm 2,0 \mathrm{~kg}$ (média $\pm \mathrm{DP}$ ), pertencentes ao canil experimental da Faculdade de Medicina Veterinária e Zootecnia - UNESP- Botucatu. A higidez dos animais foi comprovada através de exame clínico, hemograma, bioquímico (perfil renal e hepático), radiografia (para avaliação cardiopulmonar), eletrocardiograma e sorologia negativa para leishmaniose.

\subsection{DELINEAMENTO E PROTOCOLO EXPERIMENTAL}

Cada animal recebeu de forma aleatória, através de sorteio, um de três diferentes tratamentos pela via peridural, com intervalo mínimo de uma semana entre cada tratamento:

$\checkmark \quad$ Neostigmina (NEO) $10 \mu \mathrm{g} / \mathrm{kg}$

$\checkmark$ Clonidina (CLO) $20 \mu \mathrm{g} / \mathrm{kg}$

$\checkmark \quad$ Neostigmina $10 \mu \mathrm{g} / \mathrm{kg}$ e Clonidina $20 \mu \mathrm{g} / \mathrm{kg}$ (NEO/CLO)

O volumes de todos os tratamentos peridurais foi ajustado para um volume final de $0,25 \mathrm{~mL} / \mathrm{kg}$, com solução salina ( $\mathrm{NaCl} 0,9 \%$ ), administrado durante 1 minuto. Após a administração de cada tratamento peridural, $1 \mathrm{~mL}$ de solução salina ( $\mathrm{NaCl}$ 0,9\%) foi administrado lentamente (1 minuto) através do 
cateter peridural de forma a garantir que toda a medicação alcançasse o canal peridural, não permanecendo no espaço morto do cateter (aproximadamente 0,3 ml). A administração peridural dos tratamentos era feita após a determinação dos valores basais de CAMIso em todos os grupos.

\subsection{PREPARO E INSTRUMENTAÇÃO DOS ANIMAIS}

Antes de cada experimento, os animais foram submetidos a jejum alimentar de doze horas, com água ad libitum.

Os animais foram induzidos com isoflurano, diluído em oxigênio, por meio de máscara facial. O vaporizador calibrado ${ }^{1}$ foi ajustado de forma a vaporizar uma concentração de $5 \%$ com um fluxo de $\mathrm{O}_{2}$ de $300 \mathrm{~mL} / \mathrm{kg} / \mathrm{min}$, até que os animais apresentassem ausência de reflexo interdigital e laringotraqueal, permitindo a intubação. Após intubação os animais foram conectados em um circuito circular valvular com fluxo de oxigênio a $50 \mathrm{~mL} / \mathrm{kg} / \mathrm{min}$ sendo o vaporizador ajustado de forma a manter um plano moderado de anestesia com base em critérios clínicos (relaxamento de mandíbula, ausência de reflexo palpebral e esforços respiratórios espontâneos durante a ventilação mecânica). Todos os animais foram submetidos à ventilação com pressão controlada ${ }^{2}$, sendo a pressão inspiratória máxima mantida entre 8 e $12(10 \pm 2$, valores médios $\pm \mathrm{DP}) \mathrm{cm} \mathrm{H}_{2} \mathrm{O}$ e a freqüência respiratória mantida entre 8 e $14(12 \pm 1$, valores médios \pm DP) movimentos por minuto, visando manter a $\mathrm{PaCO}_{2}$ entre 35 e $45 \mathrm{~mm} \mathrm{Hg}$. Nos períodos coincidentes com redução acentuada da concentração expirada de isoflurano (ET ISO) ou nos momentos da estimulação elétrica nociceptiva, onde os animais apresentavam esforços respiratórios espontâneos, foi adotada a ventilação assistida mandatória intermitente. A temperatura corpórea, monitorada através de termômetro esofágico cuja extremidade foi posicionada na porção torácica

\footnotetext{
${ }^{1}$ Inter VPZ ISO - Intermed, São Paulo, SP, Brasil - FAPESP Proc. 05/56586-7.

${ }^{2}$ Aparelho de Anestesia Inter Línea C - IntermedR, São Paulo, SP, Brasil - FAPESP Proc. 05/56586-7
} 
do esôfago, foi mantida entre 37.5 e $38.5^{\circ} \mathrm{C}\left(38,2 \pm 0,1^{\circ} \mathrm{C}\right.$, valores médios \pm DP) durante todo o experimento por meio colchão térmico ${ }^{3}$ e insuflador de ar aquecido. 4

Foram fixados eletrodos do tipo adesivo nos membros para monitoração da freqüência cardíaca (FC) que foi monitorada através do traçado eletrocardiográfico $^{5}$ na derivação II. Os animais foram posicionados em decúbito lateral para cateterização da veia cefálica, ${ }^{6}$ onde foi instituída a fluidoterapia com Ringer Lactato de sódio na taxa de $3 \mathrm{~mL} / \mathrm{kg} / \mathrm{h}$ através de bomba de infusão ${ }^{7}$. Também foi cateterizada a artéria dorsal podal ${ }^{6}$ a qual foi conectada a um transdutor de pressão $^{8}$ preenchido com solução salina heparinizada (4 UI/mL) e conectado ao monitor multiparamétrico ${ }^{5}$ para mensuração da pressão arterial sistólica, diastólica e média (PAS, PAD e PAM). A via de acesso arterial também foi utilizada para coleta de amostras de sangue arterial para análise hemogasométrica ${ }^{9}$, cujos valores foram corrigidos de acordo com a temperatura corpórea.

Para administração dos tratamentos pela via peridural, após tricotomia e anti-sepsia prévia, uma agulha de Tuohy $18 \mathrm{G}^{10}$ foi inserida num ângulo de 45$60^{\circ} \mathrm{com}$ a pele no espaço lombo-sacro (entre a $7^{\mathrm{a}}$ vértebra lombar e a $1^{\mathrm{a}}$ vértebra sacral). O posicionamento correto da agulha foi confirmando através da aspiração de solução salina inserida no canhão da agulha ou através da ausência de resistência à injeção de um pequeno volume de ar (1-2 mL). O cateter peridural $^{11}$ foi introduzido, de acordo com suas marcações, de forma a manter $10 \mathrm{~cm}$ de sua extensão no interior do canal peridural. Após a introdução do cateter a agulha de Tuhoy foi então retirada e o cateter fixado a pele do animal utilizando curativo adesivo transparente ${ }^{12}$. Os animais foram então posicionados em decúbito dorsal onde, após tricotomia e anti-sepsia prévias,

\footnotetext{
${ }^{3}$ Colchão térmo-elétrico Estek®, Ortovet, SP, Brasil.

${ }^{4}$ Patient Warming System - Warmtouch ${ }^{\circledR}$ - Mallinkrodt, Pleasanton, CA, EUA - FAPESP Proc. 07/03720-3

${ }^{5}$ Datex Ëngstrom A/S 3, Helsinki, Finland - FAPESP Proc. 98/00748-3.

${ }^{6}$ Insyte $20 \mathrm{G}$, Beckton Dickinson, São Paulo, SP, Brasil

${ }^{7}$ ST 560, Samtronic, São Paulo, SP, Brasil

8 TruWaveTM Disposable Pressure Transducer - Edwards Critical Care Division, EUA

${ }^{9} 348 \mathrm{pH}$ and Blood Gas Analizer - Ciba Corning Diagnostics Ltd., Inglaterra FAPESP Proc. 98/00748-3.

${ }^{10}$ Agulha de Tuohy, Becton Dickinson Ind. Cirúrgicas LTDA, Juiz de Fora, Minas Gerais, Brasil.

${ }^{11}$ Cateter peridural, Portex, Smiths Medical International Limited, England.

${ }^{12}$ NeoDerm®TM, ConMed corporation, NY, EUA.
} 
os eletrodos para estimulação nociceptiva ${ }^{13}$ foram conectados a 2 agulhas $30 \mathrm{x}$ 8 inseridas no tecido subcutâneo.

O tempo de instrumentação foi estabelecido como tendo início na intubação e o término após o posicionamento das agulhas para estimulação elétrica no tecido subcutâneo com duração de $42 \pm 15$ min.

\subsection{DETERMINAÇÃO DA CAM}

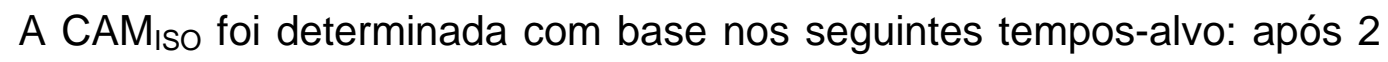

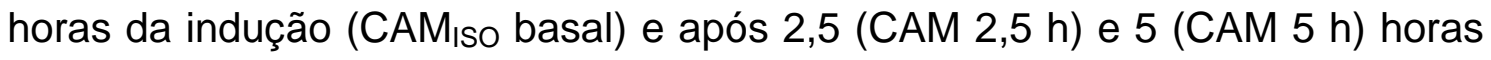
da administração dos tratamentos peridurais, com intervalo de tolerância de \pm 30 min em relação ao tempos-alvo. Caso a mensuração da CAM não fosse concluída dentro dos intervalos pré-estabelecidos o experimento era descartado e repetido posteriormente. A mensuração dos valores de ET Iso para determinação da CAM foi realizada feita através de um analisador de gases infravermelho calibrado antes do início de cada experimento e antes do início de cada determinação da CAM nos tempos alvo acima definidos com o emprego de um amostra de gás padrão ${ }^{14}$.

Após tricotomia e anti-sepsia prévias, os eletrodos para estimulação nociceptiva foram conectados a 2 agulhas $30 \times 8$ inseridas no tecido subcutâneo do terço médio da tíbia a $5 \mathrm{~cm}$ de distância entre si. O estímulo nociceptivo supramáximo utilizado neste estudo foi o modelo de estimulação elétrica baseado no padrão validado por Valverde et al. ${ }^{45}$ (2003), que consiste em uma corrente elétrica de $50 \mathrm{~V}, 50 \mathrm{~Hz}$ e $10 \mathrm{~ms}$.

Os critérios para avaliação de resposta motora negativa e positiva à estimulação nociceptiva foram avaliados por 2 observadores e baseados nas descrições de Ewing et al. (1993) $)^{113}$ (1993) e Campagnol et al. (2007) ${ }^{23}$. Desta

\footnotetext{
${ }^{13}$ Estimulador elétrico GRASS S-48, Astro-Med Inc, West Warwick, EUA - Fapesp Proc 00/02583-3

${ }^{14}$ Quick CalTM Calibration Gás, Datex-Engstrom Division Instrumentarium Corp, Helsinki, Finland.
} 
forma, foram consideradas respostas motoras negativas: flexão ou extensão única ou sustentada de membros, flexões repetidas e discretas somente da extremidade de um membro (articulação metacarpo ou metatarso falangeana), flexão única de pescoço ou sustentada muito discreta (apenas a região occipital se afasta da superfície), rotação única ou sustentada de cabeça, movimentos de mastigação, deglutição, tosse, movimentos respiratórios espontâneos ou movimentos não coincidentes com a estimulação nociceptiva. As respostas positivas foram consideradas como movimentos grosseiros de cabeça ou membros como: 2 ou mais flexões consecutivas e evidentes de membros (movimento de "pedalagem") ou pescoço, flexão sustentada de pescoço (toda região cervical se afasta da superfície), 2 ou mais rotações consecutivas de cabeça ou movimentos óbvios de tronco. Havendo dúvida com relação à caracterização da resposta motora, o padrão de estimulação nociceptiva era repetido aos 2 minutos após o término da estimulação elétrica inicial.

Caso a resposta motora à estimulação nociceptiva fosse inicialmente considerada negativa a $\mathrm{ET}_{\text {Iso }}$ era reduzida gradualmente em $10 \%$ até que uma resposta positiva fosse deflagrada, sendo então a ETiso aumentada gradualmente até que nova resposta negativa fosse obtida. Caso a resposta motora inicial fosse positiva os ajustes na ETiso eram realizados de forma inversa. Cada concentração de isoflurano foi mantida estável por 15 minutos de forma a permitir o equilíbrio entre as concentrações do agente inalatório no alvéolo, sangue arterial e cérebro, antes que a estimulação nociceptiva fosse realizada $^{41}$

O valor de CAM foi calculado através da média aritmética entre a menor concentração de isoflurano capaz de inibir a resposta motora (resposta negativa) e a maior concentração capaz de permitir tal resposta. Os valores de

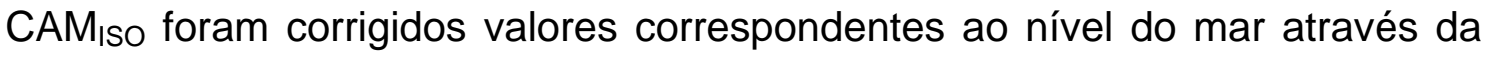
seguinte equação: 
$\mathrm{CAM}_{\text {ISO }}($ nível do mar $)=\left(\mathrm{CAM}_{\mathrm{ISO}} \times 680\right) / 760$

Onde 760 é o valor de pressão atmosférica média ao nível do mar (mmHg) e 680 o valor de pressão atmosférica na cidade de Botucatu (mm Hg).

\subsection{PARÂMETROS CARDIORESPIRATÓRIOS AVALIADOS}

Imediatamente antes da estimulação nociceptiva foram coletados os parâmetros de FC, PAS, PAD, PAM, registro do eletrocardiograma (ECG) e valores de hemogasometria. Os parâmetros cardiovasculares correspondentes à CAM foram considerados como sendo a média aritmética dos valores obtidos nas concentrações de isoflurano (ETISO) utilizados para o cálculo da CAM.

\subsection{CARACTERÍSTICAS DA RECUPERAÇÃO ANESTÉSICA AVALIADAS}

Ao término da mensuração da última CAM, todos os animais receberam uma dose de meloxicam $(0,2 \mathrm{mg} / \mathrm{kg})$ pela via intravenosa e a concentração de isoflurano foi mantida em 1.2 CAM, baseando-se no último valor de CAM obtido $\left(\mathrm{CAM}_{\mathrm{ISO}} 5 \mathrm{~h}\right)$ até que os cateteres e eletrodos fossem removidos.

Após a administração de isoflurano ser interrompida foram avaliados os tempo de extubação (definida como o tempo entre o término da anestesia inalatória e o retorno do reflexo de deglutição/mastigação), tempo para retorno a posição esternal e quadrupedal, bem como a possível incidência de êmese, salivação ou ataxia. 


\subsection{ANÁLISE ESTATÍSTICA}

A análise estatística foi realizada utilizando-se o programa SAS versão 9.1.3. Para análise dos efeitos dos tratamentos (neostigmina e/ou clonidina) sobre as variáveis paramétricas (CAMISO, FC, PAS, PAD, PAM, hemogasometria) foi empregado um delineamento em medidas repetidas no tempo analisadas através do PROC MIXED. As comparações múltiplas entre tratamentos foram realizadas pelo teste de Tukey-Kramer pela opção PDIFF. A comparação do efeito do tratamento em relação ao tempo basal foi realizada pelo teste de Dunnett pela opção DIFF. As variáveis de recuperação anestésica foram comparadas através de ANOVA seguida pelo teste de Tukey. As variáveis paramétricas serão apresentadas com média \pm desvio padrão. A hipótese nula (ausência de diferença entre tratamentos) foi rejeitada quando $P$ $<0.05$. 
6. Resultados 
Os percentuais de redução da CAM $_{\text {ISo }}$ observados para 1 animal $(14,8$ $\mathrm{Kg}$ ) com a administração de clonidina ou associação clonidina/neostigmina diferiram substancialmente dos percentuais observados para o restante da população. Neste animal a CAM Iso as 2,5 e 5,0 horas se elevou 8\% em relação aos valores basais com a administração de clonidina; enquanto que no restante da população a administração de clonidina causou redução na CAM ISo que variou de 24 a 45\% às 2,5 horas e de 3 a $38 \%$ às 5 horas. Quando 0 tratamento clonidina/neostigmina foi administrado neste animal, também se observou elevação da $\mathrm{CAM}_{\mathrm{ISo}}$ em 9\%, enquanto para o restante de população a associação clonidina/neostigmina causou redução da $\mathrm{CAM}_{1 \mathrm{SO}}$ da ordem de 8 a 36\% após 2,5 e 5 horas da administração peridural. A administração peridural

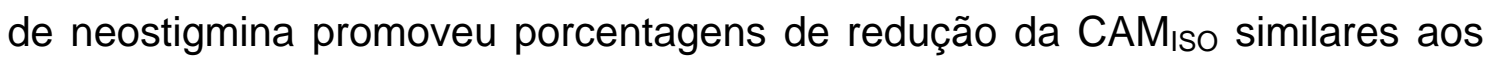
outros animais deste estudo (tabela 1).

O teste de Grubb para detecção de valores assimétricos numa população de distribuição Gaussiana (outlier) apresentou tendência a significância estatística no animal 6 (valor de Z calculado [1,87] próximo do valor de Z significativo para detecção de valor assimétrico 1,89). Devido à resposta atípica deste animal no que se refere à redução da $\mathrm{CAM}_{\mathrm{ISO}}$ em resposta a clonidina $\mathrm{e}$ clonidina/neostigmina, este não foi incluído na análise estatística para a amostra populacional em estudo, sendo os resultados de CAM deste animal apresentados separadamente (Tabela 1). Não houve complicações durante a recuperação da anestesia, sendo que tempo de retorno à posição quadrupedal ocorreu com 27, 28 e 23 minutos, para os tratamentos clonidina, nesotigmina e associação clonidina/neostigmina respectivamente. 
Tabela 1 - Valores da concentração alveolar mínima do isoflurano (CAMISO) basal e após aproximadamente 2,5 e 5 horas da administração peridural dos tratamentos: clonidina (CLO) $20 \mu \mathrm{g} / \mathrm{kg}$, neostigmina (NEO) $10 \mu \mathrm{g} / \mathrm{kg} \mathrm{e}$ associação clonidina $(20 \mu \mathrm{g} / \mathrm{kg})$ e neostigmina $(10 \mu \mathrm{g} / \mathrm{kg})(\mathrm{CLO} / \mathrm{NEO})$ em 1 cadela.

\begin{tabular}{|c|c|c|c|}
\hline & \multicolumn{3}{|c|}{ Tratamentos } \\
\hline & CLO & NEO & CLO+NEO \\
\hline CAM ISO (\%) basal & 1,12 & 1,12 & 1,03 \\
\hline$C A M_{I S O} 2,5 h$ & 1,21 & 1,03 & 1,12 \\
\hline $\begin{array}{c}\text { \% de modificação da } \\
\text { CAM }_{\text {ISo }}\end{array}$ & $8 \%$ & $-8 \%$ & $9 \%$ \\
\hline$C A M_{I S O} 5 \mathrm{~h}$ & 1,21 & 0,94 & 1,12 \\
\hline $\begin{array}{c}\text { \% de modificação da } \\
C_{C A M_{I S O}}\end{array}$ & $8 \%$ & $-16 \%$ & $9 \%$ \\
\hline
\end{tabular}

\subsection{TEMPOS DE DETERMINAÇÃO E EFEITOS DA ADMINISTRAÇÃO PERIDURAL DE CLONIDINA, NEOSTIGMINA OU ASSOCIAÇÃO SOBRE OS VALORES DA CONCENTRAÇÃO ALVEOLAR MÍNIMA DO ISOFLURANO (CAMISO).}

Os tempos para determinação da CAM Iso não apresentaram diferença significativa entre tratamentos (Tabela 2). Não houve diferença significativa entre os valores de $\mathrm{CAM}_{\mathrm{ISO}}$ basal para os tratamentos clonidina, neostigmina e associação clonidina/neostigmina (Tabela 2, Figuras 4 e 5).

Após 2,5 horas da administração peridural dos tratamentos, houve

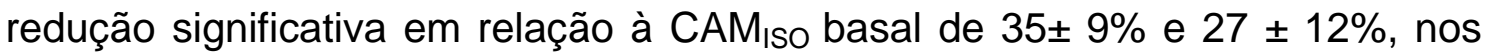
tratamentos clonidina e associação clonidina/neostigmina, respectivamente. Neste tempo, a redução da CAM Iso proporcionada pela neostigmina (11 $\pm 5 \%)$, não foi significativa em relação à $\mathrm{CAM}_{\mathrm{ISO}}$ basal.

Após 5 horas da administração peridural da clonidina e

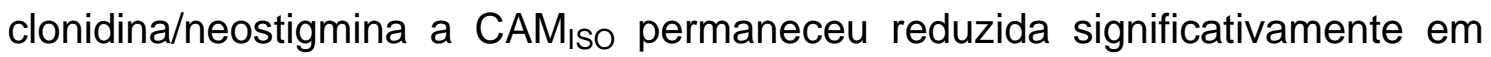
relação aos valores de $\mathrm{CAM}_{\mathrm{ISO}}$ basais $(22 \pm 14 \%$ e $25 \pm 11 \%$ de redução nos grupos clonidina e clonidina/neostigmina, respectivamente). Os valores de 
CAM ISo após 5 horas da administração da neostigmina peridural não diferiram significativamente em relação aos valores basais (8 \pm 9\%).

Comparando-se o efeito dos tratamentos sobre a CAM ${ }_{\text {ISo }}$ após 2,5 horas da administração peridural, não houve diferença significativa entre os tratamentos clonidina e associação clonidina/neostigmina, embora somente o tratamento clonidina tenha apresentado redução significativamente maior em relação ao tratamento neostigmina. Após 5 horas da administração peridural, não houve diferença significativa entre os tratamentos clonidina, neostigmina e associação clonidina/neostigmina.

Tabela 2 - Valores médios ( \pm desvio padrão) da concentração alveolar mínima do isoflurano $\left(\mathrm{CAM}_{\mathrm{ISO}}\right)$ após 2,5 e 5 horas da administração peridural de clonidina (CLO: $20 \mu \mathrm{g} / \mathrm{kg}$ ), neostigmina (NEO: $10 \mu \mathrm{g} / \mathrm{kg}$ ) e da associação clonidina $(20 \mu \mathrm{g} / \mathrm{kg})$ e neostigmina $(10 \mu \mathrm{g} / \mathrm{kg})$ (CLO/NEO) em 5 cadelas. Os valores entre parêntesis representam o tempo médio (horas) \pm desvio padrão da determinação dos valores de CAM $\mathrm{M}_{\mathrm{ISO}}$.

$A, B$ Médias seguidas da mesma letra não diferem entre si. $(p<0,05)$

*Diferença significativa em relação à CAM Iso $_{\text {basal }}(p<0,05)$

\begin{tabular}{|c|c|c|c|}
\hline & \multicolumn{3}{|c|}{ Tratamentos } \\
\hline & CLO & NEO & CLO+NEO \\
\hline $\begin{array}{c}C A M_{\text {Iso }}(\%) \text { basal } \\
\text { (tempo determinação) }\end{array}$ & $\begin{array}{l}1,49 \pm 0,26^{A} \\
(2,03 \pm 0,46)\end{array}$ & $\begin{array}{r}1,51 \pm 0,23^{A} \\
(1,98 \pm 0,24)\end{array}$ & $\begin{array}{l}1,49 \pm 0,26^{A} \\
(2,18 \pm 0,29)\end{array}$ \\
\hline $\begin{array}{c}C A M_{\text {Iso } 2,5 \text { horas }} \\
\text { (tempo determinação) }\end{array}$ & $\begin{array}{l}0,97 \pm 0,17^{A_{\star}} \\
(2,49 \pm 0,12)\end{array}$ & $\begin{array}{c}1,33 \pm 0,16^{\mathrm{B}} \\
(2,34 \pm 0,04)\end{array}$ & $\begin{array}{l}1,07 \pm 0,15^{A B_{*}} \\
(2,42 \pm 0,28)\end{array}$ \\
\hline \% Redução da CAMISo & $35 \pm 9$ & $11 \pm 5$ & $27 \pm 12$ \\
\hline $\begin{array}{c}\text { CAM Iso } 5 \text { horas } \\
\text { (tempo determinação) }\end{array}$ & $\begin{array}{l}1,16 \pm 0,27^{A_{\star}} \\
(5,08 \pm 0,33)\end{array}$ & $\begin{array}{l}1,37 \pm 0,09^{A} \\
(4,98 \pm 0,32)\end{array}$ & $\begin{array}{c}1,10 \pm 0,12^{A_{*}} \\
(4,75 \pm 0,1)\end{array}$ \\
\hline \% Redução da CAMIso & $22 \pm 14$ & $8 \pm 9$ & $25 \pm 11$ \\
\hline
\end{tabular}




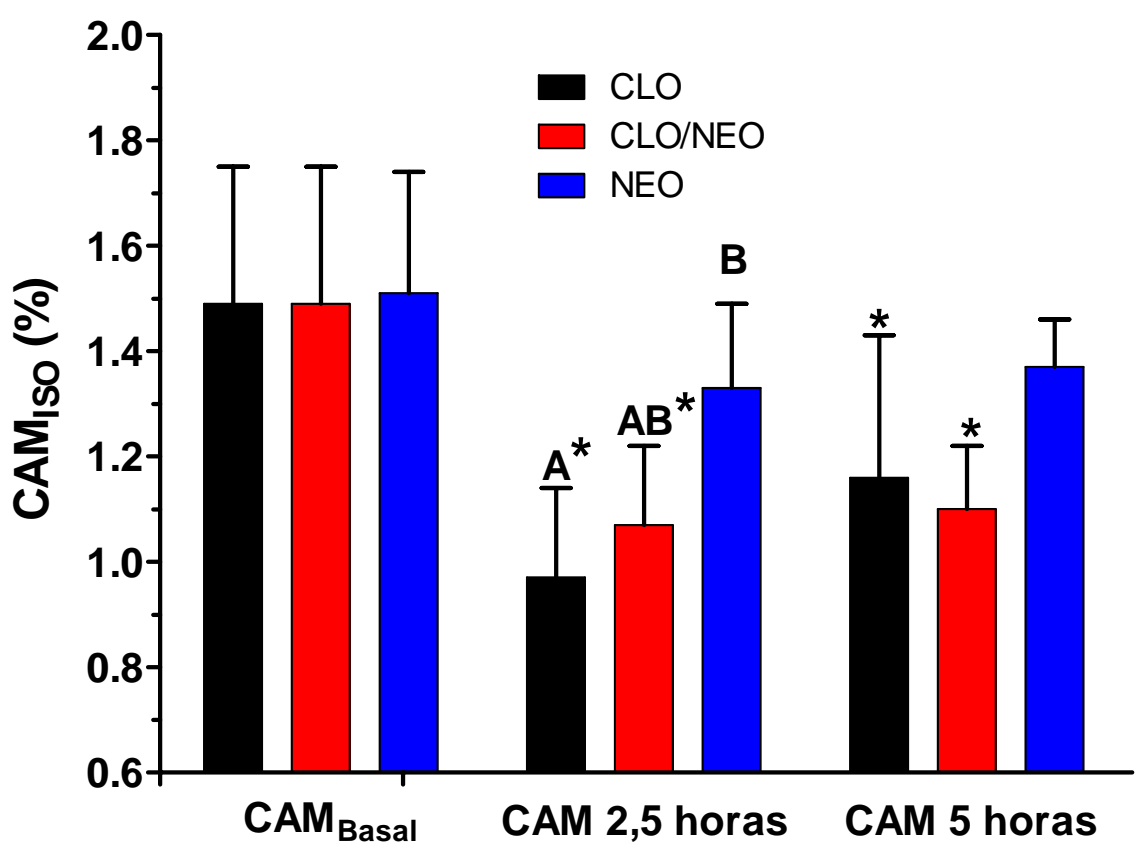

Figura 4 - Valores médios ( \pm desvio padrão) da concentração alveolar mínima do isoflurano (CAMISo) após 2,5 e 5 horas da administração peridural de clonidina (CLO: $20 \mu \mathrm{g} / \mathrm{kg}$ ), neostigmina (NEO: $10 \mu \mathrm{g} / \mathrm{kg}$ ) e da associação clonidina $(20 \mu \mathrm{g} / \mathrm{kg})$ e neostigmina $(10 \mu \mathrm{g} / \mathrm{kg})$ (CLO/NEO) em 5 cadelas.

$A, B$ Médias seguidas da mesma letra não diferem entre si. $(p<0,05)$

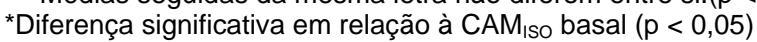

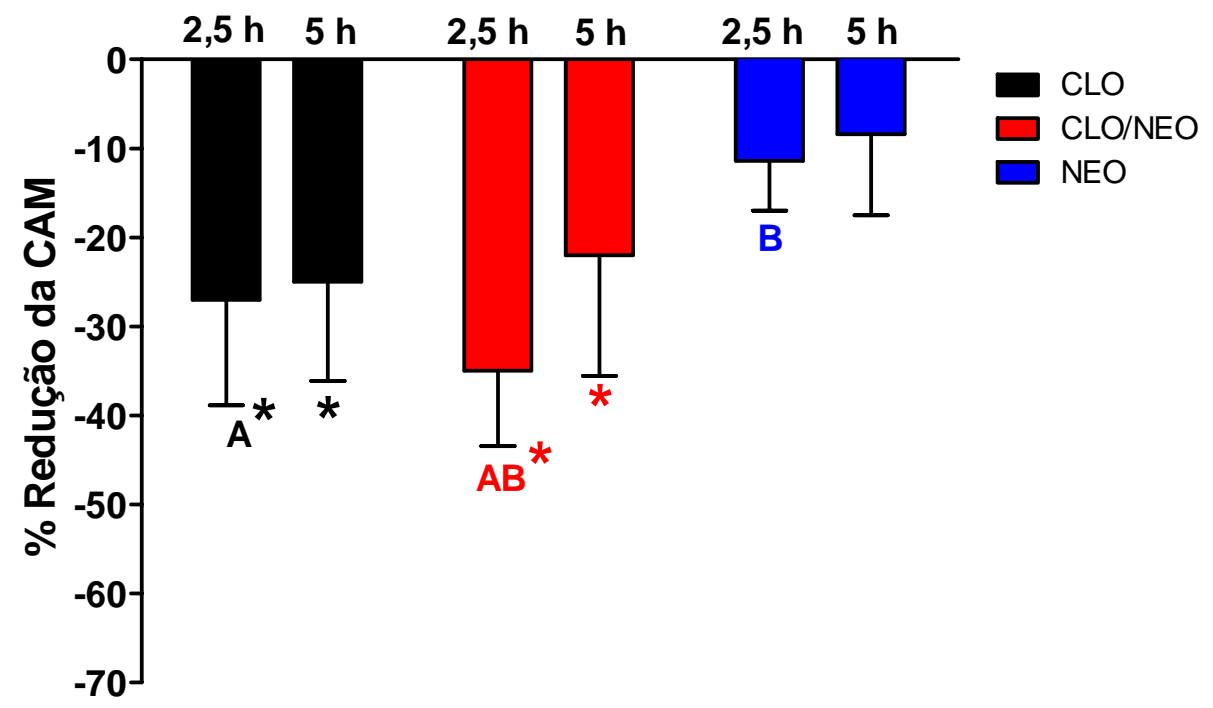

Figura 5 - Valores médios ( \pm desvio padrão) da porcentagem de redução da CAM ISo após 2,5 e 5 horas da administração peridural de clonidina (CLO: 20 $\mu \mathrm{g} / \mathrm{kg}$ ), neostigmina (NEO: $10 \mu \mathrm{g} / \mathrm{kg})$ e da associação clonidina $(20 \mu \mathrm{g} / \mathrm{kg})$ e neostigmina $(10 \mu \mathrm{g} / \mathrm{kg})(\mathrm{CLO} / \mathrm{NEO})$ em 5 cadelas.

${ }^{A, B}$ Médias seguidas da mesma letra não diferem entre si. $(p<0,05)$

*Diferença significativa em relação à CAM ISo $_{\text {basal }}(p<0,05)$ 


\subsection{EFEITOS DA ADMINISTRAÇÃO PERIDURAL DE CLONIDINA, NEOSTIGMINA OU ASSOCIAÇÃO SOBRE OS PARÂMETROS CARDIOVASCULARES DURANTE AS DETERMINAÇÕES DE CAMISO.}

Os valores de frequência cardíaca (FC) não apresentaram diferença significativa entre os tratamentos clonidina, neostigmina e clonidina/neostigmina no momento basal. Após 2,5 e 5 horas do tratamento peridural houve redução significativa da FC nos grupos clonidina e associação clonidina/neostigmina em relação ao momento basal. A redução na FC ocorreu de forma similar nos tratamentos clonidina e associação clonidina/neostigmina. Não foi observada alteração significativa da FC no tratamento neostigmina (Tabela 3, Figura 6)

Os valores de PAS, PAD e PAM não apresentaram diferença significativa entre tratamentos em nenhum dos tempos avaliados. A PAS se elevou em relação ao valor basal após 2,5 da administração de clonidina (11\% de elevação) após 5 horas da administração de neostigmina (16\% de elevação). No tratamento clonidina observou-se redução da PAD (17\%) decorridas 2,5 horas da administração do fármaco. Nenhum animal apresentou hipotensão arterial (PAM < $60 \mathrm{mmHg}$ ) ou hipertensão arterial (PAM > $100 \mathrm{mmHg}$ ) durante os tempos de determinação da CAM ISo (Tabela 3; Figuras 7, 8 e 9)

Todos os animais dos tratamentos clonidina e associação clonidina/neostigmina apresentaram bradicardia (definida como FC $<60$ bpm $^{116}$ ) após 2,5 horas da administração dos tratamentos peridurais. Após 5 horas da administração peridural, 2 de 5 animais apresentaram bradicardia no tratamento clonidina, enquanto que na associação clonidina/neostigmina a bradicardia persistiu em todos os animais. Após a administração peridural da clonidina e associação clonidina/neostigmina, 4 e 3 animais apresentaram arritmia sinusal, respectivamente.

Dois animais da associação clonidina/neostigmina apresentaram bloqueio átrio-ventricular de $2^{\circ}$ grau após 2,5 horas da administração peridural sendo que em 1 animal esta bradiarritmia perdurou por até 5 horas da administração peridural dos fármacos. 
Tabela 3 - Valores médios ( \pm desvio padrão) da freqüência cardíaca (FC), pressão arterial sistólica (PAS), pressão arterial diastólica (PAD) e pressão arterial média (PAM) observados no tempo basal, 2,5 e 5 horas após a administração peridural dos tratamentos clonidina (CLO: $20 \mu \mathrm{g} / \mathrm{kg}$ ), neostigmina (NEO: $10 \mu \mathrm{g} / \mathrm{kg}$ ) e associação clonidina $(20 \mu \mathrm{g} / \mathrm{kg})$ e neostigmina $(10 \mu \mathrm{g} / \mathrm{kg}$ ) (CLO/NEO) em 5 cadelas.

${ }_{A, B}$ Médias seguidas da mesma letra não diferem entre si. $(p<0,05)$

*Diferença significativa em relação à $C A M_{\text {sso }}$ basal $(p<0,05)$

\begin{tabular}{|c|c|c|c|c|}
\hline & & \multicolumn{3}{|c|}{ Tratamentos } \\
\hline & & CLO & NEO & CLO+NEO \\
\hline FC (bpm) & $\begin{array}{c}\text { Basal } \\
\text { CAM 2,5 } \\
\text { horas } \\
\text { CAM } 5 \text { horas }\end{array}$ & $\begin{array}{c}99 \pm 9^{A} \\
49 \pm 7^{A_{\star}} \\
61 \pm 4^{A}\end{array}$ & $\begin{array}{c}87 \pm 9^{A} \\
91 \pm 16^{B} \\
91 \pm 11^{B}\end{array}$ & $\begin{array}{l}89 \pm 10^{A} \\
45 \pm 9^{A_{\star}} \\
51 \pm 8^{A_{\star}}\end{array}$ \\
\hline PAS (mm Hg) & $\begin{array}{c}\text { Basal } \\
\text { CAM 2,5 } \\
\text { horas } \\
\text { CAM } 5 \text { horas }\end{array}$ & $\begin{array}{c}120 \pm 16^{\mathrm{A}} \\
133 \pm 17^{\mathrm{A}_{\star}} \\
134 \pm 18^{\mathrm{A}}\end{array}$ & $\begin{array}{l}113 \pm 14^{A} \\
119 \pm 18^{A} \\
131 \pm 17^{A^{A}}\end{array}$ & $\begin{array}{l}113 \pm 18^{A} \\
123 \pm 18^{A} \\
123 \pm 18^{A}\end{array}$ \\
\hline PAD (mm Hg) & $\begin{array}{c}\text { Basal } \\
\text { CAM 2,5 } \\
\text { horas } \\
\text { CAM } 5 \text { horas }\end{array}$ & $\begin{array}{c}58 \pm 6^{A} \\
48 \pm 6^{A^{*}} \\
51 \pm 7^{A}\end{array}$ & $\begin{array}{l}54 \pm 5^{A} \\
52 \pm 8^{A} \\
59 \pm 8^{A}\end{array}$ & $\begin{array}{l}53 \pm 7^{A} \\
48 \pm 7^{A} \\
46 \pm 8^{A}\end{array}$ \\
\hline PAM (mm Hg) & $\begin{array}{c}\text { Basal } \\
\text { CAM 2,5 } \\
\text { horas } \\
\text { CAM } 5 \text { horas }\end{array}$ & $\begin{array}{c}74 \pm 6^{A} \\
68 \pm 10^{A} \\
70 \pm 9^{A}\end{array}$ & $\begin{array}{c}69 \pm 6^{A} \\
69 \pm 11^{A} \\
77 \pm 9^{A}\end{array}$ & $\begin{array}{c}69 \pm 10^{A} \\
65 \pm 9^{A} \\
62 \pm 10^{A}\end{array}$ \\
\hline
\end{tabular}




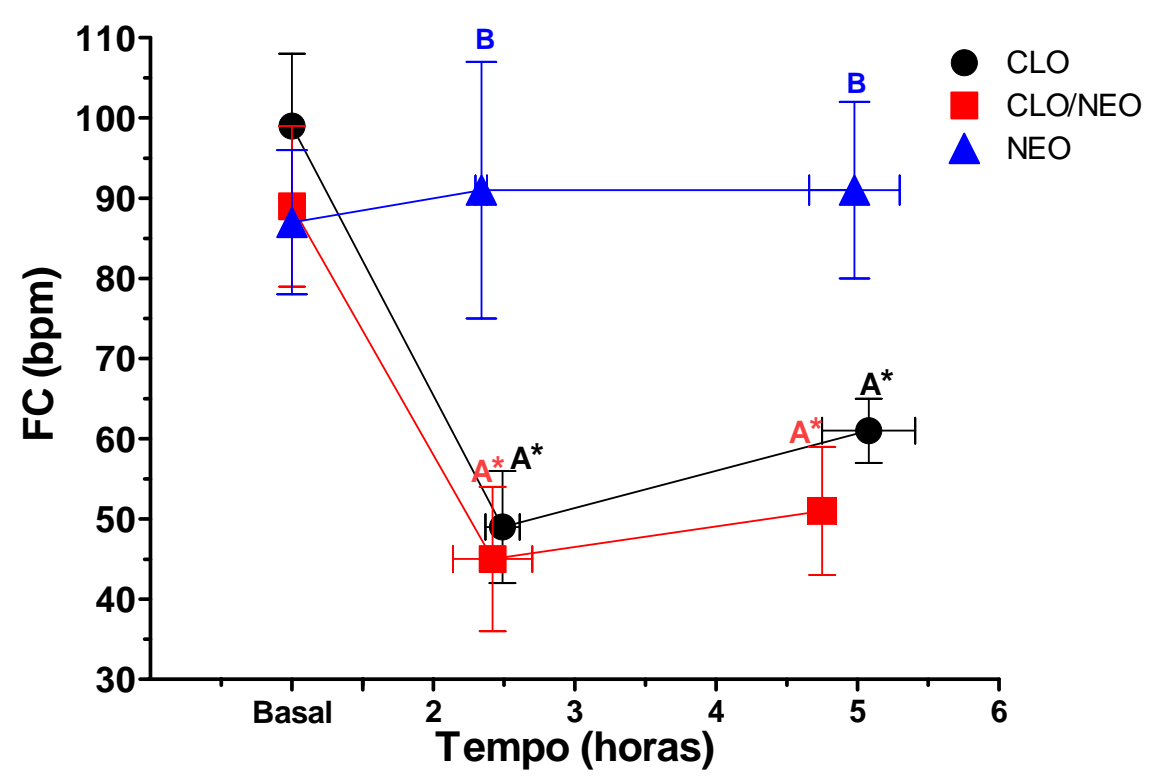

Figura 6 - Valores médios ( \pm desvio padrão) da freqüência cardíaca (FC) observados no tempo basal, 2,5 e 5 horas após a administração peridural dos tratamentos clonidina (CLO: $20 \mu \mathrm{g} / \mathrm{kg}$ ), neostigmina (NEO: $10 \mu \mathrm{g} / \mathrm{kg}$ ) e associação clonidina $(20 \mu \mathrm{g} / \mathrm{kg})$ e neostigmina $(10 \mu \mathrm{g} / \mathrm{kg})(\mathrm{CLO} / \mathrm{NEO})$ em cinco cadelas.

${ }_{A, B}$ Médias seguidas da mesma letra não diferem entre si. $(p<0,05)$

*Diferença significativa em relação à CAM $\mathrm{CM}_{\mathrm{s} o}$ basal $(p<0,05)$

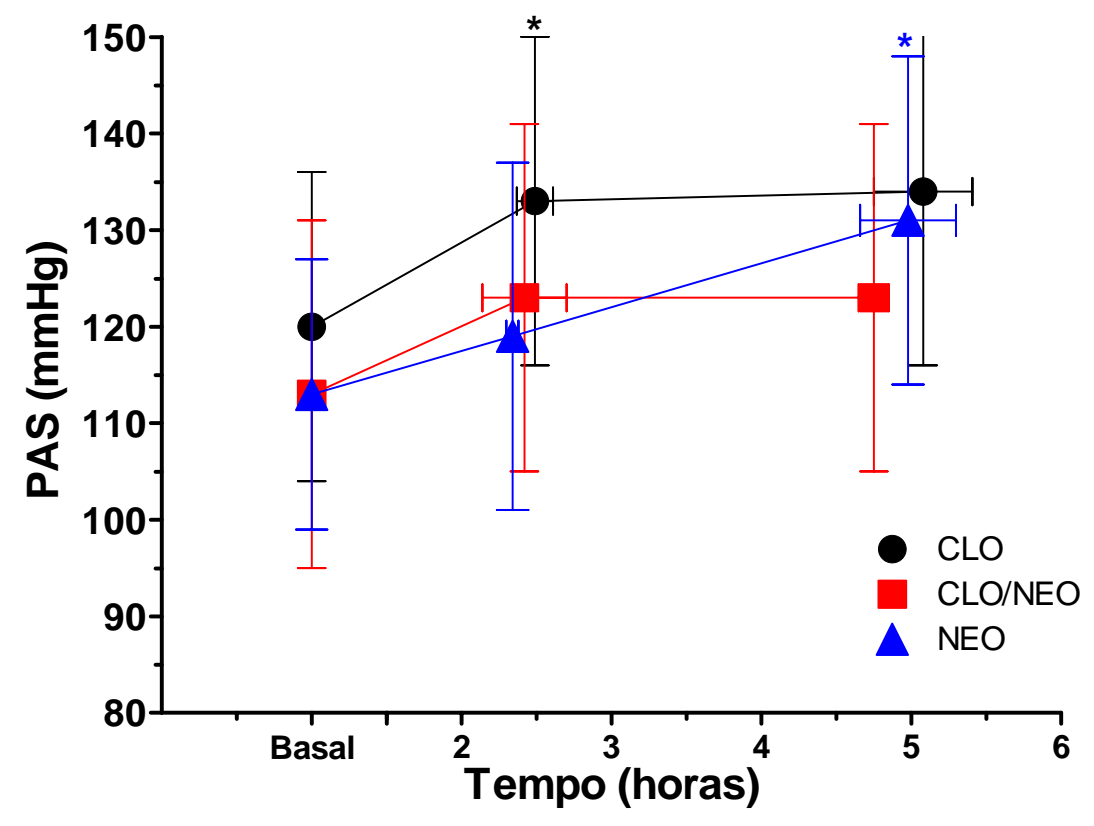

Figura 7 - Valores médios ( \pm desvio padrão) da pressão arterial sistólica (PAS), observados no tempo basal, 2,5 e 5 horas após a administração peridural dos tratamentos clonidina (CLO: $20 \mu \mathrm{g} / \mathrm{kg}$ ), neostigmina (NEO: $10 \mu \mathrm{g} / \mathrm{kg}$ ) e associação clonidina $(20 \mu \mathrm{g} / \mathrm{kg})$ e neostigmina $(10 \mu \mathrm{g} / \mathrm{kg})(\mathrm{CLO} / \mathrm{NEO})$ em cinco cadelas.

${ }^{A, B}$ Médias seguidas da mesma letra não diferem entre si. $(p<0,05)$

*Diferença significativa em relação à CAM $\mathrm{M}_{\mathrm{s} o}$ basal $(p<0,05)$ 


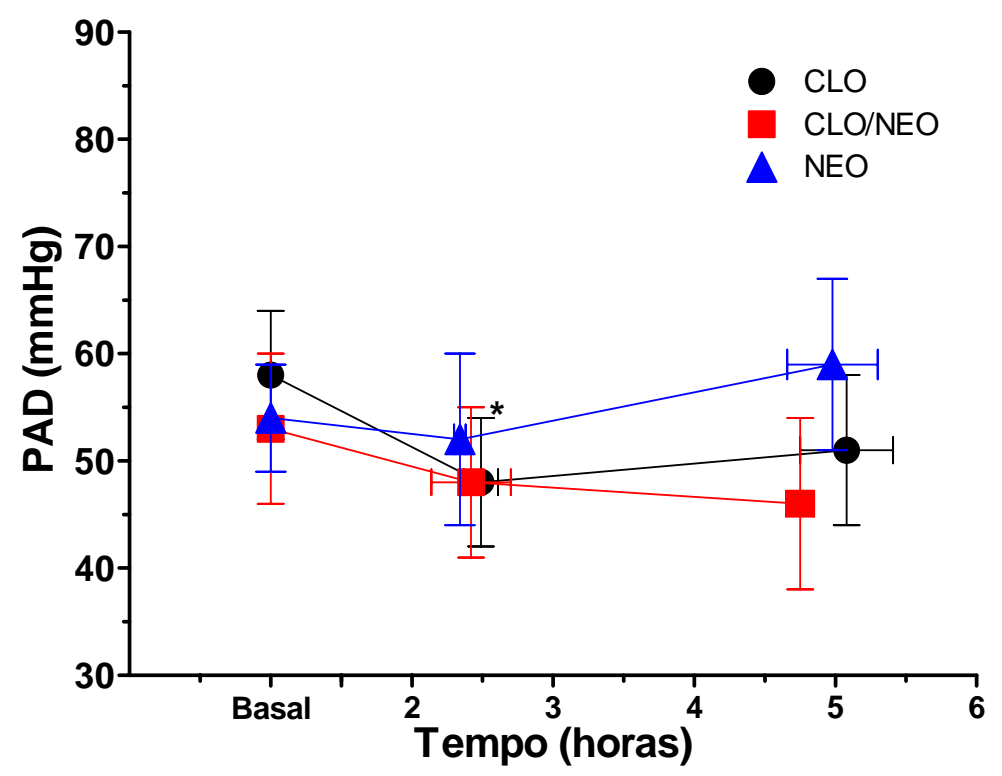

Figura 8 - Valores médios ( \pm desvio padrão) da pressão arterial diastólica (PAD) observados no tempo basal, 2,5 e 5 horas após a administração peridural dos tratamentos clonidina (CLO: $20 \mu \mathrm{g} / \mathrm{kg}$ ), neostigmina (NEO: 10 $\mu \mathrm{g} / \mathrm{kg})$ e associação clonidina $(20 \mu \mathrm{g} / \mathrm{kg})$ e neostigmina $(10 \mu \mathrm{g} / \mathrm{kg})($ CLO/NEO) em cinco cadelas.

${ }^{A, B}$ Médias seguidas da mesma letra não diferem entre si. $(p<0,05)$

*Diferença significativa em relação à CAM $_{\text {ISo }}$ basal $(p<0,05)$

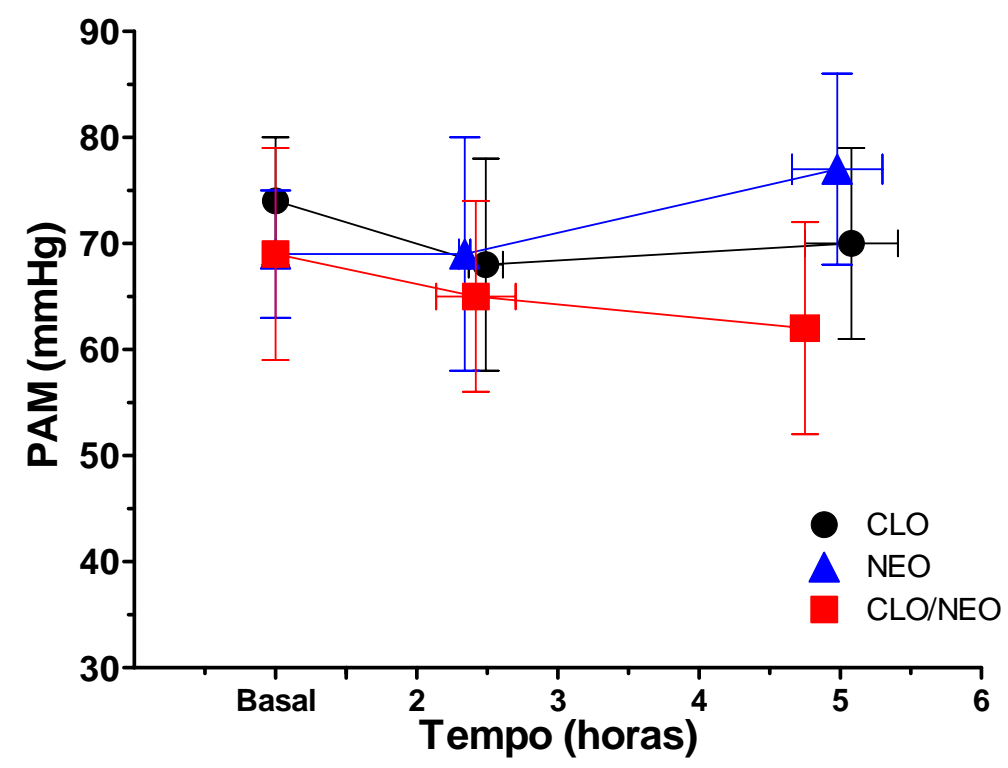

Figura 9 - Valores médios ( \pm desvio padrão) da pressão arterial média (PAM) observados no tempo basal, 2,5 e 5 horas após a administração peridural dos tratamentos clonidina (CLO: $20 \mu \mathrm{g} / \mathrm{kg}$ ), neostigmina (NEO: $10 \mu \mathrm{g} / \mathrm{kg}$ ) e associação clonidina $(20 \mu \mathrm{g} / \mathrm{kg})$ e neostigmina $(10 \mu \mathrm{g} / \mathrm{kg})(\mathrm{CLO} / \mathrm{NEO})$ em cinco cadelas.

$A, B$ Médias seguidas da mesma letra não diferem entre si. $(p<0,05)$

*Diferença significativa em relação à $\mathrm{CAM}_{\mathrm{ISo}}$ basal $(p<0,05)$ 


\subsection{EFEITOS DA ADMINISTRAÇÃO PERIDURAL DE CLONIDINA, NEOSTIGMINA OU ASSOCIAÇÃO SOBRE OS VALORES DE HEMOGASOMETRIA ARTERIAL DURANTE AS DETERMINAÇÕES DE CAMISO.}

Os valores de $\mathrm{pH}$ não apresentaram diferença significativa entre tratamentos peridurais (clonidina, neostigmina ou associação). No entanto, após 2,5 e 5 horas da administração peridural, houve aumento significativo nos valores de $\mathrm{pH}$ em relação ao momento basal em todos os tratamentos. Não foram observadas diferenças entre tratamentos ou em relação ao momento basal para os valores de $\mathrm{PaCO}_{2}, \mathrm{PaO}_{2}$ (Tabela 4).

Com relação ao íon bicarbonato $\left(\mathrm{HCO}_{3}^{-}\right)$não se observou diferença significativa entre os tratamentos. Após 2,5 horas da administração peridural nos tratamentos clonidina e associação clonidina/neostigmina observou-se elevação significativa do $\mathrm{HCO}_{3}{ }^{-}$em relação aos valores basais; enquanto após 5 horas da administração peridural os valores de $\mathrm{HCO}_{3}{ }^{-}$de todos os tratamentos se elevaram em relação ao momento basal (Tabela 4). 
Tabela 4 - Valores médios ( \pm desvio padrão) do potencial hidrogeniônico $(\mathrm{pH})$ arterial, pressão parcial de $\mathrm{CO}_{2}\left(\mathrm{PaCO}_{2}\right)$, pressão parcial de $\mathrm{O}_{2}\left(\mathrm{PaO}_{2}\right)$ e íon bicarbonato $\left(\mathrm{HCO}_{3}{ }^{-}\right)$freqüência cardíaca ( $\left.\mathrm{FC}\right)$, observados no tempo basal, 2,5 e 5 horas após a administração peridural dos tratamentos clonidina (CLO: 20 $\mu \mathrm{g} / \mathrm{kg}$ ), neostigmina (NEO: $10 \mu \mathrm{g} / \mathrm{kg}$ ) e associação clonidina (20 $\mu \mathrm{g} / \mathrm{kg}$ ) e neostigmina $(10 \mu \mathrm{g} / \mathrm{kg})(\mathrm{CLO} / \mathrm{NEO})$ em cinco cadelas.

$A, B$ Médias seguidas da mesma letra não diferem entre si. $(p<0,05)$

*Diferença significativa em relação à CAM $_{\text {Iso }}$ basal $(p<0,05)$

\begin{tabular}{|c|c|c|c|c|}
\hline & & \multicolumn{3}{|c|}{ Tratamentos } \\
\hline & & CLO & NEO & CLO+NEO \\
\hline $\mathrm{pH}$ & $\begin{array}{c}\text { Basal } \\
\text { CAM 2.5h } \\
\text { CAM 5h }\end{array}$ & $\begin{array}{c}7,357 \pm 0,022^{A} \\
7,385 \pm 0,024^{A_{*}} \\
7,401 \pm 0,028^{A_{*}}\end{array}$ & $\begin{array}{c}7,357 \pm 0,009^{A} \\
7,385 \pm 0,016^{A} \\
7,399 \pm 0,008^{A^{*}}\end{array}$ & $\begin{array}{c}7,365 \pm 0,010^{A} \\
7,392 \pm 0,019^{A_{*}} \\
7,412 \pm 0,017^{A_{*}}\end{array}$ \\
\hline $\mathrm{PaCO}_{2}$ & $\begin{array}{c}\text { Basal } \\
\text { CAM 2.5h } \\
\text { CAM 5h }\end{array}$ & $\begin{array}{l}36,4 \pm 1,6^{\mathrm{A}} \\
34,7 \pm 1,5^{\mathrm{A}} \\
33,7 \pm 1,1^{\mathrm{A}}\end{array}$ & $\begin{array}{c}36 \pm 2,4^{A} \\
34,1 \pm 1,9^{A} \\
33,8 \pm 1,3^{A}\end{array}$ & $\begin{array}{l}35,5 \pm 3,1^{A} \\
34,3 \pm 1,9^{A} \\
32,6 \pm 1,6^{A}\end{array}$ \\
\hline $\mathrm{PaO}_{2}$ & $\begin{array}{c}\text { Basal } \\
\text { CAM 2.5h } \\
\text { CAM 5h }\end{array}$ & $\begin{array}{c}513,8 \pm 46,5^{A} \\
515,1 \pm 9,3^{A} \\
516,1 \pm 31,3^{A}\end{array}$ & $\begin{array}{l}528,4 \pm 48,7^{A} \\
511,4 \pm 43,1^{A} \\
545,3 \pm 12,5^{A}\end{array}$ & $\begin{array}{c}512,9 \pm 37,6^{\mathrm{A}} \\
524,4 \pm 29,4^{\mathrm{A}} \\
538 \pm 20,4^{\mathrm{A}}\end{array}$ \\
\hline $\mathrm{HCO}_{3}{ }^{-}$ & $\begin{array}{c}\text { Basal } \\
\text { CAM 2.5h } \\
\text { CAM 5h }\end{array}$ & $\begin{array}{l}20,7 \pm 1,7^{A} \\
21,5 \pm 1,4^{A_{*}} \\
21,9 \pm 1,1^{A_{*}}\end{array}$ & $\begin{array}{c}20,6 \pm 0,9^{A} \\
21,2 \pm 0,7^{A} \\
21,9 \pm 0,7^{A_{\star}}\end{array}$ & $\begin{array}{c}20,8 \pm 1,2^{A} \\
21,7 \pm 0,7^{A_{*}} \\
22 \pm 0,6^{A_{*}}\end{array}$ \\
\hline
\end{tabular}

\subsection{EFEITOS DA ADMINISTRAÇÃO PERIDURAL DE CLONIDINA, NEOSTIGMINA OU ASSOÇIAÇÃO SOBRE O TEMPO DE EXTUBAÇÃO, DECÚBITO ESTERNAL E RETORNO A POSIÇÃO QUADRUPEDAL.}

Não foram observadas diferenças entre o tempo total de anestesia, tempo de extubação, retorno ao decúbito esternal ou posição quadrupedal entre os tratamentos (tabela 5).

Nenhum animal apresentou complicações no período de recuperação anestésica, como êmese, náusea, sialorréia ou ataxia. 
Tabela 5 - Tempo total de anestesia, tempo de extubação, tempo de retorno a decúbito esternal e posição quadrupedal em cinco animais anestesiados com isoflurano que receberam pela via peridural os tratamentos clonidina (CLO) 20 $\mu \mathrm{g} / \mathrm{kg}$, neostigmina (NEO) $10 \mu \mathrm{g} / \mathrm{kg}$ e associação clonidina $20 \mu \mathrm{g} / \mathrm{kg}$ e neostigmina10 $\mu \mathrm{g} / \mathrm{Kg}$ (CLO/NEO). Os valores expressos como média \pm desvio padrão.

A,B Médias seguidas da mesma letra não diferem entre si. $(p<0,05)$

*Diferença significativa em relação à $\mathrm{CAM}_{\text {Iso }}$ basal $(p<0,05)$

\begin{tabular}{lccc}
\hline & \multicolumn{3}{c}{ Tratamentos } \\
\cline { 2 - 4 } & CLO & NEO & CLO+NEO \\
\hline Tempo total de anestesia (horas) & $7.4 \pm 0.2^{\mathrm{A}}$ & $7.3 \pm 0.5^{\mathrm{A}}$ & $7.3 \pm 0.1^{\mathrm{A}}$ \\
Extubação (min) & $13 \pm 8^{\mathrm{A}}$ & $12 \pm 7^{\mathrm{A}}$ & $16 \pm 5^{\mathrm{A}}$ \\
Decúbito esternal (min) & $14 \pm 7^{\mathrm{A}}$ & $13 \pm 7^{\mathrm{A}}$ & $16 \pm 4^{\mathrm{A}}$ \\
Posição quadrupedal (min) & $20 \pm 8^{\mathrm{A}}$ & $17 \pm 6^{\mathrm{A}}$ & $18 \pm 4^{\mathrm{A}}$ \\
\hline
\end{tabular}


7. Discussão 
Os resultados do presente estudo indicam que a administração peridural de neostigmina $(10 \mu \mathrm{g} / \mathrm{kg})$ não resultou em uma redução significativa da CAM ISo em relação ao valor basal após 2,5 ou 5 horas da administração. Enquanto a clonidina $(20 \mu \mathrm{g} / \mathrm{kg})$ promoveu um efeito redutor significativo sobre a CAM ISo após 2,5 e 5 horas da administração peridural, porém tal redução não foi potencializada pela associação de um anticolinesterásico (neostigmina $10 \mu \mathrm{g} / \mathrm{kg}$ ) administrado pela mesma via.

A metodologia para determinação da CAM deve respeitar três requisitos básicos: estímulo nociceptivo supramáximo, concentração de agente inalatório estável e resposta motora bem definida. ${ }^{41}$

O estímulo nociceptivo supramáximo, tem por definição ser um estímulo o qual ao se aumentar a intensidade do mesmo, não se observa um aumento dos valores de CAM. ${ }^{40-41}$ No cão, os estímulos comumente utilizados são obtidos através de pinçamento ou estímulo elétrico, não havendo diferença entre local ou tipo de estímulo utilizado. ${ }^{45} \mathrm{O}$ estímulo utilizado este estudo, foi o modelo de estimulação elétrica $(50 \mathrm{~V}, 50 \mathrm{~Hz}$ e $10 \mathrm{~ms}$ ) baseado no padrão validado por Valverde et al. $^{45}$ (2003), e utilizado em estudos prévios neste mesmo laboratório. ${ }^{23,117}$

Com relação à estabilidade da concentração do anestésico previamente à estimulação nociceptiva, no presente estudo a concentração expirada de isoflurano foi mantida constante por no mínimo 15 minutos antes da estimulação elétrica de forma a obter um equilíbrio entre a concentração alveolar, no sangue arterial e no sistema nervoso central. ${ }^{40-41} \mathrm{O}$ tempo mínimo de 15 minutos é o preconizado para equilíbrio de pelo menos 95\% das concentrações arterial e cerebral com o uso de halotano em cães, sendo o isoflurano um agente com menor coeficiente de solubilidade que o halotano, 0 tempo de 15 min é considerado suficiente para promover um equilíbrio próximo a $100 \%$ das concentrações arterial e cerebral do isoflurano. ${ }^{41}$

Os critérios de avaliação da resposta motora positiva utilizados neste estudo foram previamente utilizados em outros estudos neste laboratório, ${ }^{23,117}$ 
sendo avaliados por dois observadores experientes sendo que em caso de resposta duvidosa o mesmo estímulo era repetido após 2 minutos ou após o retorno das variáveis cardiorrespiratórias aos valores basais.

A variação dos valores de CAM deve ser inferior a $20 \%$ para a maioria das espécies, ${ }^{41}$ no entanto os valores de $\mathrm{CAM}_{\mathrm{ISO}}$ para a espécie canina, encontrados na literatura variam de $1,18 \%$ a 1,8\%, ${ }^{4,102,118-121}$ tal variação pode ser explicada pela diferença de metodologia utilizada, tipo de estímulo empregado, além de outros fatores como diferença de idade ${ }^{64}$, temperatura ${ }^{61-62}$ ou ritmo circadiano. ${ }^{41,45}$ No presente estudo, visando minimizar a influência destes fatores foram selecionados animais adultos jovens; a temperatura foi mantida entre $38,2 \pm 0,1^{\circ} \mathrm{C}$ e todos os experimentos iniciaram-se no período da manhã (aproximadamente 08h00min) Quanto às variáveis hemogasométricas (que também podem influenciar os valores de CAM, como situações de acidose ou alcalose metabólica ou hipo e hipercapnia) ${ }^{40,55-56}$, a $\mathrm{PaCO}_{2}$ foi mantida dentro da normalidade $(34,6 \pm 2,1 \mathrm{~mm} \mathrm{Hg})$ e embora exista diferença nos valores de $\mathrm{pH}$ e $\mathrm{HCO}_{3}{ }^{-}$basal em relação aos valores de $\mathrm{CAM}_{\mathrm{ISO}} 2,5$ e $5 \mathrm{~h}$ para todos os tratamentos, os valores médios dos mesmos permaneceram dentro dos valores de referências para cães ( $\mathrm{pH}$ entre 7.35 e 7,45 e $\mathrm{HCO}_{3}{ }^{-}$entre 19 e $24 \mathrm{mmHg}$ ). Os valores de $\mathrm{CAM}_{\mathrm{ISO}}$ basal encontrados neste estudo foram de $1,49 \pm 0,26 \% ; 1,51 \pm 0,23$ e 1,49 $\pm 0,26 \%$, para os tratamentos CLO, NEO e CLO/NEO respectivamente, sendo ligeiramente superiores aos encontrados pelos pesquisadores que padronizaram o estímulo utilizado $\left(\mathrm{CAM}_{\mathrm{ISO}}=1,35 \pm\right.$ $0,04 \%)^{45}$ e demais estudos realizados neste laboratório CAM ISo corrigida ao nível do mar $=1,40 \pm 0,21 \%,{ }^{23}$ e $1,24 \pm 0,18 \%{ }^{117}$

Ainda visando padronizar a metodologia e facilitar a comparação com

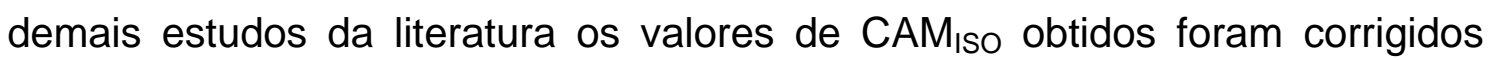
para o nível do mar, levando-se em consideração a altitude (aproximadamente 800 metros acima do nível do mar) e pressão atmosférica da cidade de Botucatu (680 $\mathrm{mm} \mathrm{Hg}$ ) onde o estudo foi realizado, isto porque as diferenças de altitude e pressão atmosférica entre os locais onde os estudos são realizados podem resultar em diferentes valores de CAM, pois segundo a Lei 
de Boyle "a uma temperatura constante, o volume ocupado por uma quantidade fixa de um gás é inversamente proporcional à sua pressão", portanto, embora a pressão parcial do anestésico inalatório (em $\mathrm{mm} \mathrm{Hg}$ ) seja a mesma para diferentes altitudes, os valores da CAM, que expressam a concentração do agente (vol \%) sofrem influência da pressão atmosférica ambiente. ${ }^{42,122}$

Os efeitos antinociceptivos da neostigmina parecem mais eficazes em fêmeas que em machos. ${ }^{68,70}$ Sendo o mecanismo de antinocicepção de fármacos colinérgicos utilizados pela via espinhal, baseado em um aumento da liberação de acetilcolina na medula espinhal e estimulação de receptores muscarínicos e nicotínicos, ${ }^{68-69}$ esta diferença é possivelmente relacionada ao tipo de receptor (nicotínico) que ocorre em maior quantidade em fêmeas. ${ }^{68,70}$ Visando eliminar este tipo de interferência, no presente estudo foram utilizadas apenas fêmeas castradas.

A dose de neostigmina peridural utilizada neste estudo foi a mesma utilizada em estudo prévio onde o fármaco apresentou efeito analgésico satisfatório em cadelas submetidas a ovariosalpingohisterectomia ${ }^{19}$ e foi similar a dose empregada em estudos realizados em humanos, onde a neostigmina peridural nas doses de $750 \mu \mathrm{g}(8-9 \mu \mathrm{g} / \mathrm{kg})$ ou $10 \mu \mathrm{g} / \mathrm{kg}$ apresentou efeito sinérgico com outros fármacos (clonidina e bupivacaína) administrados pela via peridural. ${ }^{17,33}$ Aparentemente, doses mais elevadas que a dose de neostigmina peridural empregada no presente estudo podem resultar em maior incidência de efeitos colaterais. Em estudo piloto com 3 animais realizado no laboratório da FMVZ-UNESP (anexo L) onde foram administradas doses cumulativas de neostigmina $(5,10$ e $20 \mu \mathrm{g} / \mathrm{kg}$ ) pela via peridural a cada 2,5 horas, houve profusa sialorréia durante a anestesia após a administração da dose de 20 $\mu \mathrm{g} / \mathrm{kg}$.

Em humanos a administração peridural de neostigmina (1 $\mu \mathrm{g} / \mathrm{kg})$ isoladamente, promoveu analgesia pós operatória satisfatória em pacientes submetidos à cirurgia de joelho. ${ }^{81}$ No entanto, seu emprego isolado em doses inferiores a $750 \mu \mathrm{g}$ (aproximadamente 8-9 $\mu \mathrm{g} / \mathrm{kg}$ ) não foi eficaz em promover 
analgesia pós-operatória em mulheres em trabalho de parto. ${ }^{33} \mathrm{Em}$ cães submetidos à ovariosalpingohisterectomia, a neostigmina $(10 \mu \mathrm{g} / \mathrm{kg})$ pela via peridural, promoveu analgesia pós operatória superior ao grupo controle não apresentando, no entanto, efeito aditivo ou sinérgico na analgesia promovida pela administração de morfina peridural possivelmente pelo tipo de estímulo/cirurgia utilizada (ovariosalpingohisterectomia) não favorecer a potencialização analgésica da morfina pela neostigmina no período pós operatório. $^{19}$

Neste estudo a neostigmina $(10 \mu \mathrm{g} / \mathrm{kg})$ administrada pela via peridural não apresentou efeito redutor da CAM Iso em cães após 2,5 e 5 horas da administração. Uma explicação para a não detecção de um efeito significativo da neostigmina sobre a CAM Iso seria o poder estatístico reduzido para detectar diferenças de pequena magnitude entre tratamentos (entre 8 e 11\%) devido ao número relativamente reduzido de animais empregado neste estudo. Contudo, de forma semelhante, outros estudos demonstram que fármacos, como os antiinflamatórios não esteroidais (AINE), com comprovada eficácia analgésica no controle da dor pós operatória também não apresentaram efeito redutor significativo no requerimento de anestésicos inalatórios ${ }^{118,123-125}$ De fato, a porcentagem de redução sobre a CAM dos AINE (aproximadamente 10\%) é muito semelhante à redução promovida pela neostigmina neste estudo (11 \pm $5 \%$ e $8 \pm 9 \%$ após 2,5 e 5 horas da administração da neostigmina peridural), não apresentando diferença significativa em relação aos valores basais de CAM. Yamashita et al. ${ }^{126}$ (2008) encontram uma redução significativa após o uso de carprofeno ou meloxicam sobre a CAM do sevoflurano em cães (11,3 \pm $8,3 \%$ e 12,9 $\pm 10,2 \%$, respectivamente), contudo a porcentagem de redução é semelhante aos demais estudos com AINE, não apresentando relevância clínica devido à pequena magnitude da redução da CAM obtida. Assim sendo, embora a administração peridural de neostigmina $(10 \mu \mathrm{g} / \mathrm{kg})$ não promova um

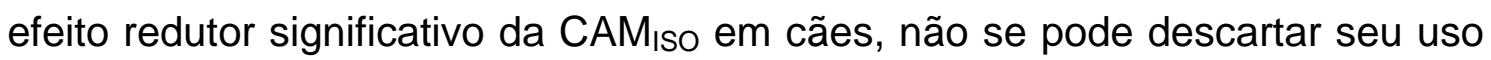
potencial como analgésico em cães como observado em estudos anteriores. $^{19,31}$ 
Para a determinação da dose de clonidina empregada neste estudo procurou-se utilizar doses previamente relatadas na literatura para possíveis comparações e segurança no que diz respeito à toxicidade. Desta forma, as doses de clonidina previamente utilizadas por Bloor et al. ${ }^{20}$ (1982) de 5 e 20 $\mu \mathrm{g} / \mathrm{kg}$ pela via intravenosa foram analisadas através de estudo piloto (Anexo $\mathrm{M}$ ) e empregadas neste estudo. A segurança dessas doses pela via peridural em cães foi estabelecida por Yaksh et al. ${ }^{31}$ (1994), onde doses de 80 a $320 \mu \mathrm{g}$ (aproximadamente 5 a $21 \mu \mathrm{g} / \mathrm{kg}$ ) de clonidina foram utilizadas pela via peridural durante 28 dias sem causar evidências de toxicidade ou alterações histopatológicas na medula espinhal. A escolha da dose de $20 \mu \mathrm{g} / \mathrm{kg}$ foi baseada em estudo piloto, realizado em três animais. Neste estudo a dose de 5

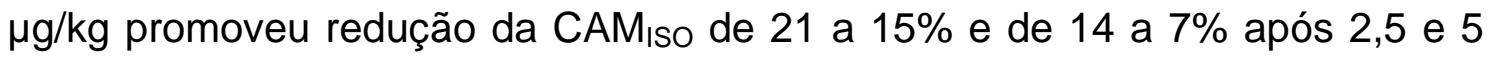
horas da administração do fármaco pela via peridural, respectivamente. Portanto, optou-se pela dose maior $(20 \mu \mathrm{g} / \mathrm{kg}$ ) esperando-se obter maior redução da CAM do isoflurano com o alfa-2 agonista. Não sendo o objetivo deste estudo determinar a dose ótima de clonidina para utilização peridural em cães e sim o efeito sinérgico de sua associação com a neostigmina, sugere-se a realização de estudos visando avaliar os efeitos da administração de doses crescentes de clonidina peridural sobre o requerimento de anestésicos inalatórios, visando estabelecer uma relação dose-efeito que auxilie na determinação das doses ótimas de clonidina peridural para uso em casos clínicos.

Com base nos resultados obtidos neste estudo, a clonidina induziu

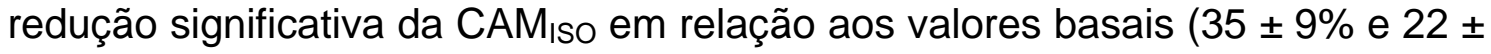
14\% após 2,5 e 5 horas de sua administração peridural, respectivamente), sendo esta redução clinicamente significativa. Bloor et $\mathrm{al}^{20}$. (1982), avaliaram os efeitos da administração intravenosa de clonidina (20 $\mathrm{gg} / \mathrm{kg})$ sobre a CAM do halotano em cães, encontrando reduções de aproximadamente 48, 40 e 5\% após 2 - 3,3 e 7,3 horas, respectivamente. A diferença entre as percentagens de redução obtidas pode ser explicada pela diferença de metodologia e estímulo nociceptivo empregados. Além disso, os tempos decorridos entre a administração da clonidina peridural e as determinações da CAM diferem entre 
os estudos, dificultando a comparação entre resultados. Estudos mais recentes utilizando o mesmo tipo de estímulo nociceptivo (elétrico) apresentaram resultados onde, após 2 horas da administração peridural de agonistas alfa-2 adrenérgicos, as reduções na CAM $_{1 \text { so }}$ foram de $33 \%$ com a xilazina $(0,4$ $\mathrm{mg} / \mathrm{kg})^{102}$ e de 29 e $31 \%$ com a dexmedetomidina (3 e $6 \mu \mathrm{\mu g} / \mathrm{kg}$ ), respectivamente. ${ }^{23}$ Estas percentagens foram próximas as encontradas no presente estudo (35 \pm 9\% após 2,5 horas).

A combinação de agonistas alfa-2 adrenérgicos (clonidina) com fármacos colinomiméticos (neostigmina) pela via espinhal é associada a um efeito sinérgico na antinocicepção. Acredita-se que este efeito analgésico sinérgico seja atribuído ao fato de ambos os fármacos induzirem ativação colinérgica com liberação de acetilcolina no corno dorsal da medula e conseqüente aumento deste neurotransmissor no líquido cérebro espinhal. $^{37,66,111}$ No entanto, os resultados deste estudo falharam em demonstrar este sinergismo após associação de neostigmina e clonidina pela via peridural, uma vez que a redução da CAM $_{\mid S O}$ encontrada após a administração de clonidina isolada não diferiu significativamente da redução da $\mathrm{CAM}_{\mathrm{ISO}}$ obtida após combinação de clonidina e neostigmina peridural. Duas explicações são possíveis para estes resultados: 1) A dose de neostigmina utilizada não foi suficiente para potencializar os efeitos redutores na CAM da clonidina. No entanto, estudo prévio comprovou a eficácia dessa dose em potencializar os efeitos antinociceptivos da clonidina peridural em humanos ${ }^{33}$; 2) A dose de clonidina empregada neste estudo pode ter sido foi capaz de exercer um "efeito teto" sobre a CAM, não sendo possível se obter um incremento maior na redução da CAM através de um aumento de dose ou utilização de outro fármaco com semelhante mecanismo de ação colinérgico. De fato, esta parece a explicação mais plausível uma vez que diversos estudos comprovam a existência de um "efeito teto" após administração de doses crescentes de agonistas alfa-2 adrenérgicos ${ }^{23,102}$. No presente estudo, a porcentagem de redução da $\mathrm{CAM}_{\mathrm{ISO}}$ obtida com a clonidina isolada ou associada à neostigmina (35\% e 29\%, respectivamente) foi próxima a porcentagem de redução da CAM $_{\text {sSo }}$ produzida pela dexmedetomidina (29 e 
31\% após a administração de 3 e $6 \mu \mathrm{g} / \mathrm{kg}$, respectivamente). ${ }^{23}$ No estudo de Campagnol et al. ${ }^{23}$ (2007), hipotetizou-se que um efeito teto (máximo de $30 \%$ de redução da $\left.C A M_{I S O}\right)$ teria sido obtido com a dose de $3 \mu \mathrm{g} / \mathrm{kg}$; uma vez que ao se dobrar a dose do alfa-2 agonista $(6 \mu \mathrm{g} / \mathrm{kg})$, não houve redução adicional da CAM.

A principal alteração hemodinâmica encontrada neste estudo foi a bradicardia presente em todos os cães do tratamento clonidina ou associação clonidina/neostigmina após 2,5 horas da administração peridural e perdurando por até 5 horas em alguns animais. Somente 2 animais do tratamento clonidina/neostigmina apresentaram BAV $2^{\circ}$ grau até 2,5 horas após administração dos fármacos, sendo que em 1 animal a ocorrência desta bradiarritmia perdurou por até 5 horas. Em humanos, tanto a administração peridural como intravenosa de clonidina promoveu efeitos colaterais semelhantes, como sedação e hipotensão, independentemente da via utilizada. ${ }^{29}$ Os autores atribuíram a ocorrência de tais efeitos a uma possível absorção sistêmica apesar das baixas concentrações plasmáticas de clonidina. ${ }^{29}$ A mesma explicação pode ser extrapolada para o presente estudo, onde uma possível absorção sistêmica do fármaco pode ter sido responsável pela bradicardia observada após administração peridural de clonidina.

Os percentuais de redução da $\mathrm{CAM}_{\mathrm{ISO}}$ observados em 1 animal foram menores que os intervalos gerados pela média $\pm 2 \times$ desvio padrão do restante de população ( $n=5$ ), que incorporam 95,4\% dos valores em uma distribuição Gaussiana. Houve tendência a análise estatística identificar este animal como de comportamento assimétrico (outlier), e portanto este não foi incluído na análise estatística final e os valores de CAM deste animal foram apresentados separadamente (tabela 1). A explicação para a ocorrência deste resultado ainda é incerta, embora uma possível explicação possa ser inferida de estudos no homem onde a clonidina, utilizada como agente antihipertensivo, apresenta diferentes padrões de resposta entre indivíduos brancos e negros, contudo a razão exata dessa diferença não é conhecida. ${ }^{127-128}$ Variáveis genéticas relacionadas à expressão gênica de certas proteínas ou aminoácidos, parecem 
diferir substancialmente entre grupos étnicos, representando uma possível causa das diferenças de resposta de alguns agonistas alfa-2 adrenérgicos entre brancos e negros. ${ }^{129-130}$ Não é possível afirmar a causa do diferente padrão de resposta apresentado por este animal, contudo, os autores acreditam que a explicação para este resultado esteja baseada na farmacogenética e de forma similar ao que ocorre no homem a expressão gênica de algumas proteínas/receptores interfira na resposta de alguns fármacos, como a clonidina.

Os animais deste estudo não apresentaram diferenças nos tempos de recuperação anestésica (extubação, posição esternal e retorno a posição quadrupedal) entre os tratamentos. Sedação, êmese e náusea são efeitos colaterais observados após administração de agonistas alfa-2 adrenérgicos e/ou neostigmina, podendo ocorrer mesmo utilizando-se a via peridural, em humanos e no cão, ${ }^{18,23,30,131}$ contudo estes efeitos não foram observados neste estudo independentemente do tipo de tratamento utilizado. 
8. Conclusões 
Diante dos resultados do presente estudo é possível concluir que:

A neostigmina peridural $(10 \mu \mathrm{g} / \mathrm{kg})$ não potencializa o efeito redutor da $\mathrm{CAM}_{\mathrm{ISO}}$ proporcionado pela clonidina peridural $(20 \mu \mathrm{g} / \mathrm{kg})$ em cadelas.

A administração peridural de neostigmina (10 $\mu \mathrm{g} / \mathrm{kg})$ não apresenta efeito redutor clinicamente importante sobre a CAM ${ }_{\mathrm{ISO}}$ em cães.

A clonidina (20 $\mu \mathrm{g} / \mathrm{kg}$ peridural) potencializou o isoflurano, induzindo

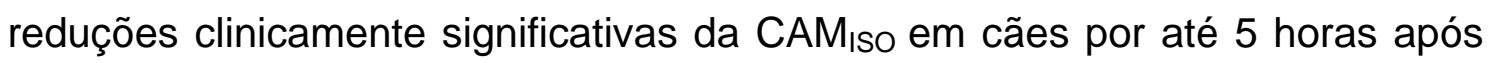
sua administração

O emprego de clonidina pela via peridural, não evitou a ocorrência de efeitos hemodinâmicos como bradicardia (FC $<60$ bpm) e BAV $2^{\circ}$ grau, sendo estes efeitos persistentes por até 5 horas de sua administração. Contudo efeitos hipotensores dos fármacos não foram observados em nenhum dos tratamentos peridurais.

O uso de clonidina e/ou neostigmina pela via peridural não foi relacionado a efeitos colaterais indesejáveis no período de recuperação anestésica em cães anestesiados com isoflurano. 
Referências Bübliográficas 
1. Wetmore LA, Glowaski MM. Epidural analgesia in veterinary critical care. Clin Tech Small Anim Pract 2000;15:177-188.

2. Sabbe MB, Penning JP, Ozaki GT, et al. Spinal and systemic action of the alpha 2 receptor agonist dexmedetomidine in dogs. Antinociception and carbon dioxide response. Anesthesiology 1994;80:1057-1072.

3. Mathews KA. Pain assessment and general approach to management. Vet Clin North Am Small Anim Pract 2000;30:729-755, v.

4. Bonath $\mathrm{KH}$, Saleh AS. Long term pain treatment in the dog by peridural morphine. Proceedings of the 2nd International Congress of Veterinary Anesthesia 1985;p. 153-154.

5. Valverde A, Dyson DH, McDonell WN. Epidural morphine reduces halothane MAC in the dog. Can J Anaesth 1989;36:629-632.

6. Valverde A, Dyson DH, Cockshutt JR, et al. Comparison of the hemodynamic effects of halothane alone and halothane combined with epidurally administered morphine for anesthesia in ventilated dogs. Am J Vet Res 1991;52:505-509.

7. Popilskis S, Kohn D, Sanchez JA, et al. Epidural vs. intramuscular oxymorphone analgesia after thoracotomy in dogs. Vet Surg 1991;20:462-467.

8. Walker SM, Goudas LC, Cousins MJ, et al. Combination spinal analgesic chemotherapy: a systematic review. Anesth Analg 2002;95:674-715.

9. Bevan DR, Donati F. Muscle Relaxants. Clinical Anesthesia 4th edn. 4th edn ed: Linppicott Williams \& Wilkings Publishers, 2001;p. 312-333. 
10. Yaksh TL, Dirksen R, Harty GJ. Antinociceptive effects of intrathecally injected cholinomimetic drugs in the rat and cat. Eur $\mathrm{J}$ Pharmacol 1985;117:81-88.

11. Bouaziz H, Tong C, Eisenach JC. Postoperative analgesia from intrathecal neostigmine in sheep. Anesth Analg 1995;80:1140-1144.

12. Lauretti GR, Mattos $A L$, Reis MP, et al. Intrathecal neostigmine for postoperative analgesia after orthopedic surgery. $\mathrm{J}$ Clin Anesth 1997;9:473-477.

13. Lauretti GR, Reis MP. Postoperative analgesia and antiemetic efficacy after subarachnoid neostigmine in orthopedic surgery. Reg Anesth 1997;22:337-342.

14. Klamt JG, Garcia LV, Prado WA. Analgesic and adverse effects of a low dose of intrathecally administered hyperbaric neostigmine alone or combined with morphine in patients submitted to spinal anaesthesia: pilot studies. Anaesthesia 1999;54:27-31.

15. Hood DD, Eisenach JC, Tuttle R. Phase I safety assessment of intrathecal neostigmine methylsulfate in humans. Anesthesiology 1995;82:331-343.

16. Omais M, Lauretti GR, Paccola CA. Epidural morphine and neostigmine for postoperative analgesia after orthopedic surgery. Anesth Analg 2002;95:1698-1701, table of contents.

17. Nakayama M, Ichinose H, Nakabayashi K, et al. Analgesic effect of epidural neostigmine after abdominal hysterectomy. J Clin Anesth 2001;13:86-89. 
18. Lauretti GR, de Oliveira R, Reis MP, et al. Study of three different doses of epidural neostigmine coadministered with lidocaine for postoperative analgesia. Anesthesiology 1999;90:1534-1538.

19. Marucio RL, Luna SP, Neto FJ, et al. Postoperative analgesic effects of epidural administration of neostigmine alone or in combination with morphine in ovariohysterectomized dogs. Am J Vet Res 2008;69:854860.

20. Bloor BC, Flacke WE. Reduction in halothane anesthetic requirement by clonidine, an alpha-adrenergic agonist. Anesth Analg 1982;61:741-745.

21. Aantaa R, Jaakola ML, Kallio A, et al. Reduction of the minimum alveolar concentration of isoflurane by dexmedetomidine. Anesthesiology 1997;86:1055-1060.

22. Kuusela E, Raekallio M, Vaisanen M, et al. Comparison of medetomidine and dexmedetomidine as premedicants in dogs undergoing propofolisoflurane anesthesia. Am J Vet Res 2001;62:1073-1080.

23. Campagnol D, Teixeira Neto FJ, Giordano T, et al. Effects of epidural administration of dexmedetomidine on the minimum alveolar concentration of isoflurane in dogs. Am J Vet Res 2007;68:1308-1318.

24. Bonnet F, Boico O, Rostaing S, et al. Clonidine-induced analgesia in postoperative patients: epidural versus intramuscular administration. Anesthesiology 1990;72:423-427.

25. Bernard JM, Hommeril JL, Passuti N, et al. Postoperative analgesia by intravenous clonidine. Anesthesiology 1991;75:577-582. 
26. Bernard JM, Kick O, Bonnet F. Comparison of intravenous and epidural clonidine for postoperative patient-controlled analgesia. Anesth Analg 1995;81:706-712.

27. Pal SK, Cortiella J, Herndon D. Adjunctive methods of pain control in burns. Burns 1997;23:404-412.

28. Persec J, Persec Z, Husedzinovic I. Postoperative pain and systemic inflammatory stress response after preoperative analgesia with clonidine or levobupivacaine: a randomized controlled trial. Wien Klin Wochenschr 2009;121:558-563.

29. De Kock M, Crochet B, Morimont C, et al. Intravenous or epidural clonidine for intra- and postoperative analgesia. Anesthesiology 1993;79:525-531.

30. Farmery AD, Wilson-MacDonald J. The analgesic effect of epidural clonidine after spinal surgery: a randomized placebo-controlled trial. Anesth Analg 2009;108:631-634.

31. Yaksh TL, Rathbun M, Jage J, et al. Pharmacology and toxicology of chronically infused epidural clonidine. $\mathrm{HCl}$ in dogs. Fundam Appl Toxicol 1994;23:319-335.

32. Volchkov VA. Morphofunctional changes in spinal cord tissues and spinal ganglia after epidural administration of clofelin. Neurosci Behav Physiol 2003;33:375-378.

33. Roelants F, Lavand'homme PM, Mercier-Fuzier V. Epidural administration of neostigmine and clonidine to induce labor analgesia: evaluation of efficacy and local anesthetic-sparing effect. Anesthesiology 2005;102:1205-1210. 
34. Hood DD, Mallak KA, Eisenach JC, et al. Interaction between intrathecal neostigmine and epidural clonidine in human volunteers. Anesthesiology 1996;85:315-325.

35. Bouaziz H, Hewitt C, Eisenach JC. Subarachnoid neostigmine potentiation of alpha 2-adrenergic agonist analgesia. Dexmedetomidine versus Clonidine. Reg Anesth 1995;20:121-127.

36. Lothe $\mathrm{A}$, Li $\mathrm{P}$, Tong $\mathrm{C}$, et al. Spinal cholinergic alpha-2 adrenergic interactions in analgesia and hemodynamic control: role of muscarinic receptor subtypes and nitric oxide. J Pharmacol Exp Ther 1994;270:1301-1306.

37. Detweiler DJ, Eisenach JC, Tong C, et al. A cholinergic interaction in alpha 2 adrenoceptor-mediated antinociception in sheep. J Pharmacol Exp Ther 1993;265:536-542.

38. Merkel G, Eger El, 2nd. A comparative study of halothane and halopropane anesthesia including method for determining equipotency. Anesthesiology 1963;24:346-357.

39. Saidman LJ, Eger El, 2nd. Effect of Nitrous Oxide and of Narcotic Premedication on the Alveolar Concentration of Halothane Required for Anesthesia. Anesthesiology 1964;25:302-306.

40. Eger EI, 2nd, Saidman LJ, Brandstater B. Minimum alveolar anesthetic concentration: a standard of anesthetic potency. Anesthesiology 1965;26:756-763.

41. Quasha AL, Eger El, 2nd, Tinker JH. Determination and applications of MAC. Anesthesiology 1980;53:315-334. 
42. $\mathrm{E}$ PS, K RM. Inhalation Anesthetics In: Tranquilli WJ, Thurmon JC,Grimm KA, eds. Lumb \& Jones' Veterinary Anesthesia and Analgesia. 4th Edition ed, 2007;p.355-398.

43. Docquier MA, Lavand'homme $\mathrm{P}$, Ledermann $\mathrm{C}$, et al. Can determining the minimum alveolar anesthetic concentration of volatile anesthetic be used as an objective tool to assess antinociception in animals? Anesth Analg 2003;97:1033-1039, table of contents.

44. Zbinden AM, Maggiorini M, Petersen-Felix S, et al. Anesthetic depth defined using multiple noxious stimuli during isoflurane/oxygen anesthesia. I. Motor reactions. Anesthesiology 1994;80:253-260.

45. Valverde A, Morey TE, Hernandez J, et al. Validation of several types of noxious stimuli for use in determining the minimum alveolar concentration for inhalation anesthetics in dogs and rabbits. Am J Vet Res 2003;64:957-962.

46. Roizen MF, Horrigan RW, Frazer BM. Anesthetic doses blocking adrenergic (stress) and cardiovascular responses to incision--MAC BAR. Anesthesiology 1981;54:390-398.

47. Campagnol D, Neto FJT, Giordano T, et al. Determination of the minimum alveolar concentration of isoflurane based on the bispectral index and on purposeful movement in dogs. In: Proccedings of the 9th World Congress of Veterinary Anaesthesiology 2006;p. 138.

48. March PA, Muir WW. Bispectral analysis of the electroencephalogram: a review of its development and use in anesthesia. Vet Anaesth Analg 2005;32:241-255.

49. March PA, Muir WW, 3rd. Minimum alveolar concentration measures of central nervous system activation in cats anesthetized with isoflurane. Am J Vet Res 2003;64:1528-1533. 
50. Rampil IJ, Laster MJ. No correlation between quantitative electroencephalographic measurements and movement response to noxious stimuli during isoflurane anesthesia in rats. Anesthesiology 1992;77:920-925.

51. Rampil IJ, Mason P, Singh H. Anesthetic potency (MAC) is independent of forebrain structures in the rat. Anesthesiology 1993;78:707-712.

52. Antognini JF, Schwartz K. Exaggerated anesthetic requirements in the preferentially anesthetized brain. Anesthesiology 1993;79:1244-1249.

53. Antognini JF, Carstens E. A simple, quantifiable, and accurate method for applying a noxious mechanical stimulus. Anesth Analg 1998;87:14461449.

54. Johansen JW, Sebel PS. Development and clinical application of electroencephalographic bispectrum monitoring. Anesthesiology 2000;93:1336-1344.

55. Eisele JH, Eger EI, 2nd, Muallem M. Narcotic properties of carbon dioxide in the dog. Anesthesiology 1967;28:856-865.

56. Cullen DJ, Eger El, 2nd. The effect of extreme hypocapnia on the anaesthetic requirement (MAC) of dogs. Br J Anaesth 1971;43:339-343.

57. Cullen DJ, Eger EI, 2nd. The effects of hypoxia and isovolemic anemia on the halothane requirement (MAC) of dogs. I. The effect of hypoxia. Anesthesiology 1970;32:28-34.

58. Tanifuji Y, Eger El, 2nd. Effect of arterial hypotension on anaesthetic requirement in dogs. Br J Anaesth 1976;48:947-952. 
59. Mattson SF, Kerr CL, Dyson DH, et al. The effect of hypovolemia due to hemorrhage on the minimum alveolar concentration of isoflurane in the dog. Vet Anaesth Analg 2006;33:296-301.

60. Palahniuk RJ, Shnider SM. Maternal and fetal cardiovascular and acidbase changes during halothane and isoflurane anesthesia in the pregnant ewe. Anesthesiology 1974;41:462-472.

61. Eger EI, 2nd, Saidman LJ, Brandstater B. Temperature dependence of halothane and cyclopropane anesthesia in dogs: correlation with some theories of anesthetic action. Anesthesiology 1965;26:764-770.

62. Steffey EP, Eger El, 2nd. Hyperthermia and halothane MAC in the dog. Anesthesiology 1974;41:392-396.

63. Gregory GA, Eger El, 2nd, Munson ES. The relationship between age and halothane requirement in man. Anesthesiology 1969;30:488-491.

64. Stevens WD, Dolan WM, Gibbons RT, et al. Minimum alveolar concentrations (MAC) of isoflurande with and without nitrous oxide in patients of various ages. Anesthesiology 1975;42:197-200.

65. Williams JS, Tong C, Eisenach JC. Neostigmine counteracts spinal clonidine-induced hypotension in sheep. Anesthesiology 1993;78:301307.

66. Hood DD, Mallak KA, James RL, et al. Enhancement of analgesia from systemic opioid in humans by spinal cholinesterase inhibition. $J$ Pharmacol Exp Ther 1997;282:86-92.

67. Poyhia R. Cholinergic mechanisms of analgesia. Acta Anaesthesiol Scand 2000;44:1033-1034. 
68. Chiari A, Tobin JR, Pan HL, et al. Sex differences in cholinergic analgesia I: a supplemental nicotinic mechanism in normal females. Anesthesiology 1999;91:1447-1454.

69. Ghelardini C, Galeotti N, Bartolini A. Loss of muscarinic antinociception by antisense inhibition of $\mathrm{M}(1)$ receptors. $\mathrm{Br} J$ Pharmacol 2000;129:1633-1640.

70. Lavand'homme PM, Eisenach JC. Sex differences in cholinergic analgesia II: differing mechanisms in two models of allodynia. Anesthesiology 1999;91:1455-1461.

71. Yaksh TL, Grafe MR, Malkmus S, et al. Studies on the safety of chronically administered intrathecal neostigmine methylsulfate in rats and dogs. Anesthesiology 1995;82:412-427.

72. Gurun MS, Leinbach R, Moore L, et al. Studies on the safety of glucose and paraben-containing neostigmine for intrathecal administration. Anesth Analg 1997;85:317-323.

73. Hood DD, Eisenach JC, Tong C, et al. Cardiorespiratory and spinal cord blood flow effects of intrathecal neostigmine methylsulfate, clonidine, and their combination in sheep. Anesthesiology 1995;82:428-435.

74. Eisenach JC, Hood DD, Curry R. Phase I human safety assessment of intrathecal neostigmine containing methyl- and propylparabens. Anesth Analg 1997;85:842-846.

75. Klamt JG, Slullitel A, Garcia IV, et al. Postoperative analgesic effect of intrathecal neostigmine and its influence on spinal anaesthesia. Anaesthesia 1997;52:547-551. 
76. Lauretti GR, Lima IC. The effects of intrathecal neostigmine on somatic and visceral pain: improvement by association with a peripheral anticholinergic. Anesth Analg 1996;82:617-620.

77. Lauretti GR, Reis MP, Prado WA, et al. Dose-response study of intrathecal morphine versus intrathecal neostigmine, their combination, or placebo for postoperative analgesia in patients undergoing anterior and posterior vaginoplasty. Anesth Analg 1996;82:1182-1187.

78. Krukowski JA, Hood DD, Eisenach JC, et al. Intrathecal neostigmine for post-cesarean section analgesia: dose response. Anesth Analg 1997;84:1269-1275.

79. Chung CJ, Kim JS, Park HS, et al. The efficacy of intrathecal neostigmine, intrathecal morphine, and their combination for postcesarean section analgesia. Anesth Analg 1998;87:341-346.

80. Tan $\mathrm{PH}, \mathrm{Kuo} \mathrm{JH}$, Liu K, et al. Efficacy of intrathecal neostigmine for the relief of postinguinal hemiorrhaphy pain. Acta Anaesthesiol Scand 2000;44:1056-1060.

81. Lauretti GR, de Oliveira R, Perez MV, et al. Postoperative analgesia by intraarticular and epidural neostigmine following knee surgery. $\mathrm{J}$ Clin Anesth 2000;12:444-448.

82. Roelants F, Mercier-Fuzier V, Lavand'homme PM. The effect of a lidocaine test dose on analgesia and mobility after an epidural combination of neostigmine and sufentanil in early labor. Anesth Analg 2006;103:1534-1539.

83. Ross $\mathrm{VH}$, Pan $\mathrm{PH}$, Owen MD, et al. Neostigmine decreases bupivacaine use by patient-controlled epidural analgesia during labor: a randomized controlled study. Anesth Analg 2009;109:524-531. 
84. Roelants F, Lavand'homme PM. Epidural neostigmine combined with sufentanil provides balanced and selective analgesia in early labor. Anesthesiology 2004;101:439-444.

85. Van de Velde M, Berends N, Kumar A, et al. Effects of epidural clonidine and neostigmine following intrathecal labour analgesia: a randomised, double-blind, placebo-controlled trial. Int J Obstet Anesth 2009;18:207214.

86. Sinclair MD. A review of the physiological effects of alpha2-agonists related to the clinical use of medetomidine in small animal practice. Can Vet J 2003;44:885-897.

87. Moss J, Renz CL. The Autonomic Nervous System In: R.D M, ed. Miller's Anesthesia. 5th ed ed. Pennsylvania: Elsevier Churchill Livinstone, 2000;p. 514-556.

88. Vickery RG, Sheridan BC, Segal IS, et al. Anesthetic and hemodynamic effects of the stereoisomers of medetomidine, an alpha 2-adrenergic agonist, in halothane-anesthetized dogs. Anesth Analg 1988;67:611-615.

89. Kojima K, Nishimura R, Mutoh T, et al. Effects of medetomidinemidazolam, acepromazine-butorphanol, and midazolam-butorphanol on induction dose of thiopental and propofol and on cardiopulmonary changes in dogs. Am J Vet Res 2002;63:1671-1679.

90. Bloor BC, Frankland M, Alper G, et al. Hemodynamic and sedative effects of dexmedetomidine in dog. J Pharmacol Exp Ther 1992;263:690-697.

91. Dyson DH, Maxie MG, Schnurr D. Morbidity and mortality associated with anesthetic management in small animal veterinary practice in Ontario. J Am Anim Hosp Assoc 1998;34:325-335. 
92. Klide AM, Calderwood HW, Soma LR. Cardiopulmonary effects of xylazine in dogs. Am J Vet Res 1975;36:931-935.

93. Brodbelt D. Perioperative mortality in small animal anaesthesia. Vet $\mathrm{J}$ 2009;182:152-161.

94. Flacke JW, Flacke WE, Bloor BC, et al. Hemodynamic effects of dexmedetomidine, an alpha 2-adrenergic agonist, in autonomically denervated dogs. J Cardiovasc Pharmacol 1990;16:616-623.

95. Murrell JC, Hellebrekers LJ. Medetomidine and dexmedetomidine: a review of cardiovascular effects and antinociceptive properties in the dog. Vet Anaesth Analg 2005;32:117-127.

96. Pypendop $\mathrm{BH}$, Verstegen JP. Hemodynamic effects of medetomidine in the dog: a dose titration study. Vet Surg 1998;27:612-622.

97. Pagel PS, Proctor LT, Devcic A, et al. A novel alpha 2-adrenoceptor antagonist attenuates the early, but preserves the late cardiovascular effects of intravenous dexmedetomidine in conscious dogs. $J$ Cardiothorac Vasc Anesth 1998;12:429-434.

98. Gertler R, Brown HC, Mitchell DH, et al. Dexmedetomidine: a novel sedative-analgesic agent. Proc (Bayl Univ Med Cent) 2001;14:13-21.

99. Sinclair MD, O'Grady MR, Kerr CL, et al. The echocardiographic effects of romifidine in dogs with and without prior or concurrent administration of glycopyrrolate. Vet Anaesth Analg 2003;30:211-219.

100. Alvaides RK, Neto FJ, Aguiar AJ, et al. Sedative and cardiorespiratory effects of acepromazine or atropine given before dexmedetomidine in dogs. Vet Rec 2008;162:852-856. 
101. Ghignone M, Calvillo O, Quintin L, et al. Haemodynamic effects of clonidine injected epidurally in halothane-anaesthetized dogs. Can J Anaesth 1987;34:46-50.

102. Soares JH, Ascoli FO, Gremiao ID, et al. Isoflurane sparing action of epidurally administered xylazine hydrochloride in anesthetized dogs. Am J Vet Res 2004;65:854-859.

103. Sullivan AF, Dashwood MR, Dickenson AH. Alpha 2-adrenoceptor modulation of nociception in rat spinal cord: location, effects and interactions with morphine. Eur J Pharmacol 1987;138:169-177.

104. Sullivan AF, Kalso EA, McQuay HJ, et al. The antinociceptive actions of dexmedetomidine on dorsal horn neuronal responses in the anaesthetized rat. Eur J Pharmacol 1992;215:127-133.

105. Guo TZ, Jiang JY, Buttermann AE, et al. Dexmedetomidine injection into the locus ceruleus produces antinociception. Anesthesiology 1996;84:873-881.

106. Takano M, Takano Y, Yaksh TL. Release of calcitonin gene-related peptide (CGRP), substance $P(S P)$, and vasoactive intestinal polypeptide (VIP) from rat spinal cord: modulation by alpha 2 agonists. Peptides 1993;14:371-378.

107. Li X, Eisenach JC. alpha2A-adrenoceptor stimulation reduces capsaicininduced glutamate release from spinal cord synaptosomes. J Pharmacol Exp Ther 2001;299:939-944.

108. Eisenach JC, Rauck RL, Buzzanell C, et al. Epidural clonidine analgesia for intractable cancer pain: phase I. Anesthesiology 1989;71:647-652. 
109. Eisenach JC, Dewan DM, Rose JC, et al. Epidural clonidine produces antinociception, but not hypotension, in sheep. Anesthesiology 1987;66:496-501.

110. Eisenach J, Detweiler D, Hood D. Hemodynamic and analgesic actions of epidurally administered clonidine. Anesthesiology 1993;78:277-287.

111. De Kock M, Eisenach J, Tong C, et al. Analgesic doses of intrathecal but not intravenous clonidine increase acetylcholine in cerebrospinal fluid in humans. Anesth Analg 1997;84:800-803.

112. Asano T, Dohi S, Ohta S, et al. Antinociception by epidural and systemic alpha(2)-adrenoceptor agonists and their binding affinity in rat spinal cord and brain. Anesth Analg 2000;90:400-407.

113. Ewing KK, Mohammed HO, Scarlett JM, et al. Reduction of isoflurane anesthetic requirement by medetomidine and its restoration by atipamezole in dogs. Am J Vet Res 1993;54:294-299.

114. Kida K, Ohtani N, Shoji K, et al. Postoperative pain status after intraoperative systemic dexmedetomidine and epidural neostigmine in patients undergoing lower abdominal surgery. Eur $J$ Anaesthesiol 2008;25:869-875.

115. Roelants F, Rizzo M, Lavand'homme $P$. The effect of epidural neostigmine combined with ropivacaine and sufentanil on neuraxial analgesia during labor. Anesth Analg 2003;96:1161-1166, table of contents.

116. Hall LW, Clarke KW, Trim CM. Patient monitoring and clinical measurement. Veterinary anaesthesia. London: WB Saunders, 2001;p. 29-59. 
117. Monteiro ER, Teixeira-Neto FJ, Campagnol D, et al. Effects of remifentanil on the minimum alveolar concentration of isoflurane in dogs. Am J Vet Res 2010;71:p. 150-156.

118. Ko JC, Weil AB, Inoue T. Effects of carprofen and morphine on the minimum alveolar concentration of isoflurane in dogs. J Am Anim Hosp Assoc 2009;45:19-23.

119. Machado CE, Dyson DH, Grant Maxie M. Effects of oxymorphone and hydromorphone on the minimum alveolar concentration of isoflurane in dogs. Vet Anaesth Analg 2006;33:70-77.

120. Hellyer PW, Mama KR, Shafford HL, et al. Effects of diazepam and flumazenil on minimum alveolar concentrations for dogs anesthetized with isoflurane or a combination of isoflurane and fentanyl. Am $\mathrm{J}$ Vet Res 2001;62:555-560.

121. Steffey EP, Howland D, Jr. Isoflurane potency in the dog and cat. Am J Vet Res 1977;38:1833-1836.

122. Aguiar AJA. História da Anestesia. In: Anestesia em cães e gatos. 1st ed. São Paulo: Roca Editora, 2002;p. 3-25.

123. Alibhai $\mathrm{HI}$, Clarke $\mathrm{KW}$. Influence of carprofen on minimum alveolar concentration of halothane in dogs. J Vet Pharmacol Ther 1996;19:320321.

124. Santos M, Kunkar V, Garcia-Iturralde P, et al. Meloxicam, a specific COX-2 inhibitor, does not enhance the isoflurane minimum alveolar concentration reduction produced by morphine in the rat. Anesth Analg 2004;98:359-363, table of contents. 
125. Turner PV, Kerr CL, Healy AJ, et al. Effect of meloxicam and butorphanol on minimum alveolar concentration of isoflurane in rabbits. Am J Vet Res 2006;67:770-774.

126. Yamashita K, Okano Y, Yamashita M, et al. Effects of carprofen and meloxicam with or without butorphanol on the minimum alveolar concentration of sevoflurane in dogs. J Vet Med Sci 2008;70:29-35.

127. Materson BJ, Reda DJ, Cushman WC, et al. Single-drug therapy for hypertension in men. A comparison of six antihypertensive agents with placebo. The Department of Veterans Affairs Cooperative Study Group on Antihypertensive Agents. N Engl J Med 1993;328:914-921.

128. Lang CC, Stein CM, He HB, et al. Blunted blood pressure response to central sympathoinhibition in normotensive blacks: increased importance of nonsympathetic factors in blood pressure maintenance in blacks. Hypertension 1997;30:157-162.

129. Nurnberger J, Dammer S, Mitchell A, et al. Effect of the C825T polymorphism of the $G$ protein beta 3 subunit on the systolic blood pressure-lowering effect of clonidine in young, healthy male subjects. Clin Pharmacol Ther 2003;74:53-60.

130. Kurnik D, Muszkat M, Sofowora GG, et al. Ethnic and genetic determinants of cardiovascular response to the selective alpha 2adrenoceptor agonist dexmedetomidine. Hypertension 2008;51:406-411.

131. Bonhomme V, Doll A, Dewandre PY, et al. Epidural administration of lowdose morphine combined with clonidine for postoperative analgesia after lumbar disc surgery. J Neurosurg Anesthesiol 2002;14:1-6. 
Apêndice 
Apêndice A - Valores individuais em cinco cães de concentração alveolar mínima do isoflurano (CAM ${ }_{\text {ISo }}$ ) corrigidos ao nível do mar, porcentagem de redução e tempo real de determinação (em horas) para o momento basal e após 2,5 e 5 horas da administração peridural de clonidina $20 \mu \mathrm{g} / \mathrm{kg}$

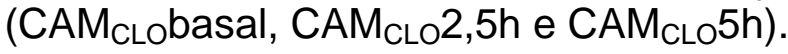

\begin{tabular}{cccc}
\hline \multicolumn{4}{c}{ CAM $_{\text {ISO }}($ Vol \%) } \\
\hline Animal 1 & 1,57 & CAM $_{\text {CLO 2,5h }}$ & CAM $_{\text {CLO }}$ 5h \\
\hline Animal 2 & 1,12 & 1,12 & 1,21 \\
Animal 3 & 1,39 & 0,85 & 0,94 \\
Animal 4 & 1,83 & 0,76 & 0,85 \\
Animal 5 & 1,57 & 1,16 & 1,30 \\
\hline
\end{tabular}

\begin{tabular}{cccc}
\hline \multicolumn{4}{c}{ Tempo de determinação (horas) } \\
\hline Animal 1 & CAM basal & CAM 2,5h & CAMo 5h \\
\hline Animal 2 & 1,90 & 2,50 & 5,20 \\
Animal 3 & 2,32 & 2,67 & 4,83 \\
Animal 4 & 2,67 & 2,50 & 4,75 \\
Animal 5 & 1,53 & 2,45 & 5,03 \\
\hline
\end{tabular}

\begin{tabular}{cccc}
\hline \multicolumn{4}{c}{ Porcentagem de redução da CAM ISO } \\
\hline & CAM basal & CAM 2,5h & CAM 5h \\
\hline Animal 1 & -- & 29 & 23 \\
Animal 2 & -- & 24 & 16 \\
Animal 3 & -- & 45 & 39 \\
Animal 4 & -- & 37 & 29 \\
Animal 5 & -- & 40 & 3 \\
\hline
\end{tabular}


Apêndice B - Valores individuais em cinco cães de concentração alveolar mínima do isoflurano (CAM ${ }_{\text {ISo }}$ ) corrigidos ao nível do mar, porcentagem de redução e tempo real de determinação (em horas) para o momento basal e após 2,5 e 5 horas da administração peridural de neostigmina $10 \mu \mathrm{g} / \mathrm{kg}$

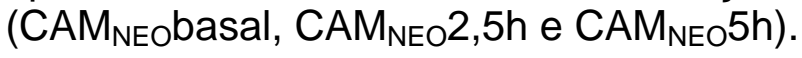

\begin{tabular}{|c|c|c|c|}
\hline \multicolumn{4}{|c|}{ CAM ISo $_{\text {(Vol \%) }}$} \\
\hline & $C_{\text {NEO }}$ basal & $C A M_{N E O} 2,5 h$ & $C A M_{N E O} 5 h$ \\
\hline Animal 1 & 1,57 & 1,48 & 1,43 \\
\hline Animal 2 & 1,21 & 1,12 & 1,21 \\
\hline Animal 3 & 1,57 & 1,39 & 1,39 \\
\hline Animal 4 & 1,83 & 1,48 & 1,43 \\
\hline Animal 5 & 1,39 & 1,21 & 1,39 \\
\hline
\end{tabular}

\begin{tabular}{cccc}
\hline \multicolumn{4}{c}{ Tempo de determinação (horas) } \\
\hline CAM basal & CAM 2,5h & CAM 5h \\
\hline Animal 1 & 1,98 & 2,33 & 4,83 \\
Animal 2 & 2,33 & 2,30 & 4,87 \\
Animal 3 & 1,67 & 2,33 & 4,67 \\
Animal 5 & 1,88 & 2,42 & 5,03 \\
\hline
\end{tabular}

\begin{tabular}{cccc}
\hline \multicolumn{4}{c}{ Porcentagem de redução da CAM ISo } \\
\hline & CAM basal & CAM 2,5h & CAM 5h \\
\hline Animal 1 & -- & 6 & 9 \\
Animal 2 & -- & 7 & 0 \\
Animal 3 & -- & 11 & 11 \\
Animal 4 & -- & 20 & 22 \\
Animal 5 & -- & 13 & 0 \\
\hline
\end{tabular}


Apêndice C - Valores individuais de concentração alveolar mínima do isoflurano ( $\left.\mathrm{CAM} \mathrm{ISO}_{\mathrm{SO}}\right)$ corrigidos ao nível do mar, em cinco cães porcentagem de redução e tempo real de determinação (em horas) para o momento basal e após 2,5 e 5 horas da administração peridural da associação clonidina $20 \mu \mathrm{g} / \mathrm{kg}$

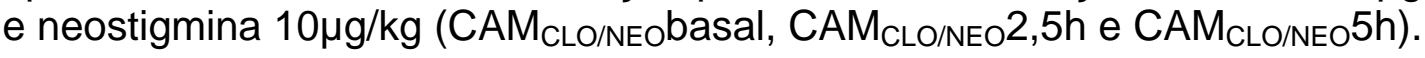

\begin{tabular}{lccc}
\hline \multicolumn{4}{c}{ CAM $_{\text {ISO }}$ (Vol \%) } \\
\hline & CAM $_{\text {CLO/NEO }}$ basal & CAM $_{\text {CLO/NEO }}$ 2,5h & CAM $_{\text {CLO/NEO5h }}$ \\
\hline Animal 1 & 1,57 & 1,21 & 1,21 \\
Animal 2 & 1,12 & 1,03 & 1,03 \\
Animal 3 & 1,48 & 0,94 & 0,94 \\
Animal 4 & 1,83 & 1,25 & 1,21 \\
Animal 5 & 1,48 & 0,94 & 1,12 \\
\hline
\end{tabular}

\begin{tabular}{cccc}
\hline \multicolumn{4}{c}{ Tempo de determinação (horas) } \\
\hline & CAM basal & CAM 2,5h & CAM 5h \\
\hline Animal 1 & 1,67 & 2,33 & 4,75 \\
Animal 2 & 2,28 & 2,25 & 4,58 \\
Animal 3 & 2,30 & 2,25 & 4,83 \\
Animal 4 & 2,33 & 2,92 & 4,83 \\
Animal 5 & 2,32 & 2,33 & 4,75 \\
\hline
\end{tabular}

\begin{tabular}{cccc}
\hline \multicolumn{4}{c}{ Porcentagem de redução da CAM Iso } \\
\hline CAM basal & CAM 2,5h & CAM 5h \\
\hline Animal 1 & -- & 23 & 23 \\
Animal 2 & -- & 8 & 8 \\
Animal 3 & -- & 36 & 36 \\
Animal 4 & -- & 32 & 34 \\
\hline
\end{tabular}


Apêndice D - Valores individuais de freqüência cardíaca (FC), pressão arterial sistólica (PAS) em cinco cães anestesiados com isoflurano, durante os temposalvo basal e após 2,5 e 5 horas (CAM basal, CAM 2,5 h e CAM 5 h) da administração peridural de clonidina $20 \mu \mathrm{g} / \mathrm{kg}$, neostigmina $10 \mu \mathrm{g} / \mathrm{kg}$ e da associação clonidina $20 \mu \mathrm{g} / \mathrm{kg}$ e neostigmina $10 \mu \mathrm{g} / \mathrm{kg}$.

\begin{tabular}{|c|c|c|c|c|c|c|c|c|c|}
\hline & \multicolumn{3}{|c|}{ Clonidina } & \multicolumn{3}{|c|}{ Neostigmina } & \multicolumn{3}{|c|}{ Clonidina/Neostigmina } \\
\hline & $\begin{array}{c}\text { CAM } \\
\text { basal }\end{array}$ & $\begin{array}{l}\text { CAM } \\
2,5 \mathrm{~h}\end{array}$ & $\begin{array}{c}\text { CAM } \\
5 \mathrm{~h}\end{array}$ & $\begin{array}{l}\text { CAM } \\
\text { basal }\end{array}$ & $\begin{array}{l}\text { CAM } \\
2,5 \mathrm{~h}\end{array}$ & $\begin{array}{c}\text { CAM } \\
5 \mathrm{~h}\end{array}$ & $\begin{array}{l}\text { CAM } \\
\text { basal }\end{array}$ & $\begin{array}{l}\text { CAM } \\
2,5 \mathrm{~h}\end{array}$ & $\begin{array}{c}\text { CAM } \\
5 \mathrm{~h}\end{array}$ \\
\hline \multicolumn{10}{|c|}{ FC (bpm) } \\
\hline Animal 1 & 90 & 43 & 60 & 90 & 105 & 98 & 72 & 40 & 44 \\
\hline Animal 2 & 92 & 55 & 65 & 81 & 85 & 89 & 90 & 54 & 56 \\
\hline Animal 3 & 104 & 46 & 57 & 95 & 79 & 88 & 91 & 42 & 57 \\
\hline Animal 4 & 112 & 57 & 67 & 94 & 112 & 104 & 96 & 55 & 58 \\
\hline Animal 5 & 98 & 42 & 58 & 75 & 76 & 74 & 96 & 36 & 42 \\
\hline \multicolumn{10}{|c|}{ PAS (mmHg) } \\
\hline Animal 1 & 122 & 125 & 147 & 113 & 140 & 148 & 108 & 122 & 117 \\
\hline Animal 2 & 136 & 158 & 146 & 132 & 135 & 144 & 134 & 142 & 137 \\
\hline Animal 3 & 130 & 143 & 147 & 98 & 104 & 138 & 125 & 137 & 145 \\
\hline Animal 4 & 94 & 114 & 107 & 102 & 103 & 116 & 87 & 96 & 103 \\
\hline Animal 5 & 119 & 126 & 124 & 119 & 113 & 110 & 112 & 120 & 112 \\
\hline
\end{tabular}


Apêndice E - Valores individuais de pressão arterial diastólica (PAD) e pressão arterial média (PAM) em cinco cães anestesiados com isoflurano, durante os tempos-alvo basal e após 2,5 e 5 horas (CAM basal, CAM 2,5 h e CAM 5h) da administração peridural de clonidina $20 \mu \mathrm{g} / \mathrm{kg}$, neostigmina $10 \mu \mathrm{g} / \mathrm{kg}$ e da associação clonidina $20 \mu \mathrm{g} / \mathrm{kg}$ e neostigmina $10 \mu \mathrm{g} / \mathrm{kg}$.

\begin{tabular}{|c|c|c|c|c|c|c|c|c|c|}
\hline & \multicolumn{3}{|c|}{ Clonidina } & \multicolumn{3}{|c|}{ Neostigmina } & \multicolumn{3}{|c|}{ Clonidina/Neostigmina } \\
\hline & $\begin{array}{r}\text { CAM } \\
\text { basal }\end{array}$ & $\begin{array}{l}\text { CAM } \\
2,5 \mathrm{~h}\end{array}$ & $\begin{array}{c}\text { CAM } \\
5 \mathrm{~h}\end{array}$ & $\begin{array}{c}\text { CAM } \\
\text { basal }\end{array}$ & $\begin{array}{l}\text { CAM } \\
2,5 \mathrm{~h}\end{array}$ & $\begin{array}{c}\text { CAM } \\
5 \mathrm{~h}\end{array}$ & $\begin{array}{c}\text { CAM } \\
\text { basal }\end{array}$ & $\begin{array}{l}\text { CAM } \\
2,5 \mathrm{~h}\end{array}$ & $\begin{array}{c}\text { CAM } \\
5 \mathrm{~h}\end{array}$ \\
\hline \multicolumn{10}{|c|}{ PAD (mmHg) } \\
\hline Animal 1 & 54 & 43 & 62 & 55 & 65 & 67 & 51 & 46 & 43 \\
\hline Animal 2 & 60 & 58 & 50 & 56 & 55 & 61 & 60 & 58 & 57 \\
\hline Animal 3 & 60 & 47 & 50 & 50 & 44 & 66 & 56 & 45 & 52 \\
\hline Animal 4 & 50 & 44 & 43 & 49 & 47 & 53 & 42 & 39 & 38 \\
\hline Animal 5 & 66 & 50 & 53 & 61 & 51 & 50 & 59 & 51 & 40 \\
\hline
\end{tabular}

\begin{tabular}{llllcccccc}
\hline & \multicolumn{7}{c}{ PAM (mmH) } \\
Animal 1 & 72 & 61 & 83 & 71 & 86 & 89 & 63 & 66 & 60 \\
Animal 2 & 80 & 86 & 70 & 74 & 75 & 82 & 78 & 79 & 75 \\
Animal 3 & 76 & 66 & 69 & 61 & 59 & 80 & 76 & 61 & 70 \\
Animal 4 & 64 & 60 & 59 & 65 & 61 & 70 & 55 & 53 & 54 \\
Animal 5 & 78 & 66 & 69 & 75 & 67 & 66 & 74 & 66 & 54 \\
\hline
\end{tabular}


Apêndice F- Valores individuais de freqüência respiratória $(f)$, pressão inspiratória (Pinsp) e temperatura esofágica ( $T$ ) em cinco cães anestesiados com isoflurano, durante os tempos-alvo basal e após 2,5 e 5 horas (CAM basal, CAM 2,5 h e CAM 5 h) da administração peridural de clonidina $20 \mu \mathrm{g} / \mathrm{kg}$, neostigmina $10 \mu \mathrm{g} / \mathrm{kg}$ e da associação clonidina $20 \mu \mathrm{g} / \mathrm{kg}$ e neostigmina 10 $\mu \mathrm{g} / \mathrm{kg}$.

\begin{tabular}{|c|c|c|c|c|c|c|c|c|c|}
\hline & \multicolumn{3}{|c|}{ Clonidina } & \multicolumn{3}{|c|}{ Neostigmina } & \multicolumn{3}{|c|}{ Clonidina/Neostigmina } \\
\hline & $\begin{array}{r}\text { CAM } \\
\text { basal }\end{array}$ & $\begin{array}{l}\text { CAM } \\
2,5 \mathrm{~h}\end{array}$ & $\begin{array}{c}\text { CAM } \\
5 \mathrm{~h}\end{array}$ & $\begin{array}{l}\text { CAM } \\
\text { basal }\end{array}$ & $\begin{array}{l}\text { CAM } \\
2,5 \mathrm{~h}\end{array}$ & $\begin{array}{c}\text { CAM } \\
5 \mathrm{~h}\end{array}$ & $\begin{array}{l}\text { CAM } \\
\text { basal }\end{array}$ & $\begin{array}{l}\text { CAM } \\
2,5 \mathrm{~h}\end{array}$ & $\begin{array}{c}\text { CAM } \\
5 \mathrm{~h}\end{array}$ \\
\hline \multicolumn{10}{|c|}{$f(m p m)$} \\
\hline Animal 1 & 15 & 14 & 10 & 13 & 12 & 12 & 13 & 13 & 11 \\
\hline Animal 2 & 13 & 17 & 12 & 14 & 14 & 12 & 15 & 12 & 12 \\
\hline Animal 3 & 11 & 10 & 10 & 13 & 12 & 13 & 14 & 14 & 13 \\
\hline Animal 4 & 12 & 14 & 11 & 16 & 14 & 12 & 12 & 11 & 15 \\
\hline Animal 5 & 13 & 12 & 12 & 15 & 15 & 12 & 13 & 8 & 9 \\
\hline \multicolumn{10}{|c|}{ Pinsp $\left(\mathrm{cm} \mathrm{H} \mathrm{H}_{2} \mathrm{O}\right)$} \\
\hline Animal 1 & 13 & 8 & 11 & 13 & 9 & 9 & 11 & 10 & 9 \\
\hline Animal 2 & 14 & 7 & 8 & 13 & 12 & 10 & 13 & 10 & 9 \\
\hline Animal 3 & 11 & 10 & 10 & 11 & 9 & 9 & 11 & 10 & 9 \\
\hline Animal 4 & 13 & 8 & 9 & 11 & 10 & 8 & 13 & 11 & 14 \\
\hline Animal 5 & 12 & 8 & 8 & 13 & 10 & 9 & 12 & 9 & 7 \\
\hline \multicolumn{10}{|c|}{$T\left({ }^{\circ} \mathrm{C}\right)$} \\
\hline Animal 1 & 38,2 & 38,3 & 38,3 & 38,2 & 38,2 & 38,2 & 38,0 & 38,4 & 38,0 \\
\hline Animal 2 & 38,0 & 38,3 & 38,1 & 38,2 & 38,2 & 38,2 & 38,1 & 38,3 & 38,2 \\
\hline Animal 3 & 38,2 & 38,3 & 38,3 & 37,9 & 38,1 & 38,2 & 38,2 & 38,0 & 38,2 \\
\hline Animal 4 & 38,2 & 38,2 & 38,2 & 38,0 & 38,1 & 38,1 & 38,1 & 38,2 & 38,2 \\
\hline Animal 5 & 38,1 & 38,2 & 38,3 & 38,1 & 38,2 & 38,1 & 38,2 & 38,3 & 38,1 \\
\hline
\end{tabular}


Apêndice G- Valores individuais de potencial hidrogeniônico $(\mathrm{pH})$ arterial, pressão parcial de $\mathrm{CO}_{2}\left(\mathrm{PaCO}_{2}\right)$, pressão parcial de $\mathrm{O}_{2}\left(\mathrm{PaO}_{2}\right)$ e íon bicarbonato $\left(\mathrm{HCO}_{3}{ }^{-}\right)$em cinco cães anestesiados com isoflurano, durante os tempos-alvo basal e após 2,5 e 5 horas (CAM basal, CAM 2,5h e CAM 5h) da administração peridural de clonidina $20 \mu \mathrm{g} / \mathrm{kg}$, neostigmina $10 \mu \mathrm{g} / \mathrm{kg}$ e da associação clonidina $20 \mu \mathrm{g} / \mathrm{kg}$ e neostigmina $10 \mu \mathrm{g} / \mathrm{kg}$.

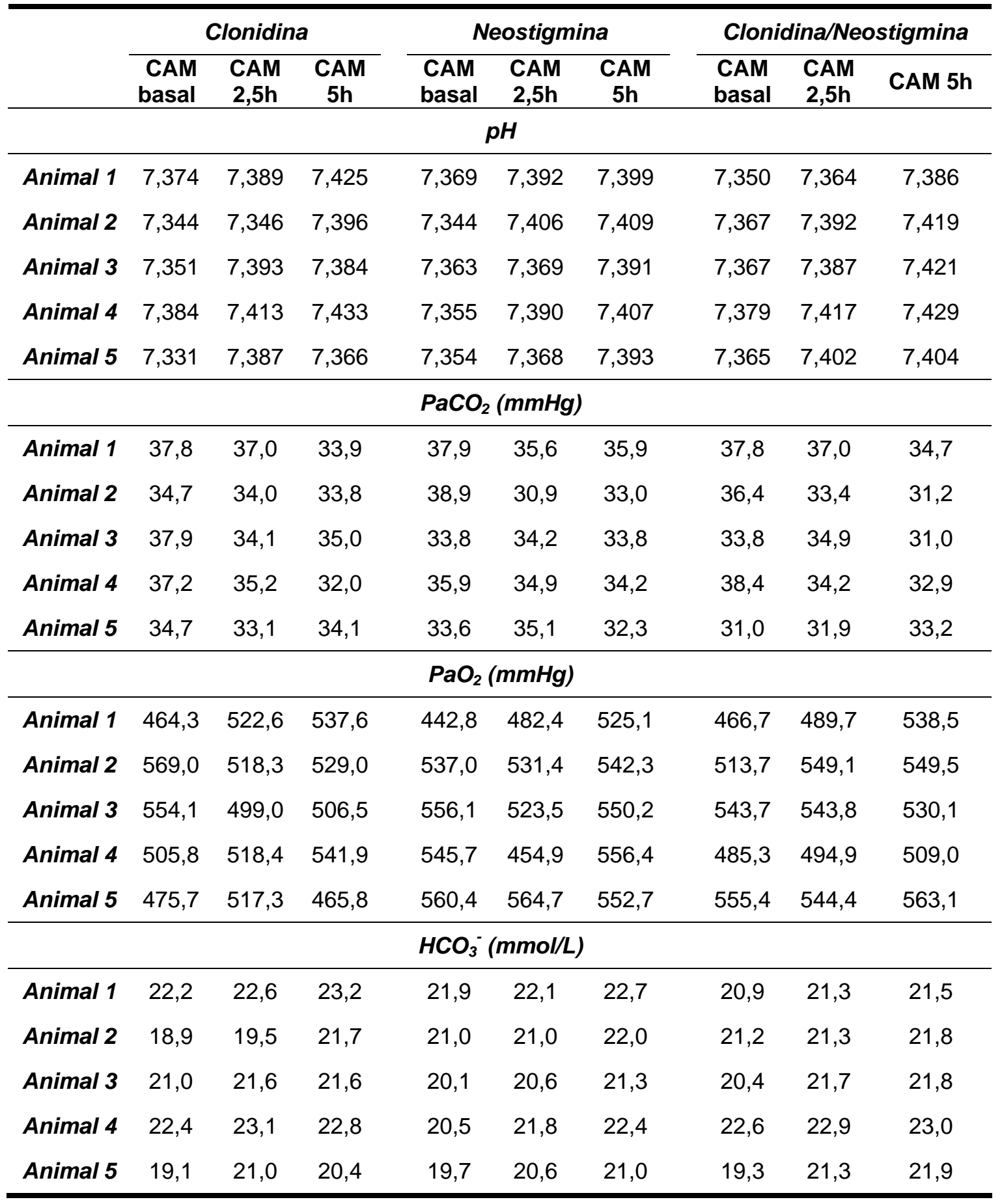


Apêndice $\mathbf{H}$ - Valores individuais do tempo de extubação (min) após o término da anestesia inalatória com isoflurano em 5 cães submetidos à administração peridural de clonidina $20 \mu \mathrm{g} / \mathrm{kg}$ (CLO), neostigmina $10 \mu \mathrm{g} / \mathrm{kg}$ (NEO) ou associação clonidina $20 \mu \mathrm{g} / \mathrm{kg}$ e neostigmina $10 \mu \mathrm{g} / \mathrm{kg}$ (CLO/NEO).

\begin{tabular}{lccc}
\hline \multicolumn{4}{c}{ Tempo de extubação (min) } \\
\hline Animal 1 & CLO & NEO & CLO/NEO \\
Animal 2 & 12 & 24 & 21 \\
Animal 3 & 5 & 11 & 10 \\
Animal 4 & 26 & 8 & 17 \\
Animal 5 & 9 & 5 & 19 \\
\hline
\end{tabular}

Apêndice I- Valores individuais do tempo de adoção do decúbito esternal após o término da anestesia inalatória com isoflurano em 5 cães submetidos à administração peridural de clonidina $20 \mu \mathrm{g} / \mathrm{kg}$ (CLO), neostigmina $10 \mu \mathrm{g} / \mathrm{kg}$ (NEO) ou associação clonidina $20 \mu \mathrm{g} / \mathrm{kg}$ e neostigmina $10 \mu \mathrm{g} / \mathrm{kg}$ (CLO/NEO).

\begin{tabular}{cccc}
\hline \multicolumn{4}{c}{ Tempo de adoção do decúbito esternal (min) } \\
\hline Animal 1 & CLO & NEO & CLO/NEO \\
\hline Animal 2 & 13 & 25 & 21 \\
Animal 3 & 7 & 11 & 11 \\
Animal 4 & 26 & 9 & 17 \\
Animal 5 & 9 & 7 & 19 \\
\hline
\end{tabular}

Apêndice J- Valores individuais do tempo de adoção do decúbito quadrupedal após o término da anestesia inalatória com isoflurano em 5 cães submetidos à administração peridural de clonidina $20 \mu \mathrm{g} / \mathrm{kg}$ (CLO), neostigmina $10 \mu \mathrm{g} / \mathrm{kg}$ (NEO) ou associação clonidina $20 \mu \mathrm{g} / \mathrm{kg}$ e neostigmina $10 \mu \mathrm{g} / \mathrm{kg}$ (CLO/NEO).

\begin{tabular}{cccc}
\hline \multicolumn{4}{c}{ Tempo de adoção do decúbito quadrupedal (min) } \\
\hline & CLO & NEO & CLO/NEO \\
\hline Animal 1 & 28 & 27 & 23 \\
Animal 2 & 12 & 17 & 13 \\
Animal 3 & 27 & 11 & 18 \\
Animal 4 & 12 & 13 & 20 \\
Animal 5 & 23 & 16 & 16 \\
\hline
\end{tabular}


Apêndice L- Valores individuais de concentração alveolar mínima do isoflurano $\left(\mathrm{CAM}_{\mathrm{ISO}}\right)$ corrigidos ao nível do mar, em três animais, após 2,5 horas da administração peridural de doses cumulativas de neostigmina 5 (NEO5), 10 (NEO10) e $20 \mu \mathrm{g} / \mathrm{kg}$ (NEO20), injetadas a cada 2,5h.

\begin{tabular}{lcccc}
\hline & \multicolumn{4}{c}{ CAM $_{\text {ISo }}($ Vol \%) } \\
\hline & CAMbasal & NEO5 & NEO10 & NEO20 \\
\hline Animal 1 & 1,75 & 1,18 & 1,18 & 0,99 \\
Animal 2 & 1,18 & 0,99 & 0,99 & 0,80 \\
Animal 3 & 1,84 & 1,56 & 1,28 & 1,28 \\
\hline
\end{tabular}

Apêndice $\mathbf{M}$ - Valores individuais de concentração alveolar mínima do isoflurano $\left(\mathrm{CAM}_{\mathrm{ISO}}\right)$, em três animais, corrigidos ao nível do mar, após administração peridural de clonidina $5 \mu \mathrm{g} / \mathrm{kg}$, durante os tempos-alvo basal e após 2,5 e 5 horas (CAM basal, CAM 2,5h e CAM 5h).

\begin{tabular}{cccc}
\hline \multicolumn{4}{c}{ CAM $_{\text {Iso }}$ (Vol \%) } \\
\hline & CAMbasal & CAM2,5h & CAM5h \\
\hline Animal 1 & 1,37 & 1,09 & 1,18 \\
Animal 2 & 1,28 & 1,09 & 1,18 \\
Animal 3 & 1,56 & 1,28 & 1,37 \\
\hline
\end{tabular}


Apêndice $\mathbf{N}$ - Valores de freqüência cardíaca (FC), pressão arterial sistólica, diastólica e média (PAS, PAD e PAM), potencial hidrogeniônico $(\mathrm{pH})$ arterial, pressão parcial de $\mathrm{CO}_{2}\left(\mathrm{PaCO}_{2}\right)$, pressão parcial de $\mathrm{O}_{2}\left(\mathrm{PaO}_{2}\right)$ e íon bicarbonato $\left(\mathrm{HCO}_{3}{ }^{-}\right)$em um animal com padrão assimétrico, anestesiado com isoflurano, durante os tempos-alvo basal e após 2,5 e 5 horas (CAM basal, CAM 2,5h e CAM 5h) da administração peridural de clonidina $20 \mu \mathrm{g} / \mathrm{kg}$, neostigmina $10 \mu \mathrm{g} / \mathrm{kg}$ e da associação clonidina $20 \mu \mathrm{g} / \mathrm{kg}$ e neostigmina 10 $\mu \mathrm{g} / \mathrm{kg}$.

\begin{tabular}{|c|c|c|c|c|c|c|c|c|c|}
\hline & \multicolumn{3}{|c|}{ Clonidina } & \multicolumn{3}{|c|}{ Neostigmina } & \multicolumn{3}{|c|}{ Clonidina/Neostigmina } \\
\hline & $\begin{array}{l}\text { CAM } \\
\text { basal }\end{array}$ & $\begin{array}{l}\text { CAM } \\
2,5 h\end{array}$ & $\begin{array}{c}\text { CAM } \\
5 \mathrm{~h}\end{array}$ & $\begin{array}{l}\text { CAM } \\
\text { basal }\end{array}$ & $\begin{array}{l}\text { CAM } \\
2,5 \mathrm{~h}\end{array}$ & $\begin{array}{c}\text { CAM } \\
5 \mathrm{~h}\end{array}$ & $\begin{array}{l}\text { CAM } \\
\text { basal }\end{array}$ & $\begin{array}{l}\text { CAM } \\
2,5 \mathrm{~h}\end{array}$ & $\begin{array}{c}\text { CAM } \\
5 \mathrm{~h}\end{array}$ \\
\hline$F C$ & 73 & 61 & 64 & 58 & 71 & 78 & 63 & 44 & 48 \\
\hline PAS & 154 & 109 & 126 & 158 & 146 & 147 & 160 & 138 & 139 \\
\hline$P A D$ & 81 & 44 & 46 & 73 & 57 & 59 & 77 & 46 & 55 \\
\hline PAM & 101 & 60 & 62 & 93 & 78 & 79 & 98 & 65 & 75 \\
\hline$p H$ & 7,35 & 7,40 & 7,43 & 7,36 & 7,38 & 7,44 & 7,37 & 7,40 & 7,44 \\
\hline $\mathrm{PaCO}_{2}$ & 34,6 & 34,1 & 30,1 & 36,7 & 37,2 & 32,3 & 33,5 & 34,5 & 30,4 \\
\hline $\mathrm{PaO}_{2}$ & 511,6 & 534,0 & 530,6 & 535,0 & 534,4 & 522,5 & 529,4 & 479,5 & 512,7 \\
\hline $\mathrm{HCO}_{3}^{-}$ & 20,0 & 21,9 & 21,8 & 21,0 & 22,4 & 23,3 & 20,3 & 22,3 & 22,5 \\
\hline
\end{tabular}

